\title{
Venous graft remodeling : novel mechanisms and pharmaco-modulation strategies
}

Citation for published version (APA):

de Graaf, R. (2008). Venous graft remodeling : novel mechanisms and pharmaco-modulation strategies. [Doctoral Thesis, Maastricht University]. D\&L Graphics. https://doi.org/10.26481/dis.20081113rg

Document status and date:

Published: 01/01/2008

DOI:

10.26481/dis.20081113rg

Document Version:

Publisher's PDF, also known as Version of record

\section{Please check the document version of this publication:}

- A submitted manuscript is the version of the article upon submission and before peer-review. There can be important differences between the submitted version and the official published version of record.

People interested in the research are advised to contact the author for the final version of the publication, or visit the DOI to the publisher's website.

- The final author version and the galley proof are versions of the publication after peer review.

- The final published version features the final layout of the paper including the volume, issue and page numbers.

Link to publication

\footnotetext{
General rights rights.

- You may freely distribute the URL identifying the publication in the public portal. please follow below link for the End User Agreement:

www.umlib.nl/taverne-license

Take down policy

If you believe that this document breaches copyright please contact us at:

repository@maastrichtuniversity.nl

providing details and we will investigate your claim.
}

Copyright and moral rights for the publications made accessible in the public portal are retained by the authors and/or other copyright owners and it is a condition of accessing publications that users recognise and abide by the legal requirements associated with these

- Users may download and print one copy of any publication from the public portal for the purpose of private study or research.

- You may not further distribute the material or use it for any profit-making activity or commercial gain

If the publication is distributed under the terms of Article $25 \mathrm{fa}$ of the Dutch Copyright Act, indicated by the "Taverne" license above, 


\title{
Venous Graft Remodeling
}

\author{
Novel Mechanisms and \\ Pharmaco-modulation Strategies
}

Rick de Graaf 


\section{Venous Graft Remodeling}

\section{Novel Mechanisms and Pharmaco-modulation Strategies}

\section{PROEFSCHRIFT}

ter verkrijging van de graad van doctor aan de Universiteit Maastricht, op gezag van de Rector Magnificus, Prof. mr. G.P.M.F. Mols volgens het besluit van het College van Decanen, in het openbaar te verdedigen op donderdag 13 november 2008 om 12.00 uur

door

Rick de Graaf

Geboren op 28 augustus 1972 te Borger 


\section{Promotores:}

Prof. dr. C.A. Bruggeman

Prof. dr. P.J.E.H.M. Kitslaar

\section{Copromotor:}

Dr. F. Stassen

\section{Beoordelingscommissie:}

Prof. dr. J.L. Waltenberger (voorzitter)

Prof. dr. J.G.R. de Mey

Prof. dr. J.G. Maessen

Prof. dr. J. Van Hooff

\section{Design and Layout:}

D\&L Graphics

www.dlgraphics.nl

Print:

Drukkerij Bykorf

Published by:

D\&L Graphics

ISBN/EAN: 978-90-8590-032-0

Financial support by the Netherlands Heart Foundation for the publication of this thesis is gratefully acknowledged. 


\section{Contents}

Chapter 1 General introduction

Chapter 2 Presence of inflammatory cells in saphenous veins used for peripheral bypass surgery predicts

early graft failure

Chapter 3 Human Heat Shock Protein 60 Stimulates Vascular Smooth Muscle Cell Proliferation Through Toll Like Receptor 2 and 4

Chapter $4 \mathrm{~N}$-acetylcysteine attenuates hyperoxia induced venous smooth muscle cell proliferation and neointima formation in a rat venous graft model

Chapter 5 Detection of cell-cycle regulators in failed arteriovenous fistulas for hemodialysis

Chapter 6 The new immunosuppressive agent FK778 attenuates neointima formation in an experimental bypass model

Chapter 7 General discussion

Summary

Samenvatting

Dankbetuigingen

About the author

List of scientific papers

Color figures 



\section{Chapter 1}

\section{General introduction}


Chapter 1 
Cardiovascular disease, mainly due to atherosclerotic degeneration of the arterial vasculature, continues to be the prominent cause of death and disablement in the modern Western world. In particular large and mediumsized elastic and muscular arteries are involved, leading to ischemia of the heart, brain, or extremities ${ }^{1}$. To preserve blood flow, the saphenous vein was first successfully employed to bypass a peripheral arterial obstruction by Kunlin in $1948^{2}$. Also in coronary heart disease, the introduction of bypass grafting ${ }^{3}$ was prosperous and has lead to dramatic increases in life expectancy. Even percutaneous transluminal angioplasty (PTA ${ }^{4}$, a minimal invasive, relatively easy and fast technique has never been able to challenge bypass graft supremacy. Up till now, bypass surgery has proven to confer superior patency rates in the treatment of coronary as well as peripheral arterial obstructive disease ${ }^{5-7}$. However, also in bypass grafting the problem of stenosis and subsequent bypass failure exists. To maximize patency, different conduits and surgical techniques have been considered. In coronary bypass surgery for instance, alternatives have been found in arterial conduits like the internal thoracic artery, and radial artery. Though favored by superior long-term outcome, difficulties in obtaining the artery and an increased risk of spasm hamper efficacy of this option. Moreover, due to fragility and small size, arterial conduits are not feasible as peripheral bypass grafts. Other alternatives like prosthetic grafts from polytetrafluoroethylene (PTFE) or Dacron have been used when autologous veins were considered unsuitable due to degenerative disease. However, concluding evidence shows a clear difference in patency, favoring non-diseased autogenous conduits ${ }^{5}$.

\section{Pathology of vein graft disease}

The course of venous graft disease can be subdivided into three more or less distinct sequential processes: thrombosis, intimal hyperplasia, and atherosclerosis (Figure 1).

\section{Thrombosis}

Graft thrombosis is a major complication in the first month after surgery ${ }^{8,9}$. Early graft failure, as a rule within one week of operation, is mostly due to surgical imperfection, inaccurate inflow of the graft or poor runoff as a result of occlusive disease elsewhere in the arterial tract. Other negative aspects emerge later after implantation of the autologous vein, when alterations in the vessel wall, altered flow dynamics, and changes in blood rheology cause thrombosis 

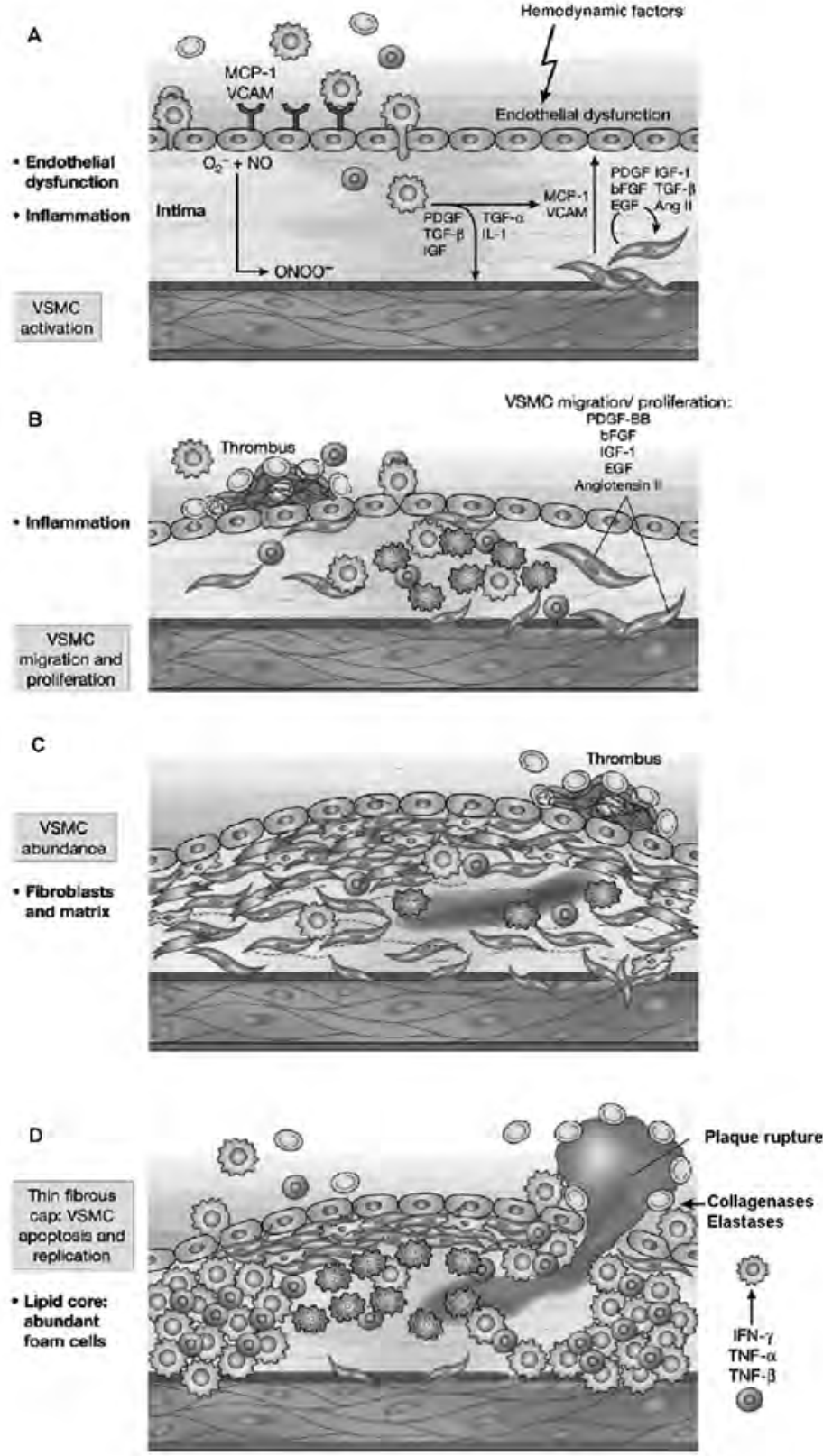

\begin{tabular}{|c|c|c|c|c|c|}
\hline$\therefore$ & vSMC & 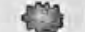 & Foam coll & 2000 & Matrix \\
\hline (a) & Endothelial cell & 6 & T-lymphocyte & $\Leftrightarrow$ & Calcification \\
\hline & Monocyte & 2es & Fibroblast & & Platelet and fibrin \\
\hline
\end{tabular}




\section{Figure 1.}

Different stages of vein graft disease. A. Hemodynamic forces (shear stress, tangential strain) alter the vascular endothelium, which triggers a cascade of events, like recruitment of leukocytes and platelets. B. Aggregation of platelets on the surface of the vessel wall induces thrombus formation which hampers vein graft survival. C. Cytokines and growth factors are released by inflammatory cells, generating a mitogenic milieu. SMCs migrate, proliferate and synthesize extracellular matrix components. D. Late atherosclerosis. Accumulation of macrophages, T-lymphocytes, and foam cells in a fibrocalcific lesion. Inflammatory mediators and proteases induce thinning of the fibrous cap, rendering the plaque weak and susceptible to rupture and thrombus formation. Modified from Dzau et al, 2002.

(Virchow's triad). First, surgical manipulation of the venous conduit might lead to endothelial disruption, which in turn relates to a procoagulent condition of the graft by fibrin accumulation on the luminal surface, and adherence of platelets and neutrophils ${ }^{10}$. This process is aggravated by the altered hemodynamic milieu, i.e., high pulsatile pressure and increased flow. Consequently, endothelial and smooth muscle cells express (or fail to express) genes that govern the production of molecules and surface receptors that affect vessel thrombogenicity. Thrombomodulin, a membrane-bound anti-thrombotic regulatory protein, modulates the activity of thrombin from that of a procoagulent to an anticoagulant protease ${ }^{11}$. When bound to thrombomodulin, thrombin is unable to generate fibrin or activate platelets but instead leads to activation of the circulating anticoagulant molecule, protein C. Undesirably, harvesting of the vein as well as arterial perfusion of the vein graft have negative effects on thrombomodulin activity ${ }^{12,13}$. Furthermore, intrinsic differences between arteries and veins make the antithrombotic properties of veins less pronounced, indicated by decreased nitric oxide (NO) and prostacyclin production capacity. Finally, the hampered vein is more susceptible to circulating vasoconstricting agents (e.g. endothelin-1), which might lead to decreased flow, increased risk of stasis, and consequent graft failure ${ }^{10}$.

\section{Intimal hyperplasia}

Early in embryological development the establishment of blood flow and increase of blood pressure instigate distinct differences between veins and arteries. Vasculogenesis refers to the process of blood vessel development from mesoderm-derived angioblasts, which differentiate into endothelial cells (EC) and form a tubular network. This primitive vascular system then later is extended by the budding of preexisting vessels (angiogenesis). Subsequently, recruitment and incorporation of primordial vascular smooth muscle cells (SMC) 
around the endothelial tubes takes place to form the definitive vascular structures. Again, hemodynamic forces seem to govern this progress into arteries, arterioles, venules, and veins ${ }^{14}$.

The human vein consists of three layers. The normal intima is thin, overlying an often incomplete internal elastic lamina. The media is more heterogeneous than that of arteries of similar size, consisting of a mixture of mostly circularly arranged SMCs, extracellular matrix proteins and some elastic fibers with no distinct external elastic lamina. The adventitia is composed of abundant amounts of collagen with a lesser amount of elastic fibers.

Generally, veins implanted in the arterial circulation attempt to adapt to the changed environment, and all of afore mentioned three venous layers undergo significant changes during adjustment to the arterial circumstances. Briefly, venous neointima formation is the most prominent adjustment which is characterized by medial SMC proliferation and migration to the intima, further proliferation in the intima and matrix deposition by these SMCs. The first step in this process is endothelial denudation caused by vein handling during surgery and hemodynamic stress once in circulation ${ }^{15}$. The areas where there is a lack of endothelium get covered by platelets, over which a new endothelial cell layer can be formed. These platelets secrete growth factors (PDGF, TGFb), which promote SMC migration and proliferation ${ }^{10}$. The still present, but often damaged endothelium usually is activated and releases growth factors and cytokines which in turn activate SMCs (see further). Further thickening of the tunica media and neointima is caused by invading perivascular fibroblasts, which acquire alpha-smooth muscle actin and differentiate into myofibroblasts. Migration of SMCs and fibroblasts is facilitated by matrix degeneration, more specifically basement membrane degradation. Matrix metalloproteinases (MMP) are capable of matrix and basement membrane degradation and are upregulated in vein graft disease ${ }^{16,17,18}$. In addition, neutrophil and monocyte/macrophage recruitment and progress into the vascular wall is augmented by local upregulation of adhesion molecules. This leucocyte invasion further adds to the ongoing inflammatory process and neointima formation induced by cytokine secretion.

\section{Atherosclerosis}

After surviving the risk of early (thrombosis) and mid-early (intima hyperplasia) failure, beyond the first year after surgery the dominant process underlying the attrition of vein grafts is atherosclerosis. In principle, the fundamental process of atheroma development is not different from which occurs in arteries. However, vein graft atherosclerosis differs in the rapidly progressive nature of 
atheroma formation. Moreover, histological and morphological differences have been described whereas vein graft atherosclerotic lesions exhibit more inflammatory cells and are more diffuse, concentric, and vulnerable. These differences might be explained by inferior compensatory mechanisms in veins. For example, veins show higher levels of oxidative stress and inferior lipid handling ${ }^{19}$. Furthermore, more extensive endothelial cell injury and dysfunction is suggested to cause accelerated atherosclerosis ${ }^{20}$.

\section{Role of endothelium in venous remodeling}

Physiologically, the endothelial cell layer provides a non-permeable barrier protecting underlying SMCs from humoral factors, inflammatory mediators, and physical forces. It also produces a number of basement membrane components to further exclude harmful stimuli. Furthermore, the intact endothelium modulates vascular tone and local hemostasis, and maintains SMC quiescence by production of regulating agents such as nitric oxide $(\mathrm{NO})$ and prostacyclin $(\mathrm{PGI} 2)^{21,22}$. Injury of the endothelium upsets the balance between vasoconstriction and vasodilatation and initiates a number of processes that induce unfavorable remodeling ${ }^{23}$.

\section{Hemodynamics}

Endothelial cells have the capacity to sense fluctuations in physical forces caused by alterations in blood flow. Variations in blood flow are translated into fluid shear stress and mechanical cyclic strain, which both have been implicated in endothelial dysfunction and vascular remodeling ${ }^{24,25}$. Long-term increase in blood flow is seen in surgical vein grafts implanted in the arterial circulation. Consequently, the vessel answers by structural remodeling, such that the diameter is reshaped to restore shear stress and cyclic strain to its baseline levels. The early remodeling response is shear stress mediated and involves predominantly $\mathrm{NO}$ and $\mathrm{PGl}_{2}$, highly potent vasodilators which cause a sudden increase in lumen diameter. Detailed expositions of the biology of flow-induced vasodilatation can be found elsewhere ${ }^{26}$. Briefly, eNOS, a constitutively expressed endothelial enzyme, is activated by intracellular $\left[\mathrm{Ca}^{++}\right]$ increase following acute shear stress elevation and in turn catalyzes $\mathrm{NO}$ production. Released NO reduces $\mathrm{Ca}^{++}$influx in SMCs and blocks the phosphorylation of troponin, thereby inhibiting the activation of the $\mathrm{Ca}^{++}$-dependent myosin light chain kinase, effectuating SMC relaxation and vasodilatation or 'outward remodeling ${ }^{27,28}$. $\mathrm{NO}$, in addition to a key regulator 
of vascular tone, also possesses strong anti-inflammatory, anti-apoptotic, antimitogenic, and anti-thrombotic properties ${ }^{29}$ (Figure 2).

However, NO bioavailability is markedly reduced in vein grafts within 1 day after implantation in de arterial circulation, and NO-mediated endothelium-dependent relaxation is $\operatorname{lost}^{30}$. Mechanisms underlying alterations in NO bioavailability are varied and multifactorial. Nevertheless, NO bioactivity is strongly reduced by reactive oxygen species (ROS), more specifically superoxide $\left(\mathrm{O}_{2}{ }^{-}\right)$. Superoxide is one of the most important ROS in the vasculature, and is markedly increased in saphenous vein grafts, while ROS scavengers are downregulated ${ }^{19}$. Superoxide degrades NO thus generating other ROS like peroxynitrite $\left(\mathrm{ONOO}^{-}\right)^{31}$ (Figure 1). Loss of $\mathrm{NO}$ and increase in oxidative stress leads to activation of nuclear factor-kappa $\beta$ (NF)-KB, a transcription factor which is a profound indicator of (endothelial) cell activation. NF-KB is also activated by altered hemodynamic flow, inflammatory mediators, growth factors and other cardiovascular risk factors ${ }^{32,33}$.

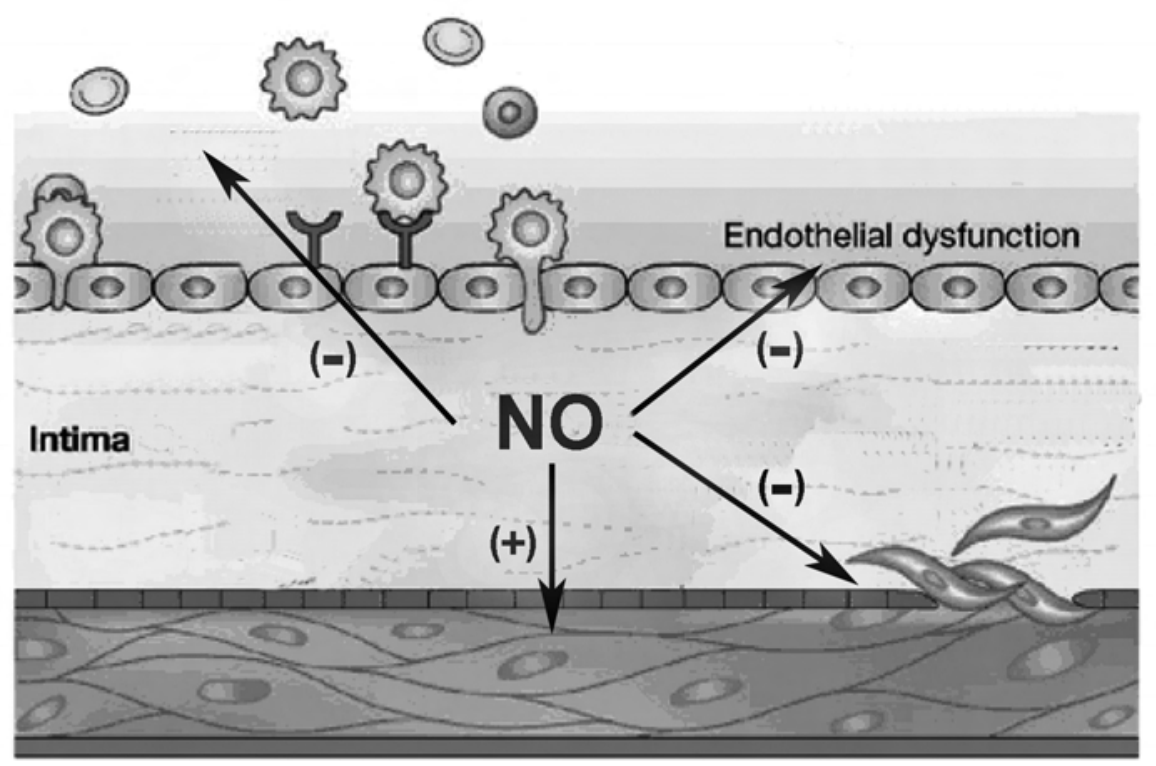

Figure 2.

Illustration showing the beneficial effects of nitric oxide (NO). NO exerts its protective effects by inducing SMC relaxation; inhibiting SMC proliferation, migration, and extracellular matrix synthesis; inhibiting platelet and leukocyte adhesion and activation; and protecting endothelial integrity. Modified from Dzau et al, 2002. 
Furthermore, the active form of NF-KB is present at different locations of cardiovascular disease, and is responsible for the expression of several proinflammatory genes, including shear force related genes ${ }^{33}$. Thus, NF-KB might play an integral role in gene regulatory responses to flow ${ }^{34,35}$. Many of these gene products have modulating effects on neointima formation, by direct stimulation of SMC migration and proliferation, or by facilitating and boosting the inflammatory response. PDGF, bFGF, TGF- $\beta$ and endothelin- 1 are upregulated in endothelium due to increased shear stress, and directly induce SMC activation/proliferation via a paracrine mechanism ${ }^{36,37,38}$. Interleukin (IL)$1 \beta^{39}, \mathrm{IL}-8^{40}$, and vascular endothelial growth factor (VEGF) ${ }^{38}$ are also upregulated by disturbed flow but have pro-inflammatory effects. Inflammatory mechanisms have been implicated in neointima formation, particularly via the afore mentioned NF-KB pathway ${ }^{41}$. Upon activation several pro-inflammatory cytokines are released, which in turn stimulate recruited leukocytes to secrete growth factors and proteases, further aggravating inflammation and neointima formation. Initially, these immune cells (e.g. monocyte derived macrophages and T-lymphocytes) are drawn towards the injured vascular wall by chemotactic factors, one of which is the very potent monocyte chemotactic protein-1 (MCP-1). MCP-1 is secreted by various cells like SMCs ${ }^{42}$, fibroblasts ${ }^{43}$, and shear stressed $\mathrm{ECs}^{44}$, and is associated with development of intimal hyperplasia in vein grafts $^{45}$. Recruitment of inflammatory cells out of the blood stream into the vascular wall is facilitated by adhesion molecules expressed on $\mathrm{ECS}^{46}$. Initial adhesion of leukocytes to the endothelium is mediated by adhesion molecules $\mathrm{E}-$ and P-selectin, which establish a relatively low strength interaction ${ }^{47,48}$. More stable adhesion involves vascular cell adhesion molecule-1 (VCAM-1), intercellular adhesion molecule-1 (ICAM-1), and platelet cell adhesion molecule-1 (PECAM-1), which are responsible for transmigration into the subendothelial area of leukocytes that secrete growth factors promoting neointima formation ${ }^{49,50,51}$. In culured ECs, increased shear stress up-regulates ICAM-1 and P-selectin, while E-selectin is unaffected, and VCAM-1 even seems to be down-regulated ${ }^{52,53,54}$. However, a study of adhesion molecule expression in saphenous vein segments revealed up-regulation of ICAM-1, Pselectin, but also VCAM-1 after distention pressure ${ }^{55}$. Up-regulation of adhesion molecules facilitates leukocyte binding and migration through the endothelial cell layer and the underlying tunica media. An additional strategy for enhanced cell migration is degradation of extracellular matrix (ECM) components by matrix metallo-proteinases (MMP). Two members of the MMP family, proteolytic enzymes MMP-2 and MMP-9, have recently been implicated in venous remodeling after bypass grafting ${ }^{17}$. Their activity is tightly regulated 
by tissue inhibitors of metalloproteinases $(\mathrm{TIMP})^{56}$, but in activated form they can digest several ECM and basement membrane components, suggesting to be a prerequirement for most, if not all, cellular migration processes. Interestingly, MMP-2 and MMP-9 have been found up-regulated in different vascular cells by several culprits of vein graft disease $\mathrm{s}^{57,58,59}$ (see further). In addition to earlier mentioned contributors to venous neointima formation, also the expression and activity of MMP-2 and MMP-9 are increased in saphenous vein endothelium by 'arterial' shear stress and in saphenous vein grafts by mechanical stretching and surgical preparative injury $60,61,16,62$.

Relatively new in the pathogenesis of vein graft disease are some members of the heat shock protein (HSP) family. HSPs are constitutionally expressed in virtual all eukaryotic cell types and show high homologous sequences between different species (molecular mimicry), from bacteria to humans ${ }^{63}$. To protect their integrity, cells produce high levels of HSP in response to several stress stimuli like heat shock, mechanical stress, infection, oxidants, and cytokine exposure $^{64,65,66}$. Recently, autogenous HSPs emerged as potential targets of the innate immune system, thus being linked to several autoimmune-related diseases. The introduction of HSPs in the pathogenesis of cardiovascular diseases is of even more recent history. In fact, it was only in 1990 when Berberian et al. for the first time found HSP expression in atherosclerotic plaques, which not much later was followed by Wick et al. who showed a clear relationship between HSP65 and induction of atherosclerotic lesions, suggesting involvement of an autoimmune response to $\mathrm{HSPs}^{67,68}$. ECs respond to unfavorable flow circumstances by a marked increase in HSP production, which attracts immune cells to the endothelium and induces an autoimmune response. In harmony, it was found that serum levels of antibodies against human HSP60 are markedly correlated to cardiovascular disease ${ }^{69}$. Moreover, human HSP60 was found to induce E-selectin, ICAM-1, and VCAM-1 expression on ECs, mentioned above as important molecules in adhesion and migration of inflammatory cells ${ }^{70}$. The pro-inflammatory potential of HSP60 was stretched even further by the observation that HSP60 induced IL-6 production by vascular SMCs and activated monocytes/macrophages, thus promoting the innate immune response ${ }^{71}$. All together, this suggests that unfavorable flow dynamics trigger the endothelium to cause and facilitate a generalized inflammatory response, that in turn adds to the process of growth factor induced neointima formation.

Infection, inflammation and the endothelium

The endothelium is the first line of defense in protecting the vascular wall 
against the harmful potential of blood elements. It has been well understood that systemic inflammation and other cardiovascular risk factors can compromise endothelial function, giving rise to atherosclerotic deformation of the vascular wall ${ }^{23}$. Reports on the effect of circulating risk factors and systemic inflammation in the pathogenesis of venous intimal thickening are rare, but since endothelial dysfunction is tightly associated with vein graft disease, this risk pattern might very well apply to venous neointima formation as well. First, experimental inflammation impairs endothelium-dependent vasodilatation and antithrombotic properties of the vascular endothelium in arteries and veins, thus increasing the risk of vasospasm, thrombosis and consequent graft failure after venous bypass surgery ${ }^{72}$. Furthermore, acute inflammation results in a boost of circulating cytokines, like IL-1, IL-6, IL-8, and TNF- $\alpha$, and several of these inflammatory markers have been associated with the development and reoccurrence of cardiovascular disease ${ }^{73,74}$. Initially, many of these cytokines were believed to be merely circulating markers of cardiovascular disease, but recently there has been awareness of a potential mediating role in the initiation and progression of atherosclerosis and neointima formation. Interesting support for this assumption is provided by the current attention for C-reactive protein (CRP). CRP is an acute phase reactant that is markedly increased after inflammation, infection and surgery, but promptly returns to baseline levels with resolution of disease ${ }^{75}$. Elevated levels of CRP have been associated with recurrent events in patients with preceding cardiovascular disease ${ }^{76}$, but also with the risk of isolated events in men and women without a history of cardiovascular disease $\mathrm{e}^{77,78}$. Further, CRP has been put forward as a prognostic marker for restenosis following percutaneous coronary intervention ${ }^{79}$, and recurrent ischemia after coronary bypass graft surgery ${ }^{80}$.

The ability of CRP to induce the release of proinflammatory cytokines by endothelial cells, SMCs, and macrophages further emphasizes its candidature as culprit mediator of cardiovascular disease ${ }^{81,82,83}$. CRP also facilitates the inflammatory process by upregulation of adhesion molecules (e.g. ICAM-1) and MCP-1 on endothelial cells ${ }^{84}$, which enhances monocyte/macrophage recruitment into the vascular wall (see above). Taken together, CRP can no longer be seen solely as an innocent predictor of cardiovascular disease, but has surely been exposed as a true partner in crime.

Initial suggestion of direct involvement of micro-organisms in the pathogenesis of vascular disease dates from the late eighteen hundreds, when Gilbert and Lion linked Bacillus typhosus to atherosclerotic disease ${ }^{85}$. Of great importance for our current interest in the involvement of micro-organisms in cardiovascular disease was the finding by Saikku et al who demonstrated the 
relation between Chlamydia pneumoniae (Cpn) infection and coronary artery disease for the first time ${ }^{86}$. Many other seroepidemiological studies followed, with the majority of them finding a positive relation between Cpn and the development and progression of atherosclerosis ${ }^{87,88,89}$, but also some negative seroepidemiological studies emerged over the last few years ${ }^{90,91}$. Further disagreement over the role of $\mathrm{Cpn}$ in cardiovascular disease comes from histological studies trying to locate Cpn in atherosclerotic plaques and occluded vein grafts. Although several studies demonstrated the presence of Cpn in various atherosclerotic intimal hyperplastic lesions using a variety of detection techniques ${ }^{92,93,94,95}$, the significance of this finding in the pathogenesis of atherosclerosis was argued in the "innocent bystander" hypothesis. This states that although Cpn might be present in atherosclerotic plaques, presumably by transport in circulatory monocytes from the lung, it would merely be a secondary passenger without pathological implication in atherosclerotic disease, something that again has been refuted by others ${ }^{96}$. Presently, the quarrel about the role for Cpn in cardiovascular disease is stretched by results from interventional studies trying to eradicate Cpn from the vasculature by antibiotic therapy to prevent cardiovascular events ${ }^{97,98,99,100}$. In succession to Cpn, several other viral and bacterial pathogens (Herpes simplex virus, cytomegalovirus, helicobacter pylori) have been linked with vascular pathology ${ }^{101}$, but an indisputable role for these and other pathogens in (venous) neointimal formation could not be confirmed thus far ${ }^{102,103}$.

It is nevertheless possible that infection with micro-organisms before, during or after venous bypass surgery may exert unfavorable effects on endothelial function and bypass patency. For example, endothelial cells express a variety of Toll-like receptors (TLR) on their surface, capable of recognizing diverse molecules derived from bacteria, viruses and fungi. To date, 10 TLR family members have been identified, of which endothelial cells predominantly express TLR4 and little TLR2, which both respond to bacterial products (i.e. lipopolysaccharides, peptidoglycans) by NF-KB activation and subsequent increased gene expression of several chemokines, cytokines, adhesion molecules, thus boosting the inflammatory response ${ }^{104}$. Furthermore, TLR signaling has been implicated in arterial remodeling and neointimal formation ${ }^{105,106}$. Interestingly, mycobacterial HSP60 also is recognized by TLR2 and TLR4, and due to molecular mimicry both human and mycobacterial HSP60 may thus signal through TLRs to exert an inflammatory response ${ }^{107}$. The high sequence homology between microbial and human HSPs could have additional implications in vascular pathology, by cross-reactions of antibodies and T cells against HSPs of microbes and humans. Consequently, human anti- 
HSP60 antibodies might react with HSP60 on the surface of stressed endothelial cells (see above), thereby inducing a cytotoxic response and lyses of the endothelium ${ }^{108}$. The rationale for this mechanism in vivo has been supplied by serological studies demonstrating an association between serum antibodies against microbial and human HSP and atherosclerotic disease ${ }^{109}$. This mechanism of bacterial pathogen involvement in vascular disease was later stressed by Mayr et al. who demonstrated that anti-mycobacterial HSP60/65 antibody levels correlated strongly with human IgA to Cpn and with IgG to Helicobacter pylori ${ }^{110}$.

\section{Role of smooth muscle cells in venous remodeling}

As mentioned above, venous intimal thickening after vein graft implantation is mainly caused by an increase of SMCs in the intima of the vein by migration from the media and sustained proliferation, followed by extracellular matrix accumulation ${ }^{111}$. SMCs in the media of normal adult veins proliferate at a very low rate $(<0.1 \% /$ day $)$, exhibit minimal synthetic activity, and express distinct proteins and cellular structures sustaining the contractile phenotype of the SMC. However, unlike some other cells of the cardiovascular system (i.e. cardiomyocytes) that are terminally differentiated, SMCs can switch very rapidly from quiescence to a proliferative state in response to appropriate stimuli $^{112,113}$. This so called plasticity of vascular SMCs is physiologically important during morphogenesis of the blood vessel, when SMC proliferate, migrate, and produce extracellular matrix components like collagen, elastin, and proteoglycans, while at the same time acquiring contractile capabilities ${ }^{114}$. Adversely, in a changed hemodynamic environment (e.g. arterial flow) the high degree in plasticity of venous SMCs gives rise to a pathological synthetic and proliferative phenotype. In addition, altered regulation of genes for several extracellular matrix molecules, proteases and inflammatory cytokines enhances and facilitates the process of intimal thickening ${ }^{115,116}$. This type of SMC differentiation is generally referred to as "phenotypic modulation", and is a prerequisite for migration and proliferation of SMCs during the development of venous neointima formation ${ }^{117,118}$.

\section{Migration of smooth muscle cells}

Mechanisms of SMC migration in the pathogenesis of venous neointima formation are poorly understood. Extensive research revealed numerous potential mediators, but as yet no common signaling pathway for migration has 
been presented. Environmental factors that have been discussed earlier obviously are important mediators of chemoattractant signaling by vascular and blood derived cells. One of the most potent chemoattractants is PDGF which is produced by activated platelets, macrophages, and endothelial cells and stimulates SMC migration in vein grafts ${ }^{19}$. PDGF expression is elevated during the first week after vein graft surgery, but gradually returns to its baseline levels by the fourth week postoperatively, which is in concert with the progress of neointima formation that ceases to continue 4 weeks post-operatively. Further evidence of a significant role for PDGF in venous intimal thickening was supplied by Peppel and coworkers who found that inhibition of PDGF receptor- $\beta$ signaling reduced intimal hyperplasia in autologous vein grafts ${ }^{120}$. In addition to PDGF several other cytokines like TNF- $\alpha$, basic fibroblast growth factor (bFGF), insulin like growth factor (IGF) I and II, and VEGF have pro-migrating effects on SMCs, either autonomously or, more often, synergistically. For example, TNF- $\alpha$ and PDGF have been shown to promote migration of SMCs independently, but both common and complementary signaling mechanisms contributed to an increased effect when SMCs were stimulated with PDGF and TNF- $\alpha$ additively ${ }^{121}$. Reports on the effect of bFGF on SMC migration have been more conflicting. Jackson et $\mathrm{al}^{122}$ found that SMC migration was enhanced by bFGF in an artery injury model and that this effect could be neutralized with a blocking antibody against bFGF, which is in disagreement with a study from Mii and coworkers ${ }^{123}$ who reported an anti-migratory effect of bFGF. Explanation for this discrepancy can be found in the assumption that the effect of bFGF is dependent on the type of receptors present. The type II receptor is particularly associated with inhibitory responses, and this type of receptor is lost in SMCs found in atherosclerotic lesions, thus promoting intimal thickening ${ }^{124}$. IGF-I and IGF-II share substantial homology with each other, are mainly produced in the liver and constitute important metabolic functions ${ }^{125}$. However, IGF is also produced by many other cells of the human body and locally produced IGF may act as an autocrine and paracrine factor. Especially the role of IGF-I as a potent stimulus of SMC migration and subsequent arterial neointima formation is commonly acknowledged ${ }^{126,127}$. VEGF is strongly induced in endothelial cells by hemodynamic stress as well as inflammatory mediators and directly, or indirectly through the induction of other growth factors, increases SMC migration ${ }^{128,129}$. Although research on the effects of bFGF, IGF-I, and VEGF on venous SMC migration is scarce, the described mechanisms may not differ significantly for venous neointima formation.

Triggering SMCs to exit the media and enter the intima in response to aforementioned chemoattractants is facilitated by the degradation of 
extracellular components, which normally support SMCs to remain in a quiescent state. The integrity of the extracellular matrix is largely determined by the balance between production of matrix degrading MMPs, the inhibitors of MMPs or TIMPs, and matrix deposition by $\mathrm{SMCs}^{130}$. In nondiseased human veins, MMP-2 and TIMP-1 and TIMP-2 are constitutively expressed at levels providing a stable balance between endogenous matrix production and matrix degradation $^{57}$. MMPs are produced by different vascular and blood-derived cells that play a part in venous intimal thickening, mostly in response to cytokines and other growth factors. For example, MMP-9 production by monocyte derived macrophages is enhanced after stimulation with TNF- $\alpha$ and IL-1 $\beta^{131}$. In contrast, other cytokines like IFN- $\gamma$, IL-4, IL-6, and IL-10 have been reported to reduce MMP production ${ }^{132,133}$. Local MMP-9 secretion by medial venous SMCs significantly adds to MMP-9 release by inflammatory cells, and has also been found to be increased by growth factors like PDGF, TNF- $\alpha$, and VEGF ${ }^{134,135,136}$.

Environmental (e.g. hemodynamic stress) cues contribute to phenotypic switching of SMCs into a synthetic phenotype, stimulating the expression of MMP-2 and MMP-9, favoring matrix degradation, SMC migration, and subsequent intimal thickening that leads to graft failure ${ }^{61,137,62,18}$. Further evidence for MMP involvement in venous neointima formation was supplied by the finding that a synthetic MMP inhibitor drug reduced intimal hyperplasia in a vein graft model ${ }^{138}$. In contrast to the upregulation of MMPs, their endogenous inhibitors, TIMPs do not seem to be differently expressed in vein grafts by hemodynamic or surgery-related stress, consequently disturbing the MMP-to-TIMP ratio in favor of MMPs ${ }^{139,62}$. However, overexpression of TIMP1, TIMP-2, and TIMP-3 by adenovirus-mediated gene transfer independently inhibited SMC migration and neointimal formation in vein grafts, suggesting an important role for TIMP regulation in venous neointima formation ${ }^{140,141,142}$.

\section{Proliferation of smooth muscle cells}

Normal vein SMCs are quiescent and phenotypic modulation is inhibited mainly through cell-matrix interactions, interactions between basement membrane components and cell surface integrins, and soluble mediators, thus restraining SMC proliferation ${ }^{118,143,144}$. Quiescent SMCs are reserved in the $\mathrm{G}_{0}$ phase of the cell cycle where mRNA and protein synthesis are retained to a minimum, and cellular activity is mainly in support of contractile function. On stimulation, SMCs may recommence progression through the cell cycle at the first gap $\left(\mathrm{G}_{1}\right)$ phase and regenerate mRNA and protein synthesis necessary for DNA replication that takes place during the $S$ phase. Subsequently, the second 
gap $\left(\mathrm{G}_{2}\right)$ phase is entered to produce proteins that are required for the final $(M)$ phase during which the cell divides into two daughter cells. During cell cycle progression two checkpoints have to be passed to ensure that cell division proceeds normally. When the first checkpoint $\left(G_{1}-S\right.$ transition $)$ is passed, the cell reaches its "point of no return" and is committed to continue cell cycle progression, DNA synthesis, and cell division. However, the second checkpoint (G2-M transition) might still prevent mitosis when incomplete or damaged DNA replication has occured ${ }^{145}$. During SMC cycling, progression through the different transition points and checkpoints is tightly regulated by a group of regulatory molecules consisting of cyclins, cyclin-dependent kinases (CDK) and their restricting molecules, the cyclin-dependent kinase inhibitors $(\mathrm{CKI})^{146}$. The mammalian cell cycle and its complex mechanisms have been excellently reviewed before ${ }^{147}$, thus discussion of the cell cycle machinery will be confined to the mechanisms related to SMC proliferation and intimal hyperplasia. Briefly, cyclin-dependent kinases (CDK1-7) specifically bind with

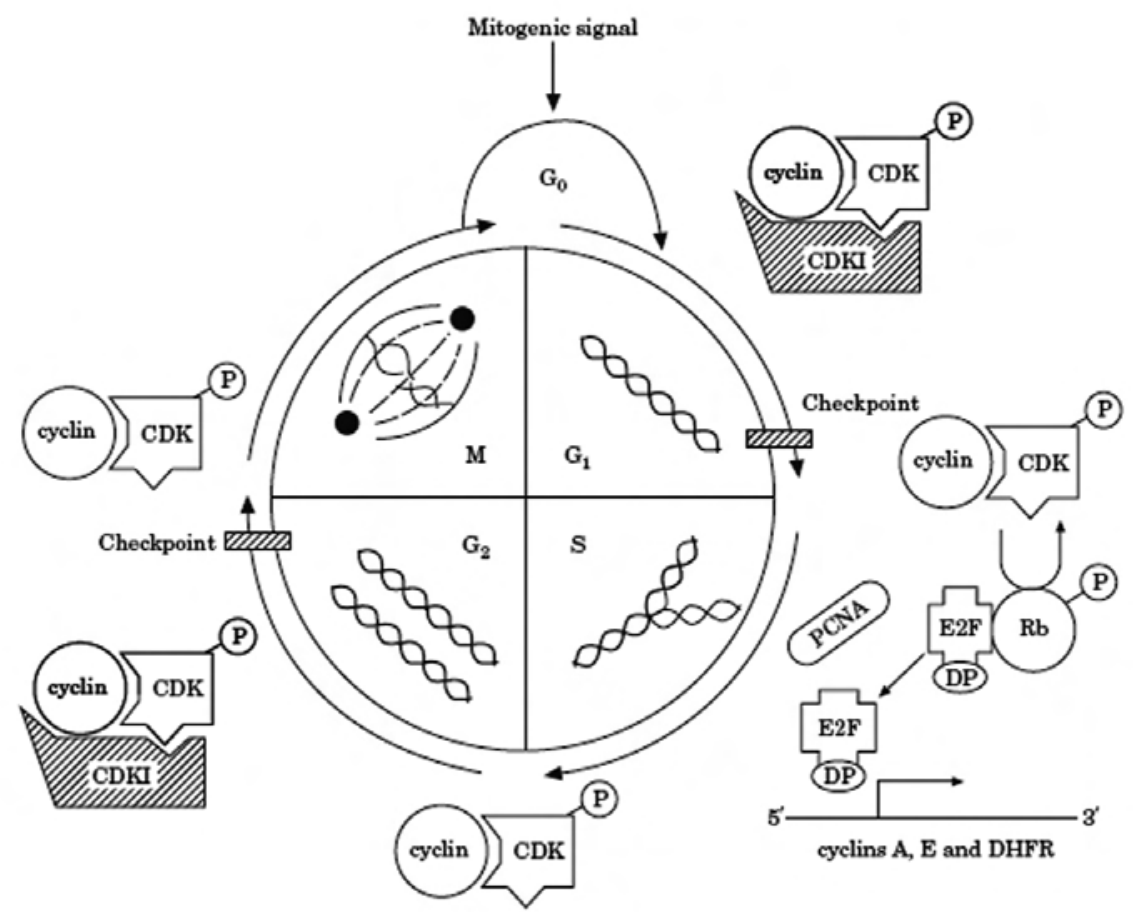

Figure 3.

Diagram showing the progression of the mammalian cell cycle and the relationship between regulatory molecules involved in cell cycle control. 
cyclins (cyclin A-H) to form active complexes able to stimulate cell cycle progression through the different phases. In the quiescent cell though, these complexes are negatively regulated by a family of CKIs (p15, p16, p18, p19, p21, p27, p57 146,147, that in turn assembles an inactive complex. This equilibrium can exist for a very long time, but is instantly lost when the cell is triggered by mitogenic stimuli like cytokines and other growth factors. Essential for the subsequent cell cycle progression is the transcription factor E2F, that appears ineffective in the $\mathrm{G}_{0}$ phase because it is bound to the retinoblastoma protein $(\mathrm{Rb})$, which is expressed throughout the entire cell cycle $\mathrm{e}^{148}$. The ability of Rb to suppress E2F activity is phosphorylation dependent, and will only occur in its hypophosphorylated state ${ }^{148}$. However, mitogenic factors can start off a signaling cascade that result in disintegration of the cyclin/CDK/CKIcomplex, a subsequent hyperphosphorylation of the $\mathrm{Rb}$ product, thereby releasing $\mathrm{E} 2 \mathrm{~F}$, that in turn regulates transcription of several genes necessary for cell division (Figure 3).

The significance of cell cycle molecule expression and vascular disease has recently been established. p27, one of the most commonly expressed CKIs, was found upregulated in SMCs during serum deprivation, leading to arrest in the $\mathrm{G}_{1}$ phase of the cell cycle, supposedly by binding of p27 to cyclin E/CDK2 complexes in these cells ${ }^{149}$. Conversely, p27 protein levels decrease drastically after arterial balloon injury, parallel to SMC proliferation levels and progress of intimal thickening during 3 weeks post injury ${ }^{149}$. Additional reports clearly show the association between cell cycle protein levels and SMC growth responses. For instance, while SMC growth inhibition correlates to high levels of $\mathrm{p} 27^{150,151}$, growth factor induced SMC proliferation corresponds with decreased p21 and p27 expression ${ }^{152}$.

Cell cycle progression and subsequent SMC proliferation in response to growth factors is of great importance in neointimal formation, and involves both paracrine and autocrine growth regulation. The potency of PDGF, bFGF, and TGF- $\beta$ on SMC proliferation has been discussed above. The most potent other stimuli of SMC proliferation will be discussed beyond. IL-1 is produced by activated macrophages within the blood vessel wall, but also by SMCs themselves when stimulated in vitro with proinflammatory cytokines ${ }^{153}$, and is a particularly effective mitogen, markedly stimulating SMC proliferation upon chronic exposure $^{154,155}$. Consequently, IL-1 has been proposed to contribute to neointimal hyperplasia in saphenous vein grafts after coronary bypass surgery, since immunoreactive IL-1 was found in SMCs of stenotic vein grafts but not in internal mammary arteries that had remained patent and in normal arteries and veins ${ }^{156}$. In addition to its role in SMC migration, IGF also effectively regulates vascular 
SMC proliferation in vitro and in vivo ${ }^{157,158}$. Furthermore, increased IGF-I gene expression after arterial injury resulted in enhanced neointimal formation through increased proliferation of SMCs ${ }^{127}$. Additionally, several other cytokines (e.g IL-6, IL-8, TGF- $\beta$ ) induce direct SMC proliferation or indirect SMC proliferation by growth factor induction in SMCs, thereby provoking an autocrine growth response (reviewed by Berk ${ }^{159}$ ).

SMC migration and proliferation as just described are very important processes in the development of venous intimal hyperplasia. It should be noted however, that SMCs derived from preexisting medial SMCs are probably not the only cells that can be retrieved in venous intimal thickenings. Transdifferentiation of ECs and adventitial fibroblasts into SMC-like cells might also add to venous neointima formation. However, since the generally used markers of SMC lineage lack specificity, it remains virtually impossible to discriminate between preexisting SMCs and SMC-like cells, making the relative contribution of these cells to neointima formation unclear. Moreover, recent research suggests that also bone marrow derived cells contribute to intimal thickening by giving rise to cells that express at least some properties of vascular SMCs ${ }^{160,161}$. However, the arterial injury model used to investigate these new insights can hardly be used to elucidate the process of venous neointima formation. Sata et al ${ }^{160}$ described a model in which severe injury was inflicted on the vascular wall, causing total loss of the endothelium and extensive medial SMC apoptosis. Han et al ${ }^{161}$ previously had shown that a relatively mild injury did not cause recruitment of any bone marrow cells into the denudated vascular wall. Furthermore, even if bone marrow derived cells do invade the vasculature in case of injury, it is very doubtful that these cells undergo differentiation into mature SMCs ${ }^{114}$.

\section{Prevention and intervention of neointima formation in vein grafts}

Well established risk factors in atherosclerotic disease have also been shown to have adverse effects on vein graft patency. Smoking is a risk factor for both early and late graft failure as a result of thrombosis and late atherosclerotic deformation ${ }^{162,163}$. Cessation of smoking within 6 months of bypass surgery resulted in significant higher graft survival rates at 10 years post-surgery ${ }^{164}$. Interestingly, another prospective follow-up study showed similar outcome results between patients who stopped smoking after surgery and nonsmokers, although both groups had a significant lower risk of cardiovascular events compared to persistent smokers ${ }^{165}$. Dyslipidemia (e.g. high cholesterol, LDL, and triglyceride levels and low HDL levels) has consistently been related to late graft atheroma development as it has been related to native arterial 
atherosclerosis before ${ }^{166,167}$. The lack of association between hyperlipidemia and early graft failure is probably due to absence of atherosclerotic vein graft lesions in the first years after bypass surgery ${ }^{168}$. The importance of lipid lowering treatment to prevent vein graft disease has been established by two trials showing that aggressive cholesterol lowering therapy by statins markedly reduced cardiovascular events and need for revascularization ${ }^{169,170}$. Likewise, since hemodynamic stress has extensively been related to endothelial dysfunction and arterial and venous intimal thickening (see above), it seems reasonable that systemic hypertension is related to the development of venous intimal hyperplasia. However, to date systemic hypertension has not been considered a risk factor for venous intimal hyperplasia ${ }^{171}$. Nonetheless, prevention of endothelial dysfunction has been proven by oral aspirin administration ${ }^{72,172}$, which is also beneficial in the prevention of platelet aggregation, another culprit mechanism in vein graft disease. However, contradicting results of studies demonstrating the effect of aspirin on venous graft patency suppress the justification for long-term aspirin administration to prevent vein graft disease $\mathrm{e}^{173,174}$.

The most promising intervention to prevent neointimal formation at this moment is probably cell cycle interference, for instance by local or systemic application of synthetic drugs like sirolimus and paclitaxel.

Following the success of anti-proliferative drug application in the prevention of restenosis after coronary PTA ${ }^{175,176}$, local release of these drugs also showed to reduce intimal thickening in vein grafts ${ }^{177,178}$. The finding that oral administration of sirolimus reduced restenosis after treatment of in-stent stenosis ${ }^{179}$ may have important implications in the prevention of neointimal formation in vein grafts. Another possibility that has been successfully employed in preventing intimal thickening by SMC cell cycle blocking is through adenovirus mediated gene delivery into the grafted vein ${ }^{180}$, but the danger of mutations hamper their safety and efficacy ${ }^{181}$.

In conclusion, neointimal formation in vein grafts is a multifactorial process, which up to now made it impossible to isolate a single mechanism suitable for interventional targeting, thus ensuing increased patency in vein grafts. 


\section{Aims of the study}

The role of inflammation in vein graft pathology has been widely established. Inflammatory cells are proven to enter the vessel wall rapidly after implantation ${ }^{182}$. It is believed that endothelial injury caused by hemodynamic stress results in upregulation of adhesion molecules. Hereby, influx of inflammatory cells is facilitated and subendothelial localization of activated cells develops. Subsequent secretion of cytokines stimulates SMC migration and proliferation leading to intimal hyperplasia. Although the pathogenesis of vein graft disease has predominantly been revealed, it remains unclear why certain vein grafts are committed to early failure, while others remain patent for many years. It would be of great value if one could predict the destiny of vein at the time of implantation. Anti-inflammatory treatment might thus be employed in specific cases to avert the detrimental events leading to vein graft failure. Earlier it has been suggested that morphological differences between native veins underlie variations in patency rates. In concord we wish to assess inflammatory cell compound in native veins used for bypass grafting and relate the inflammatory profile to patency rates.

As mentioned above hemodynamic stress has indisputably been implicated in vein graft pathology. However, we believe that additional characteristics of the arterial circulation may facilitate vessel wall injury, and need to be considered in the pathogenesis of vein graft disease. However, the cascade leading to SMC activation and proliferation is still open for investigation. Autologous HSP60 induction is directly stimulated by high cyclic stress and has been implicated in immunology related processes in the vascular wall. Due to high homology between HSPs, cross reaction between endogenous and exogenous HSP60 activate cells of the immunity system and induce inflammatory processes. Furthermore, exogenous HSP60 has been proven to induce SMC proliferation by signaling through Toll Like Receptors (TLR). We propose that endogenous HSP60 may also induce venous smooth muscle proliferation by interaction with TLR2 and 4.

Hemodynamic stress has clearly and beyond doubt been implicated in the pathogenesis of vein graft disease. Naturally, venous endothelial cells are not used to arterial flow and thus endothelial injury and dysfunction is likely to occur, proven by ample former research. Another typical difference between arterial and venous circulation is the high oxygen tension in arteries as compared to veins. Interestingly however, as yet no studies have been presented on the possible negative effects of supra-physiological oxygen levels on venous cells and vein graft survival. We want to assess the influence of 
hyperoxia on venous cells and examine the effect of antioxidant treatment on oxygen stressed cells and venous neointima formation.

Ultimately, it is the final common pathway of cell cycle progression that determines whether exposure to pro-mitogenic agents lead to proliferation, and therefore, in theory would be an excellent candidate for intervention. As mentioned above, cell cycle progression is determined by the balance between CDKs and CKIs. It has become clear that a certain temporal expression of these cell cycle regulators exist in the process of venous intimal hyperplasia. For example, it has been shown that p27, a holoenzyme which blocks cell cycle progression, is upregulated in the latest phase of intimal hyperplasia. As for the temporal expression of p21 some conflicting data has been presented. However, at the time of clinical failure, it is not evident how cell cycle regulators are interrelated. Therefore, we propose a study in which the expression of cell cycle proteins will be examined, basically to find a possible target for intervention.

Recently, an immune suppressive drug, FK778 has been suggested to exhibit anti-proliferative aspects and has been put forward to attenuate arterial restenosis in an animal model. As mentioned above, we believe that pharmacological intervention might be highly effective when directed at the final common pathway of venous SMC proliferation. The mechanisms of FK778 have been suggested to involve the de novo synthesis of pyrimidine. Without a sufficient pool of pyrimidine, cell cycle locomotion will discontinue in the late G1 phase. Therefore, we suggest that FK778 might be a promising drug to inhibit venous neointima formation. 
Chapter 1 


\section{References}

1. Ross R. Atherosclerosis--an inflammatory disease. N Eng/ J Med. 1999;340(2):115-126.

2. Kunlin J. [Long vein transplantation in treatment of ischemia caused by arteritis.]. Rev Chir. 1951;70(7-8):206-235.

3. Favaloro RG. Saphenous vein autograft replacement of severe segmental coronary artery occlusion: operative technique. Ann Thorac Surg. 1968;5(4):334-339.

4. Gruntzig AR, Senning A, Siegenthaler WE. Nonoperative dilatation of coronary-artery stenosis: percutaneous transluminal coronary angioplasty. N Engl J Med. 1979;301(2): 61-68.

5. Hunink MG, Wong JB, Donaldson MC, Meyerovitz MF, Harrington DP. Patency results of percutaneous and surgical revascularization for femoropopliteal arterial disease. Med Decis Making. 1994;14(1):71-81.

6. van der Zaag ES, Legemate DA, Prins MH, Reekers JA, Jacobs MJ. Angioplasty or bypass for superficial femoral artery disease? A randomised controlled trial. Eur J Vasc Endovasc Surg. 2004;28(2):132-137.

7. Comparison of coronary bypass surgery with angioplasty in patients with multivessel disease. The Bypass Angioplasty Revascularization Investigation (BARI) Investigators. N Engl J Med. 1996;335(4):217-225.

8. Bourassa MG. Fate of venous grafts: the past, the present and the future. I Am Coll Cardiol. 1991;17(5):1081-1083.

9. Fitzgibbon GM, Kafka HP, Leach AJ, Keon WJ, Hooper GD, Burton JR. Coronary bypass graft fate and patient outcome: angiographic follow-up of 5,065 grafts related to survival and reoperation in 1,388 patients during 25 years. I Am Coll Cardiol. 1996;28(3):616-626.

10. Verrier ED, Boyle EM, Jr. Endothelial cell injury in cardiovascular surgery. Ann Thorac Surg. 1996;62(3):915-922.

11. Esmon CT. Thrombomodulin as a model of molecular mechanisms that modulate protease specificity and function at the vessel surface. Faseb J. 1995;9(10):946-955.

12. Kim AY, Walinsky PL, Kolodgie FD, Bian C, Sperry JL, Deming CB, Peck EA, Shake JG, Ang GB, Sohn RH, Esmon CT, Virmani R, Stuart RS, Rade J. Early loss of thrombomodulin expression impairs vein graft thrombo-resistance: implications for vein graft failure. Circ Res. 2002;90(2):205-212.

13. Cook JM, Cook CD, Marlar R, Solis MM, Fink L, Eidt JF. Thrombomodulin activity on human saphenous vein grafts prepared for coronary artery bypass. I Vasc Surg. 1991;14(2):147-151.

14. Hu N, Clark EB. Hemodynamics of the stage 12 to stage 29 chick embryo. Circ Res. 1989;65(6):1665-1670. 
15. Cambria RP, Megerman J, Abbott WM. Endothelial preservation in reversed and in situ autogenous vein grafts. A quantitative experimental study. Ann Surg. 1985;202(1):50-55.

16. George SJ, Zaltsman AB, Newby AC. Surgical preparative injury and neointima formation increase MMP-9 expression and MMP-2 activation in human saphenous vein. Cardiovasc Res. 1997;33(2):447-459.

17. Southgate KM, Mehta D, Izzat MB, Newby AC, Angelini GD. Increased secretion of basement membrane-degrading metalloproteinases in pig saphenous vein into carotid artery interposition grafts. Arterioscler Thromb Vasc Biol. 1999;19(7):1640-1649.

18. Aguilera CM, George SJ, Johnson JL, Newby AC. Relationship between type IV collagen degradation, metalloproteinase activity and smooth muscle cell migration and proliferation in cultured human saphenous vein. Cardiovasc Res. 2003;58(3):679-688.

19. Shi Y, Patel S, Davenpeck KL, Niculescu R, Rodriguez E, Magno MG, Ormont ML, Mannion JD, Zalewski A. Oxidative stress and lipid retention in vascular grafts: comparison between venous and arterial conduits. Circulation. 2001;103(19):2408-2413.

20. Boyle EM, Jr., Lille ST, Allaire E, Clowes AW, Verrier ED. Endothelial cell injury in cardiovascular surgery: atherosclerosis. Ann Thorac Surg. 1997;63(3):885-894.

21. Garg UC, Hassid A. Nitric oxide-generating vasodilators and 8-bromo-cyclic guanosine monophosphate inhibit mitogenesis and proliferation of cultured rat vascular smooth muscle cells. J Clin Invest. 1989;83(5):1774-1777.

22. Fleming I, Bauersachs J, Busse R. Paracrine functions of the coronary vascular endothelium. Mol Cell Biochem. 1996;157(1-2):137-145.

23. Davignon J, Ganz P. Role of endothelial dysfunction in atherosclerosis. Circulation. 2004;109(23 Suppl 1):III27-32.

24. Yamaguchi S, Yamaguchi M, Yatsuyanagi E, Yun SS, Nakajima N, Madri JA, Sumpio BE. Cyclic strain stimulates early growth response gene product 1-mediated expression of membrane type 1 matrix metalloproteinase in endothelium. Lab Invest. 2002; 82(7):949-956.

25. Zhao S, Suciu A, Ziegler T, Moore JE, Jr., Burki E, Meister JJ, Brunner HR. Synergistic effects of fluid shear stress and cyclic circumferential stretch on vascular endothelial cell morphology and cytoskeleton. Arterioscler Thromb Vasc Biol. 1995;15(10):1781-1786.

26. Inagami T, Naruse M, Hoover R. Endothelium as an endocrine organ. Annu Rev Physiol. 1995;57:171-189.

27. Morgan JP, Perreault CL, Morgan KG. The cellular basis of contraction and relaxation in cardiac and vascular smooth muscle. Am Heart J. 1991;121(3 Pt 1):961-968.

28. Murray KJ. Cyclic AMP and mechanisms of vasodilation. Pharmacol Ther. 1990;47(3):329-345.

29. Harrison DG, Widder J, Grumbach I, Chen W, Weber M, Searles C. Endothelial mechanotransduction, nitric oxide and vascular inflammation. J Intern Med. 2006;259(4):351-363. 
30. Yang Z, Luscher TF. Basic cellular mechanisms of coronary bypass graft disease. Eur Heart J. 1993;14 Suppl I:193-197.

31. Taniyama Y, Griendling KK. Reactive oxygen species in the vasculature: molecular and cellular mechanisms. Hypertension. 2003;42(6):1075-1081.

32. Lan Q, Mercurius KO, Davies PF. Stimulation of transcription factors NF kappa B and AP1 in endothelial cells subjected to shear stress. Biochem Biophys Res Commun. 1994;201(2):950-956.

33. De Martin R, Hoeth M, Hofer-Warbinek R, Schmid JA. The transcription factor NFkappa B and the regulation of vascular cell function. Arterioscler Thromb Vasc Biol. 2000;20(11):E83-88.

34. Resnick N, Gimbrone MA, Jr. Hemodynamic forces are complex regulators of endothelial gene expression. Faseb J. 1995;9(10):874-882.

35. Davies PF. Mechanisms involved in endothelial responses to hemodynamic forces. Atherosclerosis. 1997;131 Suppl:S15-17.

36. Lindner V, Lappi DA, Baird A, Majack RA, Reidy MA. Role of basic fibroblast growth factor in vascular lesion formation. Circ Res. 1991;68(1):106-113.

37. Ohno M, Cooke JP, Dzau VJ, Gibbons GH. Fluid shear stress induces endothelial transforming growth factor beta-1 transcription and production. Modulation by potassium channel blockade. J Clin Invest. 1995;95(3):1363-1369.

38. Passerini AG, Milsted A, Rittgers SE. Shear stress magnitude and directionality modulate growth factor gene expression in preconditioned vascular endothelial cells. J Vasc Surg. 2003;37(1):182-190.

39. Jiang Z, Berceli SA, Pfahnl CL, Wu L, Goldman D, Tao M, Kagayama M, Matsukawa A, Ozaki CK. Wall shear modulation of cytokines in early vein grafts. J Vasc Surg. 2004;40(2):345-350.

40. Chen H, Wu L, Liu X, Chen Y, Wang B. Effects of laminar shear stress on IL-8 mRNA expression in endothelial cells. Biorheology. 2003;40(1-3):53-58.

41. Newby AC, Zaltsman AB. Molecular mechanisms in intimal hyperplasia. J Pathol. 2000;190(3):300-309.

42. Graves DT, Jiang YL, Williamson MJ, Valente AJ. Identification of monocyte chemotactic activity produced by malignant cells. Science. 1989;245(4925):1490-1493.

43. Rollins BJ, Stier P, Ernst T, Wong GG. The human homolog of the JE gene encodes a monocyte secretory protein. Mol Cell Biol. 1989;9(11):4687-4695.

44. Shyy YJ, Hsieh HJ, Usami S, Chien S. Fluid shear stress induces a biphasic response of human monocyte chemotactic protein 1 gene expression in vascular endothelium. Proc Natl Acad Sci U S A. 1994;91(11):4678-4682.

45. Stark VK, Hoch JR, Warner TF, Hullett DA. Monocyte chemotactic protein-1 expression is associated with the development of vein graft intimal hyperplasia. Arterioscler Thromb Vasc Biol. 1997;17(8):1614-1621. 
46. McEver RP. Adhesive interactions of leukocytes, platelets, and the vessel wall during hemostasis and inflammation. Thromb Haemost. 2001;86(3):746-756.

47. Abbassi O, Kishimoto TK, Mclntire LV, Anderson DC, Smith CW. E-selectin supports neutrophil rolling in vitro under conditions of flow. J Clin Invest. 1993;92(6): 2719-2730.

48. Lawrence MB, Springer TA. Leukocytes roll on a selectin at physiologic flow rates: distinction from and prerequisite for adhesion through integrins. Cell. 1991;65(5): 859-873.

49. Springer TA. Traffic signals for lymphocyte recirculation and leukocyte emigration: the multistep paradigm. Cell. 1994;76(2):301-314.

50. Muller WA, Weigl SA, Deng X, Phillips DM. PECAM-1 is required for transendothelial migration of leukocytes. J Exp Med. 1993;178(2):449-460.

51. Liao F, Ali J, Greene T, Muller WA. Soluble domain 1 of platelet-endothelial cell adhesion molecule (PECAM) is sufficient to block transendothelial migration in vitro and in vivo. J Exp Med. 1997;185(7):1349-1357.

52. Nagel T, Resnick N, Atkinson WJ, Dewey CF, Jr., Gimbrone MA, Jr. Shear stress selectively upregulates intercellular adhesion molecule-1 expression in cultured human vascular endothelial cells. J Clin Invest. 1994;94(2):885-891.

53. Morigi M, Zoja C, Figliuzzi M, Foppolo M, Micheletti G, Bontempelli M, Saronni M, Remuzzi G, Remuzzi A. Fluid shear stress modulates surface expression of adhesion molecules by endothelial cells. Blood. 1995;85(7):1696-1703.

54. Sampath R, Kukielka GL, Smith CW, Eskin SG, McIntire LV. Shear stress-mediated changes in the expression of leukocyte adhesion receptors on human umbilical vein endothelial cells in vitro. Ann Biomed Eng. 1995;23(3):247-256.

55. Chello M, Mastroroberto P, Frati G, Patti G, D'Ambrosio A, Di Sciascio G, Covino E. Pressure distension stimulates the expression of endothelial adhesion molecules in the human saphenous vein graft. Ann Thorac Surg. 2003;76(2):453-458; discussion 458.

56. Murphy G, Docherty AJ. The matrix metalloproteinases and their inhibitors. Am J Respir Cell Mol Biol. 1992;7(2):120-125.

57. Galis ZS, Johnson C, Godin D, Magid R, Shipley JM, Senior RM, Ivan E. Targeted disruption of the matrix metalloproteinase-9 gene impairs smooth muscle cell migration and geometrical arterial remodeling. Circ Res. 2002;91(9):852-859.

58. Ardans JA, Economou AP, Martinson JM, Jr., Zhou M, Wahl LM. Oxidized low-density and high-density lipoproteins regulate the production of matrix metalloproteinase-1 and -9 by activated monocytes. J Leukoc Biol. 2002;71(6):1012-1018.

59. Hanemaaijer R, Koolwijk P, le Clercq L, de Vree WJ, van Hinsbergh VW. Regulation of matrix metalloproteinase expression in human vein and microvascular endothelial cells. Effects of tumour necrosis factor alpha, interleukin 1 and phorbol ester. Biochem J. 1993;296 (Pt 3):803-809. 
60. Sultan S, Gosling M, Nagase H, Powell JT. Shear stress-induced shedding of soluble intercellular adhesion molecule-1 from saphenous vein endothelium. FEBS Lett. 2004;564(1-2):161-165.

61. Meng X, Mavromatis K, Galis ZS. Mechanical stretching of human saphenous vein grafts induces expression and activation of matrix-degrading enzymes associated with vascular tissue injury and repair. Exp Mol Pathol. 1999;66(3):227-237.

62. Berceli SA, Jiang Z, Klingman NV, Pfahnl CL, Abouhamze ZS, Frase CD, Schultz GS, Ozaki CK. Differential expression and activity of matrix metalloproteinases during flow-modulated vein graft remodeling. J Vasc Surg. 2004;39(5):1084-1090.

63. Morimoto RI. Cells in stress: transcriptional activation of heat shock genes. Science. 1993;259(5100):1409-1410.

64. Xu Q. Role of heat shock proteins in atherosclerosis. Arterioscler Thromb Vasc Biol. 2002;22(10):1547-1559.

65. Xu Q, Wick G. The role of heat shock proteins in protection and pathophysiology of the arterial wall. Mol Med Today. 1996;2(9):372-379.

66. Benjamin IJ, McMillan DR. Stress (heat shock) proteins: molecular chaperones in cardiovascular biology and disease. Circ Res. 1998;83(2):117-132.

67. Berberian PA, Myers W, Tytell M, Challa V, Bond MG. Immunohistochemical localization of heat shock protein-70 in normal-appearing and atherosclerotic specimens of human arteries. Am J Pathol. 1990;136(1):71-80.

68. Wick G, Kleindienst R, Schett G, Amberger A, Xu Q. Role of heat shock protein 65/60 in the pathogenesis of atherosclerosis. Int Arch Allergy Immunol. 1995;107(1-3):130-131.

69. Zhu J, Quyyumi AA, Rott D, Csako G, Wu H, Halcox J, Epstein SE. Antibodies to human heat-shock protein 60 are associated with the presence and severity of coronary artery disease: evidence for an autoimmune component of atherogenesis. Circulation. 2001;103(8):1071-1075.

70. Kol A, Bourcier T, Lichtman AH, Libby P. Chlamydial and human heat shock protein 60s activate human vascular endothelium, smooth muscle cells, and macrophages. J Clin Invest. 1999;103(4):571-577.

71. Kol A, Lichtman AH, Finberg RW, Libby P, Kurt-Jones EA. Cutting edge: heat shock protein (HSP) 60 activates the innate immune response: CD14 is an essential receptor for HSP60 activation of mononuclear cells. J Immunol. 2000;164(1):13-17.

72. Bhagat K, Vallance P. Inflammatory cytokines impair endothelium-dependent dilatation in human veins in vivo. Circulation. 1997;96(9):3042-3047.

73. Lind L. Circulating markers of inflammation and atherosclerosis. Atherosclerosis. 2003;169(2):203-214.

74. Rallidis LS, Zolindaki MG, Manioudaki HS, Laoutaris NP, Velissaridou AH, Papasteriadis EG. Prognostic value of C-reactive protein, fibrinogen, interleukin-6, and macrophage colony stimulating factor in severe unstable angina. Clin Cardiol. 2002;25(11):505-510. 
75. Pepys MB, Hirschfield GM. C-reactive protein: a critical update. J Clin Invest. 2003;111(12):1805-1812.

76. Zebrack JS, Muhlestein JB, Horne BD, Anderson JL. C-reactive protein and angiographic coronary artery disease: independent and additive predictors of risk in subjects with angina. J Am Coll Cardiol. 2002;39(4):632-637.

77. Koenig W, Sund M, Frohlich M, Fischer HG, Lowel H, Doring A, Hutchinson WL, Pepys MB. C-Reactive protein, a sensitive marker of inflammation, predicts future risk of coronary heart disease in initially healthy middle-aged men: results from the MONICA (Monitoring Trends and Determinants in Cardiovascular Disease) Augsburg Cohort Study, 1984 to 1992. Circulation. 1999;99(2):237-242.

78. Ridker PM, Buring JE, Cook NR, Rifai N. C-reactive protein, the metabolic syndrome, and risk of incident cardiovascular events: an 8-year follow-up of 14719 initially healthy American women. Circulation. 2003;107(3):391-397.

79. Chew DP, Bhatt DL, Robbins MA, Penn MS, Schneider JP, Lauer MS, Topol EJ, Ellis SG. Incremental prognostic value of elevated baseline C-reactive protein among established markers of risk in percutaneous coronary intervention. Circulation. 2001;104(9):992-997.

80. Milazzo D, Biasucci LM, Luciani N, Martinelli L, Canosa C, Schiavello R, Maseri A, Possati G. Elevated levels of C-reactive protein before coronary artery bypass grafting predict recurrence of ischemic events. Am J Cardiol. 1999;84(4):459-461, A459.

81. Verma S, Badiwala MV, Weisel RD, Li SH, Wang CH, Fedak PW, Li RK, Mickle DA. C-reactive protein activates the nuclear factor-kappaB signal transduction pathway in saphenous vein endothelial cells: implications for atherosclerosis and restenosis. J Thorac Cardiovasc Surg. 2003;126(6):1886-1891.

82. Ballou SP, Lozanski G. Induction of inflammatory cytokine release from cultured human monocytes by C-reactive protein. Cytokine. 1992;4(5):361-368.

83. Hattori Y, Matsumura M, Kasai K. Vascular smooth muscle cell activation by C-reactive protein. Cardiovasc Res. 2003;58(1):186-195.

84. Pasceri V, Willerson JT, Yeh ET. Direct proinflammatory effect of C-reactive protein on human endothelial cells. Circulation. 2000;102(18):2165-2168.

85. Ngeh J, Gupta S. Inflammation, infection and antimicrobial therapy in coronary heart disease--where do we currently stand? Fundam Clin Pharmacol. 2001;15(2):85-93.

86. Saikku P, Leinonen M, Mattila K, Ekman MR, Nieminen MS, Makela PH, Huttunen JK, Valtonen V. Serological evidence of an association of a novel Chlamydia, TWAR, with chronic coronary heart disease and acute myocardial infarction. Lancet. 1988;2(8618):983-986.

87. Saikku P, Leinonen M, Tenkanen L, Linnanmaki E, Ekman MR, Manninen V, Manttari M, Frick $\mathrm{MH}$, Huttunen JK. Chronic Chlamydia pneumoniae infection as a risk factor for coronary heart disease in the Helsinki Heart Study. Ann Intern Med. 1992;116(4): 273-278. 
88. Linnanmaki E, Leinonen M, Mattila K, Nieminen MS, Valtonen V, Saikku P. Chlamydia pneumoniae-specific circulating immune complexes in patients with chronic coronary heart disease. Circulation. 1993;87(4):1130-1134.

89. Lindholt JS, Vammen S, Lind I, Fasting H, Henneberg EW. The progression of lower limb atherosclerosis is associated with IgA antibodies against Chlamydia pneumoniae. Eur J Vasc Endovasc Surg. 1999;18(6):527-529.

90. Wald NJ, Law MR, Morris JK, Zhou X, Wong Y, Ward ME. Chlamydia pneumoniae infection and mortality from ischaemic heart disease: large prospective study. $B m j$. 2000;321(7255):204-207.

91. Danesh J, Whincup P, Walker M, Lennon L, Thomson A, Appleby P, Wong Y, BernardesSilva M, Ward M. Chlamydia pneumoniae $\lg G$ titres and coronary heart disease: prospective study and meta-analysis. Bmj. 2000;321(7255):208-213.

92. Shor A, Kuo CC, Patton DL. Detection of Chlamydia pneumoniae in coronary arterial fatty streaks and atheromatous plaques. S Afr Med J. 1992;82(3):158-161.

93. Kuo CC, Shor A, Campbell LA, Fukushi H, Patton DL, Grayston JT. Demonstration of Chlamydia pneumoniae in atherosclerotic lesions of coronary arteries. J Infect Dis. 1993;167(4):841-849.

94. Shor A, Phillips JI. Chlamydia pneumoniae and atherosclerosis. Jama. 1999; 282(21):2071-2073.

95. Bartels C, Maass M, Bein G, Brill N, Bechtel JF, Leyh R, Sievers HH. Association of serology with the endovascular presence of Chlamydia pneumoniae and cytomegalovirus in coronary artery and vein graft disease. Circulation. 2000;101(2):137-141.

96. Jackson LA, Campbell LA, Schmidt RA, Kuo CC, Cappuccio AL, Lee MJ, Grayston JT. Specificity of detection of Chlamydia pneumoniae in cardiovascular atheroma: evaluation of the innocent bystander hypothesis. Am J Pathol. 1997;150(5):1785-1790.

97. Muhlestein JB, Anderson JL, Hammond EH, Zhao L, Trehan S, Schwobe EP, Carlquist JF. Infection with Chlamydia pneumoniae accelerates the development of atherosclerosis and treatment with azithromycin prevents it in a rabbit model. Circulation. 1998;97(7):633-636.

98. Grayston JT. Antibiotic treatment of Chlamydia pneumoniae for secondary prevention of cardiovascular events. Circulation. 1998;97(17):1669-1670.

99. Anderson JL, Muhlestein JB, Carlquist J, Allen A, Trehan S, Nielson C, Hall S, Brady J, Egger M, Horne B, Lim T. Randomized secondary prevention trial of azithromycin in patients with coronary artery disease and serological evidence for Chlamydia pneumoniae infection: The Azithromycin in Coronary Artery Disease: Elimination of Myocardial Infection with Chlamydia (ACADEMIC) study. Circulation. 1999;99(12): 1540-1547. 
100. Vainas T, Stassen FR, Schurink GW, Tordoir JH, Welten RJ, van den Akker LH, Kurvers HA, Bruggeman CA, Kitslaar PJ. Secondary Prevention of Atherosclerosis Through Chlamydia pneumoniae Eradication (SPACE Trial): A Randomised Clinical Trial in Patients with Peripheral Arterial Disease. Eur J Vasc Endovasc Surg. 2005;29(4):403-411.

101. Chiu B. Multiple infections in carotid atherosclerotic plaques. Am Heart J. 1999; 138(5 Pt 2):S534-536.

102. Manegold C, Alwazzeh M, Jablonowski H, Adams O, Medve M, Seidlitz B, Heidland $U$, Haussinger D, Strauer BE, Heintzen MP. Prior cytomegalovirus infection and the risk of restenosis after percutaneous transluminal coronary balloon angioplasty. Circulation. 1999;99(10):1290-1294.

103. Carlsson J, Miketic S, Brom J, Ross R, Bachmann H, Tebbe U. Prior cytomegalovirus, Chlamydia pneumoniae or Helicobacter pylori infection and the risk of restenosis after percutaneous transluminal coronary angioplasty. Int J Cardiol. 2000;73(2):165-171.

104. de Kleijn D, Pasterkamp G. Toll-like receptors in cardiovascular diseases. Cardiovasc Res. 2003;60(1):58-67.

105. Vink A, Schoneveld AH, van der Meer JJ, van Middelaar BJ, Sluijter JP, Smeets MB, Quax PH, Lim SK, Borst C, Pasterkamp G, de Kleijn DP. In vivo evidence for a role of toll-like receptor 4 in the development of intimal lesions. Circulation. 2002; 106(15):1985-1990.

106. Hollestelle SC, De Vries MR, Van Keulen JK, Schoneveld AH, Vink A, Strijder CF, Van Middelaar BJ, Pasterkamp G, Quax PH, De Kleijn DP. Toll-like receptor 4 is involved in outward arterial remodeling. Circulation. 2004;109(3):393-398.

107. Bulut Y, Faure E, Thomas L, Karahashi H, Michelsen KS, Equils O, Morrison SG, Morrison RP, Arditi M. Chlamydial heat shock protein 60 activates macrophages and endothelial cells through Toll-like receptor 4 and MD2 in a MyD88-dependent pathway. J Immunol. 2002;168(3):1435-1440.

108. Mayr M, Metzler B, Kiechl S, Willeit J, Schett G, Xu Q, Wick G. Endothelial cytotoxicity mediated by serum antibodies to heat shock proteins of Escherichia coli and Chlamydia pneumoniae: immune reactions to heat shock proteins as a possible link between infection and atherosclerosis. Circulation. 1999;99(12):1560-1566.

109. Xu Q, Kiechl S, Mayr M, Metzler B, Egger G, Oberhollenzer F, Willeit J, Wick G. Association of serum antibodies to heat-shock protein 65 with carotid atherosclerosis: clinical significance determined in a follow-up study. Circulation. 1999;100(11): 1169-1174.

110. Mayr M, Kiechl S, Willeit J, Wick G, Xu Q. Infections, immunity, and atherosclerosis: associations of antibodies to Chlamydia pneumoniae, Helicobacter pylori, and cytomegalovirus with immune reactions to heat-shock protein 60 and carotid or femoral atherosclerosis. Circulation. 2000;102(8):833-839. 
111. Zhang WD, Bai HZ, Sawa Y, Yamakawa T, Kadoba K, Taniguchi K, Masuda J, Ogata J, Shirakura R, Matsuda H. Association of smooth muscle cell phenotypic modulation with extracellular matrix alterations during neointima formation in rabbit vein grafts. J Vasc Surg. 1999;30(1):169-183.

112. Majesky MW, Schwartz SM, Clowes MM, Clowes AW. Heparin regulates smooth muscle S phase entry in the injured rat carotid artery. Circ Res. 1987;61(2):296-300.

113. Owens GK. Regulation of differentiation of vascular smooth muscle cells. Physiol Rev. 1995;75(3):487-517.

114. Owens GK, Kumar MS, Wamhoff BR. Molecular regulation of vascular smooth muscle cell differentiation in development and disease. Physiol Rev. 2004;84(3):767-801.

115. Tan EM, Glassberg E, Olsen DR, Noveral JP, Unger GA, Peltonen J, Chu ML, Levine E, Sollberg S. Extracellular matrix gene expression by human endothelial and smooth muscle cells. Matrix. 1991;11(6):380-387.

116. Porter KE, Thompson MM, Loftus IM, McDermott E, Jones L, Crowther M, Bell PR, London NJ. Production and inhibition of the gelatinolytic matrix metalloproteinases in a human model of vein graft stenosis. Eur J Vasc Endovasc Surg. 1999;17(5):404-412.

117. Chamley-Campbell J, Campbell GR, Ross R. The smooth muscle cell in culture. Physiol Rev. 1979;59(1):1-61.

118. Thyberg J. Phenotypic modulation of smooth muscle cells during formation of neointimal thickenings following vascular injury. Histol Histopathol. 1998;13(3):871-891.

119. George SJ, Williams A, Newby AC. An essential role for platelet-derived growth factor in neointima formation in human saphenous vein in vitro. Atherosclerosis. 1996;120(1-2): 227-240.

120. Peppel K, Zhang L, Huynh TT, Huang X, Jacobson A, Brian L, Exum ST, Hagen PO, Freedman NJ. Overexpression of $\mathrm{G}$ protein-coupled receptor kinase-2 in smooth muscle cells reduces neointimal hyperplasia. J Mol Cell Cardiol. 2002;34(10):1399-1409.

121. Peppel K, Zhang L, Orman ES, Hagen PO, Amalfitano A, Brian L, Freedman NJ. Activation of vascular smooth muscle cells by TNF and PDGF: overlapping and complementary signal transduction mechanisms. Cardiovasc Res. 2005;65(3):674-682.

122. Jackson $\mathrm{CL}$, Reidy MA. Basic fibroblast growth factor: its role in the control of smooth muscle cell migration. Am J Pathol. 1993;143(4):1024-1031.

123. Mii S, Ware JA, Kent KC. Transforming growth factor-beta inhibits human vascular smooth muscle cell growth and migration. Surgery. 1993;114(2):464-470.

124. McCaffrey TA, Consigli S, Du B, Falcone DJ, Sanborn TA, Spokojny AM, Bush HL, Jr. Decreased type II/type I TGF-beta receptor ratio in cells derived from human atherosclerotic lesions. Conversion from an antiproliferative to profibrotic response to TGF-beta1. J Clin Invest. 1995;96(6):2667-2675.

125. Bayes-Genis A, Conover CA, Schwartz RS. The insulin-like growth factor axis: A review of atherosclerosis and restenosis. Circ Res. 2000;86(2):125-130. 
126. Bornfeldt KE, Raines EW, Nakano T, Graves LM, Krebs EG, Ross R. Insulin-like growth factor-I and platelet-derived growth factor-BB induce directed migration of human arterial smooth muscle cells via signaling pathways that are distinct from those of proliferation. J Clin Invest. 1994;93(3):1266-1274.

127. Zhu B, Zhao G, Witte DP, Hui DY, Fagin JA. Targeted overexpression of IGF-I in smooth muscle cells of transgenic mice enhances neointimal formation through increased proliferation and cell migration after intraarterial injury. Endocrinology. 2001;142(8):3598-3606.

128. Grosskreutz CL, Anand-Apte B, Duplaa C, Quinn TP, Terman BI, Zetter B, D'Amore PA. Vascular endothelial growth factor-induced migration of vascular smooth muscle cells in vitro. Microvasc Res. 1999;58(2):128-136.

129. Cucina A, Borrelli V, Randone B, Coluccia P, Sapienza P, Cavallaro A. Vascular endothelial growth factor increases the migration and proliferation of smooth muscle cells through the mediation of growth factors released by endothelial cells. J Surg Res. 2003;109(1):16-23.

130. Dollery CM, McEwan JR, Henney AM. Matrix metalloproteinases and cardiovascular disease. Circ Res. 1995;77(5):863-868.

131. Saren P, Welgus HG, Kovanen PT. TNF-alpha and IL-1beta selectively induce expression of 92-kDa gelatinase by human macrophages. J Immunol. 1996; 157(9):4159-4165.

132. Lacraz S, Nicod LP, Chicheportiche R, Welgus HG, Dayer JM. IL-10 inhibits metalloproteinase and stimulates TIMP-1 production in human mononuclear phagocytes. J Clin Invest. 1995;96(5):2304-2310.

133. Lacraz S, Nicod L, Galve-de Rochemonteix B, Baumberger C, Dayer JM, Welgus HG. Suppression of metalloproteinase biosynthesis in human alveolar macrophages by interleukin-4. J Clin Invest. 1992;90(2):382-388.

134. Wang $\mathrm{H}$, Keiser JA. Vascular endothelial growth factor upregulates the expression of matrix metalloproteinases in vascular smooth muscle cells: role of flt-1. Circ Res. 1998;83(8):832-840.

135. Moon SK, Cha BY, Kim CH. ERK1/2 mediates TNF-alpha-induced matrix metalloproteinase-9 expression in human vascular smooth muscle cells via the regulation of NF-kappaB and AP-1: Involvement of the ras dependent pathway. I Cell Physiol. 2004;198(3):417-427.

136. Cho A, Graves J, Reidy MA. Mitogen-activated protein kinases mediate matrix metalloproteinase-9 expression in vascular smooth muscle cells. Arterioscler Thromb Vasc Biol. 2000;20(12):2527-2532.

137. Patterson MA, Leville CD, Hower CD, Jean-Claude JM, Seabrook GR, Towne JB, Cambria RA. Shear force regulates matrix metalloproteinase activity in human saphenous vein organ culture. J Surg Res. 2001;95(1):67-72. 
138. Rotmans JI, Velema E, Verhagen HJ, Blankensteijn JD, de Kleijn DP, Stroes ES, Pasterkamp G. Matrix metalloproteinase inhibition reduces intimal hyperplasia in a porcine arteriovenous-graft model. J Vasc Surg. 2004;39(2):432-439.

139. Kranzhofer A, Baker AH, George SJ, Newby AC. Expression of tissue inhibitor of metalloproteinase-1, -2 , and -3 during neointima formation in organ cultures of human saphenous vein. Arterioscler Thromb Vasc Biol. 1999;19(2):255-265.

140. George SJ, Johnson JL, Angelini GD, Newby AC, Baker AH. Adenovirus-mediated gene transfer of the human TIMP-1 gene inhibits smooth muscle cell migration and neointimal formation in human saphenous vein. Hum Gene Ther. 1998;9(6):867-877.

141. George SJ, Baker AH, Angelini GD, Newby AC. Gene transfer of tissue inhibitor of metalloproteinase- 2 inhibits metalloproteinase activity and neointima formation in human saphenous veins. Gene Ther. 1998;5(11):1552-1560.

142. George SJ, Lloyd CT, Angelini GD, Newby AC, Baker AH. Inhibition of late vein graft neointima formation in human and porcine models by adenovirus-mediated overexpression of tissue inhibitor of metalloproteinase-3. Circulation. 2000;101(3): 296-304.

143. Hedin U, Bottger BA, Forsberg E, Johansson S, Thyberg J. Diverse effects of fibronectin and laminin on phenotypic properties of cultured arterial smooth muscle cells. J Cell Biol. 1988;107(1):307-319.

144. Thyberg J, Blomgren K, Roy J, Tran PK, Hedin U. Phenotypic modulation of smooth muscle cells after arterial injury is associated with changes in the distribution of laminin and fibronectin. J Histochem Cytochem. 1997;45(6):837-846.

145. Li JM, Brooks G. Cell cycle regulatory molecules (cyclins, cyclin-dependent kinases and cyclin-dependent kinase inhibitors) and the cardiovascular system; potential targets for therapy? Eur Heart J. 1999;20(6):406-420.

146. Reed SI, Bailly E, Dulic V, Hengst L, Resnitzky D, Slingerland J. G1 control in mammalian cells. J Cell Sci Suppl. 1994;18:69-73.

147. Murray AW. Recycling the cell cycle: cyclins revisited. Cell. 2004;116(2):221-234.

148. Weinberg RA. The retinoblastoma protein and cell cycle control. Cell. 1995;81(3): 323-330.

149. Tanner FC, Yang ZY, Duckers E, Gordon D, Nabel GJ, Nabel EG. Expression of cyclindependent kinase inhibitors in vascular disease. Circ Res. 1998;82(3):396-403.

150. Wakino S, Kintscher U, Kim S, Jackson S, Yin F, Nagpal S, Chandraratna RA, Hsueh WA, Law RE. Retinoids inhibit proliferation of human coronary smooth muscle cells by modulating cell cycle regulators. Arterioscler Thromb Vasc Biol. 2001;21(5):746-751.

151. Fasciano S, Patel RC, Handy I, Patel CV. Regulation of vascular smooth muscle proliferation by heparin: Inhibition of cyclin-dependent kinase 2 activity by p27kip1. J Biol Chem. 2005. 
152. Nathe TJ, Deou J, Walsh B, Bourns B, Clowes AW, Daum G. Interleukin-1 beta inhibits expression of $\mathrm{p} 21$ (WAF1/CIP1) and $\mathrm{p} 27(\mathrm{KIP} 1)$ and enhances proliferation in response to platelet-derived growth factor-BB in smooth muscle cells. Arterioscler Thromb Vasc Biol. 2002;22(8):1293-1298.

153. Beasley D, McGuiggin ME, Dinarello CA. Human vascular smooth muscle cells produce an intracellular form of interleukin-1 receptor antagonist. Am J Physiol. 1995;269(4 Pt 1):C961-968.

154. Libby P, Warner SJ, Friedman GB. Interleukin 1: a mitogen for human vascular smooth muscle cells that induces the release of growth-inhibitory prostanoids. I Clin Invest. 1988;81(2):487-498.

155. Beasley D, Cooper AL. Constitutive expression of interleukin-1alpha precursor promotes human vascular smooth muscle cell proliferation. Am J Physiol. 1999;276(3 Pt 2):H901-912.

156. Brody JI, Pickering NJ, Capuzzi DM, Fink GB, Can CA, Gomez F. Interleukin-1 alpha as a factor in occlusive vascular disease. Am J Clin Pathol. 1992;97(1):8-13.

157. Bornfeldt KE, Arnqvist HJ, Capron L. In vivo proliferation of rat vascular smooth muscle in relation to diabetes mellitus insulin-like growth factor I and insulin. Diabetologia. 1992;35(2):104-108.

158. Chen Y, Capron L, Magnusson JO, Wallby LA, Arnqvist HJ. Insulin-like growth factor-1 stimulates vascular smooth muscle cell proliferation in rat aorta in vivo. Growth Horm IGF Res. 1998;8(4):299-303.

159. Berk BC. Vascular smooth muscle growth: autocrine growth mechanisms. Physiol Rev. 2001;81(3):999-1030.

160. Sata M, Saiura A, Kunisato A, Tojo A, Okada S, Tokuhisa T, Hirai H, Makuuchi M, Hirata $\mathrm{Y}$, Nagai R. Hematopoietic stem cells differentiate into vascular cells that participate in the pathogenesis of atherosclerosis. Nat Med. 2002;8(4):403-409.

161. Han Cl, Campbell GR, Campbell JH. Circulating bone marrow cells can contribute to neointimal formation. J Vasc Res. 2001;38(2):113-119.

162. Neitzel GF, Barboriak JJ, Pintar K, Qureshi I. Atherosclerosis in aortocoronary bypass grafts. Morphologic study and risk factor analysis 6 to 12 years after surgery. Arteriosclerosis. 1986;6(6):594-600.

163. Solymoss BC, Nadeau P, Millette D, Campeau L. Late thrombosis of saphenous vein coronary bypass grafts related to risk factors. Circulation. 1988;78(3 Pt 2):1140-143.

164. Cavender JB, Rogers WJ, Fisher LD, Gersh BJ, Coggin CJ, Myers WO. Effects of smoking on survival and morbidity in patients randomized to medical or surgical therapy in the Coronary Artery Surgery Study (CASS): 10-year follow-up. CASS Investigators. J Am Coll Cardiol. 1992;20(2):287-294.

165. Voors AA, van Brussel BL, Plokker HW, Ernst SM, Ernst NM, Koomen EM, Tijssen JG, Vermeulen FE. Smoking and cardiac events after venous coronary bypass surgery. A 15year follow-up study. Circulation. 1996;93(1):42-47. 
166. Campeau L, Enjalbert M, Lesperance J, Bourassa MG, Kwiterovich P, Jr., Wacholder S, Sniderman A. The relation of risk factors to the development of atherosclerosis in saphenous-vein bypass grafts and the progression of disease in the native circulation. A study 10 years after aortocoronary bypass surgery. N Engl / Med. 1984;311(21):1329-1332.

167. Lie JT, Lawrie GM, Morris GC, Jr. Aortocoronary bypass saphenous vein graft atherosclerosis. Anatomic study of 99 vein grafts from normal and hyperlipoproteinemic patients up to 75 months postoperatively. Am / Cardiol. 1977;40(6): 906-914.

168. Cataldo G, Braga M, Pirotta N, Lavezzari M, Rovelli F, Marubini E. Factors influencing 1 -year patency of coronary artery saphenous vein grafts. Studio Indobufene nel Bypass Aortocoronarico (SINBA). Circulation. 1993;88(5 Pt 2):II93-98.

169. The effect of aggressive lowering of low-density lipoprotein cholesterol levels and lowdose anticoagulation on obstructive changes in saphenous-vein coronary-artery bypass grafts. The Post Coronary Artery Bypass Graft Trial Investigators. N Engl J Med. 1997;336(3):153-162.

170. Sacks FM, Pfeffer MA, Moye LA, Rouleau JL, Rutherford JD, Cole TG, Brown L, Warnica JW, Arnold JM, Wun CC, Davis BR, Braunwald E. The effect of pravastatin on coronary events after myocardial infarction in patients with average cholesterol levels. Cholesterol and Recurrent Events Trial investigators. N Engl J Med. 1996;335(14):10011009.

171. Meguro T, Nakashima H, Kawada S, Tokunaga K, Ohmoto T. Effect of external stenting and systemic hypertension on intimal hyperplasia in rat vein grafts. Neurosurgery. 2000;46(4):963-969; discussion 969-970.

172. Kharbanda RK, Walton B, Allen M, Klein N, Hingorani AD, MacAllister RJ, Vallance P. Prevention of inflammation-induced endothelial dysfunction: a novel vasculoprotective action of aspirin. Circulation. 2002;105(22):2600-2604.

173. Goldman S, Copeland J, Moritz T, Henderson W, Zadina K, Ovitt T, Doherty J, Read R, Chesler E, Sako $\mathrm{Y}$, et al. Saphenous vein graft patency 1 year after coronary artery bypass surgery and effects of antiplatelet therapy. Results of a Veterans Administration Cooperative Study. Circulation. 1989;80(5):1190-1197.

174. van der Meer J, Hillege HL, Kootstra GJ, Ascoop CA, Mulder BJ, Pfisterer M, van Gilst WH, Lie KI. Prevention of one-year vein-graft occlusion after aortocoronary-bypass surgery: a comparison of low-dose aspirin, low-dose aspirin plus dipyridamole, and oral anticoagulants. The CABADAS Research Group of the Interuniversity Cardiology Institute of The Netherlands. Lancet. 1993;342(8866):257-264.

175. Gallo R, Padurean A, Jayaraman T, Marx S, Roque M, Adelman S, Chesebro J, Fallon J, Fuster V, Marks A, Badimon JJ. Inhibition of intimal thickening after balloon angioplasty in porcine coronary arteries by targeting regulators of the cell cycle. Circulation. 1999;99(16):2164-2170. 
176. Sousa JE, Costa MA, Abizaid A, Abizaid AS, Feres F, Pinto IM, Seixas AC, Staico R, Mattos LA, Sousa AG, Falotico R, Jaeger J, Popma JJ, Serruys PW. Lack of neointimal proliferation after implantation of sirolimus-coated stents in human coronary arteries: a quantitative coronary angiography and three-dimensional intravascular ultrasound study. Circulation. 2001;103(2):192-195.

177. Schachner T, Zou Y, Oberhuber A, Tzankov A, Mairinger T, Laufer G, Bonatti JO. Local application of rapamycin inhibits neointimal hyperplasia in experimental vein grafts. Ann Thorac Surg. 2004;77(5):1580-1585.

178. Hoye A, Lemos PA, Arampatzis CA, Saia F, Tanabe K, Degertekin M, Hofma S, McFadden E, Sianos G, Smits PC, van der Giessen WJ, de Feyter P, van Domburg RT, Serruys PW. Effectiveness of the sirolimus-eluting stent in the treatment of saphenous vein graft disease. J Invasive Cardiol. 2004;16(5):230-233.

179. Hausleiter J, Kastrati A, Mehilli J, Vogeser M, Zohlnhofer D, Schuhlen H, Goos C, Pache J, Dotzer F, Pogatsa-Murray G, Dirschinger J, Heemann U, Schomig A. Randomized, double-blind, placebo-controlled trial of oral sirolimus for restenosis prevention in patients with in-stent restenosis: the Oral Sirolimus to Inhibit Recurrent In-stent Stenosis (OSIRIS) trial. Circulation. 2004;110(7):790-795.

180. Petrofski JA, Hata JA, Gehrig TR, Hanish SI, Williams ML, Thompson RB, Parsa CJ, Koch WJ, Milano CA. Gene delivery to aortocoronary saphenous vein grafts in a large animal model of intimal hyperplasia. J Thorac Cardiovasc Surg. 2004;127(1):27-33.

181. Buchschacher GL, Jr., Wong-Staal F. Development of lentiviral vectors for gene therapy for human diseases. Blood. 2000;95(8):2499-2504

182. Hoch JR, Stark VK, Hullett DA, Turnipseed WD. Vein graft intimal hyperplasia: leukocytes and cytokine gene expression. Surgery. 1994;116(2):463-470; discussion 470-461. 



\section{Chapter 2}

Presence of inflammatory cells in saphenous veins used for peripheral bypass surgery predicts early graft failure 


\section{Abstract}

Background. Intimal hyperplasia $(\mathrm{IH})$, characterized by smooth muscle cell accumulation and extracellular matrix deposition in the intima of grafted veins, is the major cause of infra-inguinal graft failure in the first post-operative year. Recent evidence suggests that these changes may be driven by inflammatory cytokines. Furthermore, preexisting saphenous vein disease has been associated with decreased graft patency. We evaluated the presence of inflammatory cells in failed venous bypass grafts and studied the effect of preexistent saphenous vein inflammatory cell accumulations on bypass graft failure.

Methods. Specimens $(n=15)$ of failed saphenous vein grafts were harvested from fifteen patients ( 8 men and 7 women; mean 59.8 years) during bypass graft revision surgery. Left-over segments $(n=17)$ of saphenous veins used as infrainguinal grafts, harvested during surgery, formalin fixed and paraffin embedded were retrieved from the histological archive of Maastricht University Hospital. By cross checking the clinical notes and vascular laboratory assessments, it was ascertained that 9 of these grafts remained open for longer than one year $(\mathrm{nDIH}=$ not developing $\mathrm{IH})$, whereas 8 grafts restenosed/ occluded within one year after implantation (DIH = developing $\mathrm{IH}$ ). The presence of macrophages, B-lymphocytes and T-lymphocytes in the occluded/ stenosed bypass grafts and the left-over segments was assessed immunohistochemically.

Results. IH lesions of failed vein grafts exhibited a significantly higher number of T-cells and macrophages compared to left-over saphenous vein segments. Among these vein segments, a significantly higher number of both macrophages and T-lymphocytes was present in those veins that subsequently stenosed/ occluded within 12 months after implantation as vein-graft. Except for gender, the prevalence of risk factors for graft occlusion (age, hypertension, smoking, diabetes and level of distal anastomosis) was similar in both groups.

Conclusion. T-cells and macrophages are abundantly present in $\mathrm{IH}$ lesion of vein-grafts. Furthermore, early presence of T-cells and macrophages in veins used as bypass grafts is associated with graft failure. This observation suggests that preexistent inflammatory changes in veins render them susceptible to develop advanced $\mathrm{IH}$ when implanted as vein-grafts. Thus, the presence of T-cells and macrophages in veins used for infra-inguinal revascularization might be a valuable a priori marker of graft failure. Such a marker could allow tailored graft monitoring and preventive medical (anti-inflammatory) treatment schemes. 


\section{Introduction}

Saphenous vein graft disease consisting of thrombosis, intimal hyperplasia or atherosclerosis is associated with decreased graft patency limiting the therapeutic effect of this surgical revasularization procedure in the treatment of arterial obstructive disease. Intimal hyperplasia $(\mathrm{IH})$, characterized by vascular smooth muscle cell (VSMC) accumulation and extracellular matrix deposition in the intima of the grafted vein, is a major cause of venous graft failure between 1 month and 1 year after implantation ${ }^{1}$. In analogy to atherosclerosis, it is increasingly being appreciated that inflammatory processes may play an important role in the development of $\mathrm{IH}$ as well ${ }^{2,3}$. The arterial shear and circumferential stresses to which the grafted vein is exposed to, as well as the endothelial damage caused by surgery, triggers venous cellular activation leading to an inflammatory response that might contribute to intimal hyperplasia ${ }^{4}$. This response starts with induction of adhesion molecule expression on VSMCs and endothelial cells (ECs), monocyte adhesion and extravasation into the vessel wall ${ }^{1}$. Initially, leukocytes (e.g. monocyte derived macrophages and T-cells) are drawn towards the injured vascular wall by chemotactic factors, among others, the very potent monocyte chemotactic protein-1 (MCP-1). MCP-1 is secreted by SMCs ${ }^{5}$, fibroblasts ${ }^{6}$, and shear stressed $\mathrm{ECs}^{7}$, and is associated with the development of intimal hyperplasia in vein grafts $^{8}$. Recruitment of T-cells and macrophages has been strongly implicated in the initiation and amplification of the inflammatory response leading to $\mathrm{IH}^{9}$. Upon activation, macrophages secrete cytokines, chemokines, growth-regulating molecules and metalloproteinases $(\mathrm{MMPs})^{10}$. Furthermore, activated macrophages are capable to present antigens to T-cells which trigger cell-mediated immune responses ${ }^{11}$. Consequently, T-cell activation results in the secretion of cytokines, including interferon-y and tumor necrosis factor, which amplifies the inflammatory response, and aggravates $\mathrm{IH}^{12}$. Although it is widely accepted that inflammatory processes play a significant role in $\mathrm{IH}$ development, it is unclear how inflammatory activity relates to the extent of $\mathrm{IH}$ and therefore bypass patency. Both in situ as well as systemic inflammatory processes may be involved in the development of $\mathrm{IH}$. Non-specific, systemic innate immune responses have been implicated in the development of intimal hyperplasia ${ }^{13}$. Therefore, preexistent activation of the immune system at the time of bypass surgery might hamper graft survival ${ }^{14}$. In-situ inflammatory processes might also facilitate disproportionate $\mathrm{IH}$ development. Wali et al showed that inflammatory cells are present in normal appearing veins used for arteriovenous fistula construction and co-localize with microscopic degenerative 
changes in the vessel wall ${ }^{15}$. Furthermore, is has been shown that preexisting vein disease is a cause of venous bypass failure ${ }^{16}$.

In the first part of the present study we observed that $\mathrm{IH}$ lesions of stenosed/occluded vein grafts were more densely populated by macrophages and T-cells compared to native veins. Considering the pronounced involvement of inflammatory cells in the development of $\mathrm{IH}$ and the assumption that preexistent pro-inflammatory changes within the saphenous vein might represent a higher risk of early vein graft failure, we wanted to see whether the simple presence of inflammatory cells within the saphenous veins is related to early bypass failure.

\section{Patients and methods}

Specimens $(n=15)$ of failed venous bypass grafts were harvested from fifteen patients ( 8 men and 7 women; mean 59.8 years) during venous bypass graft revision at the surgical department of Maastricht University Hospital. Failure of bypass grafts was suspected on clinical ground (clinical evaluation, ankle-arm index $<90$ ), and verified by high-grade stenosis or occlusion on angiography. The stenosed or occluded segment of the failed bypass grafts was formalin-fixed and paraffin embedded.

Left-over segments of greater saphenous veins were obtained from 17 patients (10 male, 7 female), undergoing autologous venous infra-inguinal bypass graft surgery for critical limb ischemia. The average age of the patients was 67.2 years (range: 49 - 80 years). The suitability of the vein as bypass graft was assessed by means of pre-operative ultrasound scan and per-operative macroscopic evaluation. Only veins of adequate size and macroscopically free of pre-existent disease (varicose, calcifications, occlusion) were actually used as bypass grafts. After explantation, the left-over vein segments were immediately perfusion-fixed at $100 \mathrm{~mm} \mathrm{Hg}$ in $4 \%$ formalin for 4 hours, followed by 18 hours in $70 \%$ ethanol, and finally paraffin-embedded for morphometric and immunohistological analyses.

The study was approved by the Medical Ethical Committee of Maastricht University Hospital and conformed with the principles outlined in the declaration of Helsinki ${ }^{17}$. All patients entered the study after giving written informed consent.

Immunohistochemistry

The failed bypass graft and left-over vein segments were cut in $4 \mu \mathrm{m}$ thick slices, 
deparaffinized and rehydrated by subsequent washing in xylene, $100 \% \mathrm{EtOH}$, $70 \% \mathrm{EtOH}, 50 \% \mathrm{EtOH}$ and phosphate buffer. Sections were stained with hematoxilin-eosin (HE) and Lawson for routine histology and morphometric analyses or were used for immunohistochemical analyses.

The cellular composition of stenosed bypass grafts and non-diseased leftover veins was assessed using anti-smooth muscle actin and anti-von Willebrand factor antibodies for detection of smooth muscle cells and endothelial cells, respectively. For the detection of inflammatory cells anti-CD68 (macrophages), anti-CD20 (B-lymphocytes), and anti-CD3 (T-cells) antibodies were used. Antigen retrieval was carried out by boiling in citrate buffer, $\mathrm{pH}$ 6.0. Prior to staining aspecific binding sites were blocked by incubation with mouse ascitic fluid in $2 \%$ BSA/TBS/tween for 20 minutes. After washing in Tris buffered saline the sections were immunohistochemically analyzed for presence of macrophages, B- and Tcells by incubation with anti-CD68 (Dako M0814), anti-CD20 (Dako M0755), and anti-CD3 (Dako M7254) antibodies respectively. Primary antibodies were diluted in TBS and applied to the slides for 60 minutes at room temperature. After 3 washes with TBS for 5 minutes, a biotinylated horse anti-mouse secondary antibody (1:400 dilution, Dako) was applied for 30 minutes at room temperature, followed by a steptavidin amplification reagent (Dako) for 30 minutes at room temperature. Finally, Fast Red was used for 10 minutes at room temperature, yielding a red reaction product. Visualization of all nuclei in the tissue sections was realized with a haematoxylin counterstain. The incidence of CD3 positive Tcells, CD20 positive B-cells and CD68 positive macrophages was determined by means of a microscope-based video image analysing system (Analysis ${ }^{\circledR}$, Soft Imaging System, Münster, Germany) at a 10 x 40 magnification. Direct quantification was done by counting total immunoreactive macrophages, B- and T-cells in the entire section. For reasons of practicability semi-quantification analysis was performed to determine immunoreactive T-cells.

\section{Statistical analysis}

Data are expressed as mean values and standard errors of the mean (SEM). Statistical significance was evaluated by the non-parametric Mann-Whitney $U$ test for independent groups using the SPSS 10.0 package for Windows (SPSS, Chicago, III., USA).

\section{Results}

All failed bypass graft sections showed considerable neointimal areas and 
increased intima-media thickness as compared to native saphenous veins. None of the removed bypass grafts failed as a result of acute thrombosis as determined by visual inspection and microscopic evaluation. Anti- $\alpha$-smooth muscle actin staining revealed smooth muscle cells as the main cellular component of the neointima.

Immunostaining against macrophages on non-diseased veins showed limited amounts of CD68 positive cells. In contrast, we observed an overwhelming increase in the number of macrophages in intimal hyperplastic lesions of stenosed venous bypass grafts. Moreover, the amounts of T-cells in failed venous bypass grafts were significantly higher throughout the examined vessel compared to normal veins (Table 1). However, variable distribution throughout the vessel wall was obvious. T-cells and macrophages were infrequent in the intima, while the adventitia showed apparent higher levels of T-cells. More interestingly, remarkable disparity in macrophage and T-cell load were seen amongst normal veins. Therefore, we hypothesized that macrophage and T-cell presence in saphenous veins before implantation as bypass grafts might be related to attrition rate. Thus, we retrospectively assessed clinical outcome (failed versus open vein graft) at 12 months post-surgery. Through cross checking the clinical notes and vascular laboratory assessments, it was ascertained that 9 venous grafts remained open for longer than one year, whereas 8 vein grafts failed within one year after implantation. The mean survival time of the failed vein grafts was $5.8 \pm 1.4$ months. Veins that developed clinical significant $\mathrm{IH}(\mathrm{DIH})$ did not show morphological differences (intima area, intima/media thickness) at base line with veins that did not develop $\mathrm{IH}(\mathrm{nDIH})$.

Table 1.

Presence of macrophages, B-cells and T-cells in failed venous bypass grafts, vs normal veins. n.int, (neo)intima; med, media; adv, adventitia.

\begin{tabular}{|c|c|c|c|c|c|c|c|c|c|c|c|}
\hline & \multicolumn{4}{|c|}{$\begin{array}{l}\text { Macrophages } \\
\text { (N) }\end{array}$} & \multicolumn{3}{|c|}{$\begin{array}{l}\text { B-cells } \\
\text { (N) }\end{array}$} & \multicolumn{4}{|c|}{$\begin{array}{l}\text { T-cells } \\
\text { (scale: 0-4) }\end{array}$} \\
\hline & n.int & med & adv & total & n.int & $\begin{array}{l}\text { med } \\
d\end{array}$ & $\mathrm{adv}$ & n.int & $\begin{array}{l}\text { med } \\
d\end{array}$ & adv & $\begin{array}{l}\text { total } \\
\text { al }\end{array}$ \\
\hline Failed bypass ( $n=15)$ & 2.2 & 6.1 & 33 & 41 & 0 & 0 & 0 & 1.0 & 0.9 & 1.8 & 3.3 \\
\hline Normal veins $(n=17)$ & 0.4 & 0.6 & 8.9 & 9.4 & 0 & 0 & 0 & 0.2 & 0.4 & 0.6 & 1.4 \\
\hline P (Mann-Whitney) & 0.54 & 0.35 & .018 & .015 & - & - & - & 0.12 & 0.19 & .035 & .023 \\
\hline
\end{tabular}

(*) 0: 0-10 T-lymphocytes, 1: few T-lymphocytes, 2: moderate number of T-lymphocytes, 3: many T-lymphocytes s; 4: excessive number of T-lymphocytes. 
Moreover, demographics between $\mathrm{DIH}$ and $\mathrm{nDIH}$ groups were compared and no differences in incidence of diabetes, hypertension, smoking, cardiac- and cerebrovascular disease were noticed. Immunhistochemical analyses revealed significantly higher amounts of T-lymphocytes and macrophages in saphenous veins that developed $\mathrm{IH}$ within one year than in the left over segments of vein grafts that remained open for more than one year (figure 1 and figure 2). As mentioned earlier for hyperplastic lesions from failed grafts, maximum inflammatory cell localization was seen in the adventitia, but average medial Tcell and macrophage count was also higher in $\mathrm{DIH}$ veins compared to $\mathrm{nDIH}$ veins (figure 1 and figure 2). In contrast to macrophage and T-cell presence no CD20 (B-cells) immunoreactivity was noticed in either native veins or intimal hyperplastic lesions. These findings support the concept that inflammatory cells might be involved in the development of $\mathrm{IH}$.

\section{Discussion}

Following implantation in the arterial circulation venous conduits undergo a sequence of events which in several cases result in infinite vein graft disease and eventual failure. Initially, the development of a diffuse intimal thickening is noticeable, which is followed by more pronounced intimal hyperplasia and progresses to atheromatous plaque formation. In these more mature stages of vein graft disease inflammatory cell deposits, in particular lymphocytes and macrophages are clearly localized within the intimal hyperplastic lesion. The present study analogously shows that intimal hyperplastic lesions are characterized by accumulation of T-cells and macrophages supporting the association between vein graft remodeling and influx of inflammatory cells. However, over recent years it became clear that inflammatory cells not merely localize in intimal hyperplastic lesions, but play an essential role in the initiation and aggravation of vein graft attrition. MCP-1 expression and subsequent monocyte infiltration have been associated with $\mathrm{IH}$ development in vein grafts ${ }^{9,18}$.

The influx of leucocytes into the graft wall may be triggered by injury of the vein during the surgical procedure (i.e. vein handling, warm ischemia and reperfusion) or may be related to adaptation of the grafted vein to arterial flow resulting in graft remodeling. Stark et al showed that monocytes infiltrate the luminal surface from day 1 post-surgery and reside in the venous wall thereafter ${ }^{19}$. Surprisingly, we found not only failed bypass grafts to express inflammatory cells but saphenous veins before implantation as well. 


\section{A. Presence of macrophages in left-over segments of venous bypass grafts}

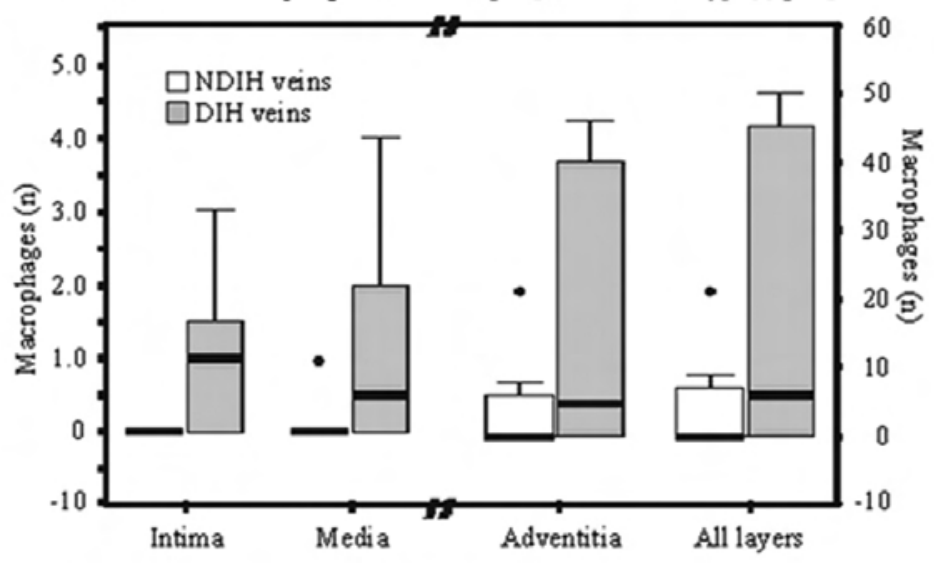

B. Presence of $T$-cells in left-over segments of venous bypass grafts

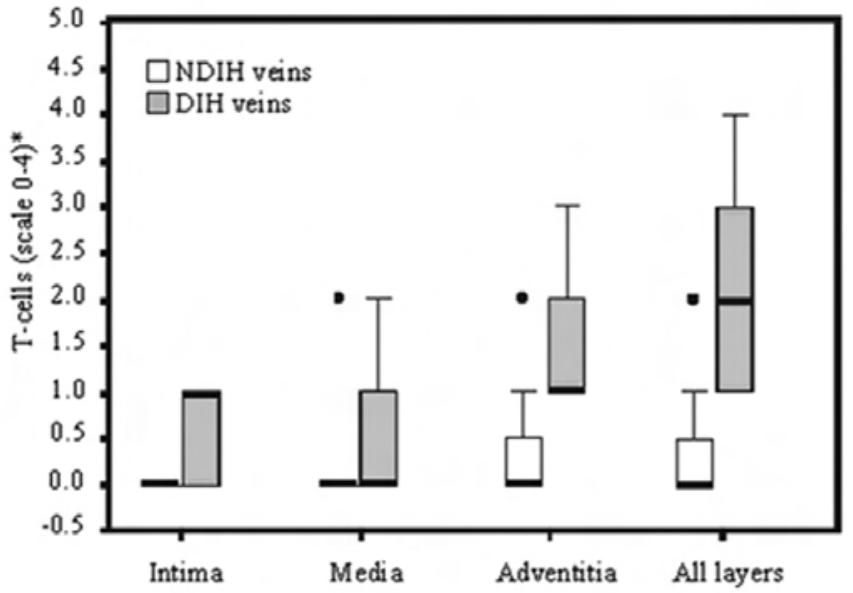

\section{Figure 1.}

Distribution of macrophages and T-lymphocytes in left over segments of saphenous veins implanted as bypass grafts. A, average number of macrophages is significantly higher in the media and adventitia of DIH veins in comparison with NDIH veins. B, semi quantification analysis* showed significantly higher amounts of T-lymphocytes in the media and adventitia of DIH veins in comparison with NDIH veins. NDIH veins: left-over segments of veins Not Developing $\mathrm{IH}$ as bypass grafts; DIH veins: left-over segments of veins Developing $\mathrm{IH}$ as bypass grafts. ${ }^{*} \mathrm{P}<.05$

(*) 0: 0-10 T-lymphocytes, 1: few T-lymphocytes, 2: moderate number of T-lymphocytes, 3: many T-lymphocytes s; 4: excessive number of T-lymphocytes. 


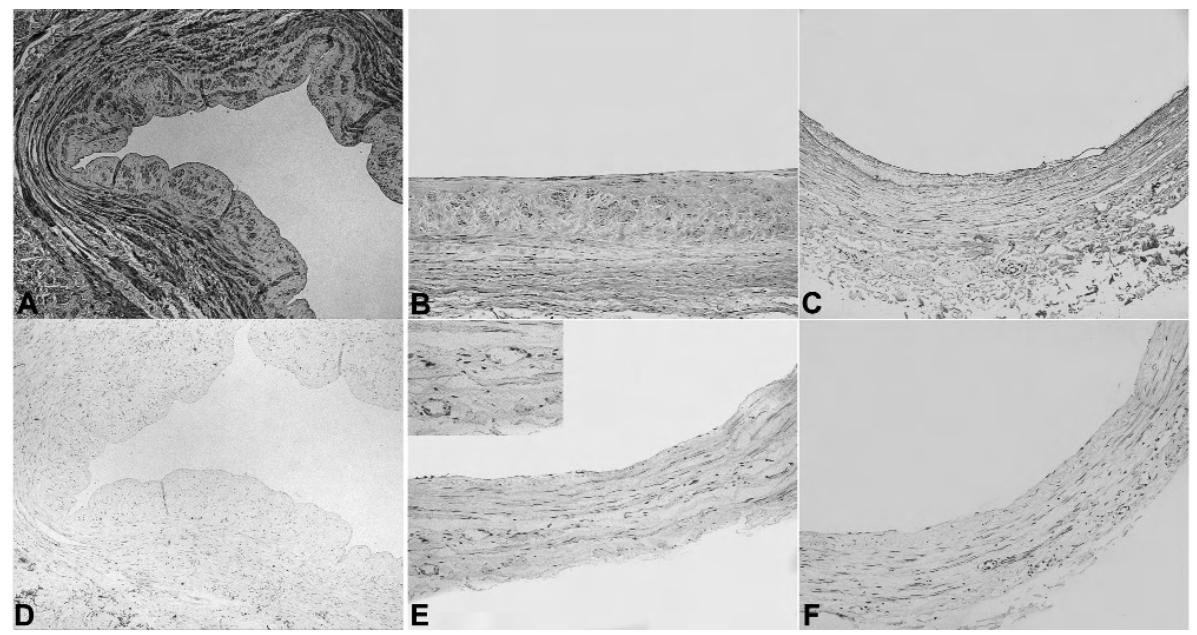

\section{Figure 2.}

Immunohistochemical representation of macrophage and T-lymphocyte distribution in failed bypass sections and saphenous vein segments. A-C: abundant expression of CD3 immunoreactivity (T-lymphocyte) in failed bypass graft segment (A), while T-cell presence in DIH vein segment is clearly less pronounced. CD3 expression in NDIH vein segment $(C)$ is virtually absent. D-F: macrophages (CD68 immunoreactivity) mainly localize in the media and adventitia of failed bypass graft segment (D). To a lesser extent, macrophages also are present in the media and adventitia of DIH vein segments (E). Macrophage count is almost nil in NDIH veins (F).

Inflammatory cell deposits in the venous wall prior to implantation have not been described as yet. Although a relatively small group of veins was available for research, we noticed a marked variability in inflammatory cell load between different saphenous veins. Since mononuclear cells has been described in the intima of non-atherosclerotic carotid arteries of children ${ }^{20}$ suggesting that a local immune-mediated process may underlie the development of atherosclerosis, we hypothesized that the early presence of inflammatory cells in saphenous veins at the time of harvest and their implantation as grafts might render these veins susceptible to develop excessive intimal hyperplasia leading to graft failure.

Interestingly, our data show that presence of T-cells and macrophages in the intima/media of veins before implantation as bypass grafts is associated with subsequent development of venous intimal hyperplasia, emphasizing the role of local inflammatory mechanisms in the early stages of the development of venous intimal hyperplasia. Firstly, this substantiates that inflammatory cells might be involved in the development of intimal hyperplasia. Secondly, the 
presence of T-cells and macrophages in veins used for infra-inguinal revascularization might therefore be a valuable a priori marker of graft failure. Such a marker could allow tailored graft monitoring and preventive medical (anti-inflammatory) treatment schemes ${ }^{21}$.

The presence of inflammatory cells in saphenous veins might relate to preexistent degenerative disease like varicose or phlebosclerosis. However, except for structural studies ${ }^{22}$, to the best of our knowledge no available studies showed inflammatory cell contents in degenerative saphenous veins. Panetta et $\mathrm{al}^{16}$ already suggested that unsuspected preexisting saphenous vein disease is a cause of vein bypass failure. As in the study form Panetta et al visual inspection revealed no signs of vein disease in our patient group.

Except for gender, the presence of risk factors for vein graft disease (age, hypertension, smoking, diabetes and level of distal anastomosis) did not differ significantly between occluded and patent grafts. Only 1 of 8 patients with occluded vein grafts was female compared to 6 of 9 patients with patent grafts. Since female sex has been associated with increased incidence of graft occlusion due to smaller caliber vessels ${ }^{22,23}$, diagnosis- and treatment-delay in women, and presence of inflammatory cells in the vascular wall is not known to be related to gender, it is unlikely that this factor has been a potential confounder in our study.

Concluding, our findings underscore the inflammatory nature of intimal hyperplasia, and suggest that the early presence of T-cells and macrophages in veins used as bypass grafts might be a predictive marker for vein graft occlusion. This observation offers a potential means to select patients at risk for graft failure allowing applying intensified monitoring and anti-inflammatory treatment schemes to these patients. 


\section{References}

1. Motwani JG, Topol EJ. Aortocoronary saphenous vein graft disease: pathogenesis, predisposition, and prevention. Circulation. 1998;97(9):916-931.

2. Christiansen JF, Hartwig D, Bechtel JF, Kluter H, Sievers H, Schonbeck U, Bartels C. Diseased vein grafts express elevated inflammatory cytokine levels compared with atherosclerotic coronary arteries. Ann Thorac Surg. 2004;77(5):1575-1579.

3. Rectenwald JE, Moldawer LL, Huber TS, Seeger JM, Ozaki CK. Direct evidence for cytokine involvement in neointimal hyperplasia. Circulation. 2000;102(14):1697-1702.

4. Serrano CV, Jr., Ramires JA, Venturinelli M, Arie S, D'Amico E, Zweier JL, Pileggi F, da Luz PL. Coronary angioplasty results in leukocyte and platelet activation with adhesion molecule expression. Evidence of inflammatory responses in coronary angioplasty. J Am Coll Cardiol. 1997;29(6):1276-1283.

5. Graves DT, Jiang YL, Williamson MJ, Valente AJ. Identification of monocyte chemotactic activity produced by malignant cells. Science. 1989;245(4925):1490-1493.

6. Rollins BJ, Stier P, Ernst T, Wong GG. The human homolog of the JE gene encodes a monocyte secretory protein. Mol Cell Biol. 1989;9(11):4687-4695.

7. Shyy YJ, Hsieh HJ, Usami S, Chien S. Fluid shear stress induces a biphasic response of human monocyte chemotactic protein 1 gene expression in vascular endothelium. Proc Natl Acad Sci U S A. 1994;91(11):4678-4682.

8. Schepers A, Eefting D, Bonta Pl, Grimbergen JM, de Vries MR, van Weel V, de Vries CJ, Egashira K, van Bockel JH, Quax PH. Anti-MCP-1 gene therapy inhibits vascular smooth muscle cells proliferation and attenuates vein graft thickening both in vitro and in vivo. Arterioscler Thromb Vasc Biol. 2006;26(9):2063-2069.

9. Stark VK, Hoch JR, Warner TF, Hullett DA. Monocyte chemotactic protein-1 expression is associated with the development of vein graft intimal hyperplasia. Arterioscler Thromb Vasc Biol. 1997;17(8):1614-1621.

10. Newby AC, Zaltsman AB. Molecular mechanisms in intimal hyperplasia. J Pathol. 2000;190(3):300-309.

11. Hansson GK, Jonasson L, Seifert PS, Stemme S. Immune mechanisms in atherosclerosis. Arteriosclerosis. 1989;9(5):567-578.

12. Ross R. Atherosclerosis—an inflammatory disease. N Engl / Med. 1999;340(2):115-126.

13. Danenberg HD, Welt FG, Walker M, 3rd, Seifert P, Toegel GS, Edelman ER. Systemic inflammation induced by lipopolysaccharide increases neointimal formation after balloon and stent injury in rabbits. Circulation. 2002;105(24):2917-2922.

14. Mitra AK, Gangahar DM, Agrawal DK. Cellular, molecular and immunological mechanisms in the pathophysiology of vein graft intimal hyperplasia. Immunol Cell Biol. 2006;84(2):115-124. 
15. Wali MA, Eid RA, Dewan M, Al-Homrany MA. Pre-existing histopathological changes in the cephalic vein of renal failure patients before arterio-venous fistula (AVF) construction. Ann Thorac Cardiovasc Surg. 2006;12(5):341-348.

16. Panetta TF, Marin ML, Veith FJ, Goldsmith J, Gordon RE, Jones AM, Schwartz ML, Gupta SK, Wengerter KR. Unsuspected preexisting saphenous vein disease: an unrecognized cause of vein bypass failure. J Vasc Surg. 1992;15(1):102-110; discussion 110-102.

17. World Medical Association Declaration of Helsinki. Recommendations guiding physicians in biomedical research involving human subjects. Cardiovasc Res. 1997;35(1):2-3.

18. Tatewaki H, Egashira K, Kimura S, Nishida T, Morita S, Tominaga R. Blockade of monocyte chemoattractant protein-1 by adenoviral gene transfer inhibits experimental vein graft neointimal formation. J Vasc Surg. 2007;45(6):1236-1243.

19. Stark VK, Warner TF, Hoch JR. An ultrastructural study of progressive intimal hyperplasia in rat vein grafts. J Vasc Surg. 1997;26(1):94-103.

20. Wick G, Romen M, Amberger A, Metzler B, Mayr M, Falkensammer G, Xu Q. Atherosclerosis, autoimmunity, and vascular-associated lymphoid tissue. Faseb J. 1997;11(13):1199-1207.

21. Leu HJ, Vogt M, Pfrunder H, Odermatt BF. Phlebosclerosis: disorder or disease? Vasa. 1991;20(3):230-236.

22. Domanski MJ, Borkowf CB, Campeau L, Knatterud GL, White C, Hoogwerf B, Rosenberg Y, Geller NL. Prognostic factors for atherosclerosis progression in saphenous vein grafts: the postcoronary artery bypass graft (Post-CABG) trial. Post-CABG Trial Investigators. J Am Coll Cardiol. 2000;36(6):1877-1883.

23. Wengerter KR, Veith FJ, Gupta SK, Ascer E, Rivers SP. Influence of vein size (diameter) on infrapopliteal reversed vein graft patency. J Vasc Surg. 1990;11(4):525-531. 



\section{Chapter 3}

Human heat shock protein 60 stimulates vascular smooth muscle cell proliferation through toll like receptor 2 and 4 


\begin{abstract}
Objective. Heat shock proteins (HSP) from endogenous and exogenous origin are suspected contributors to the initiation and aggravation of vascular pathologies, like atherosclerosis and restenosis. Toll like receptor (TLR) 2 and 4 are well known receptors for exogenous pathogen-associated molecular patterns and have recently been thought to play a role in HSP60 induced cellular activation. We hypothesized that human HSP60 directly stimulates venous smooth muscle cell (VSMC) proliferation through a TLR dependent mechanism.
\end{abstract}

Methods. Localization of HSP60, TLR2 and TLR4 was studied in failed venous grafts and normal venous tissue by double immunostaining. In vitro VSMCs were incubated for 48 hours with recombinant human HSP60. In other experiments, VSMCs were pre-incubated for 30 minutes with specific anti-TLR2 and anti-TLR4 antibodies. VSMC proliferation was determined by Ki67 immunoreactivity and mean values were compared between experimental and control groups. In addition, human embryonic kidney (HEK) cells transfected with human TLR2 or TLR4/MD-2 were exposed for 48 hours to HSP60, and proliferation was determined by using a hemocytometer.

Results. Co-localization of HSP60 and TLRs was detected in all neointimal lesions but was virtually absent in normal veins. Human HSP60 stimulated VSMC proliferation in a concentration dependent fashion. In addition, TLR 2 and TLR 4 antibodies attenuated VSMC proliferation. The role of TLR-mediated stimulation of cell proliferation by HSP60 was supported by the significant increase in proliferation of transfected HEK cells.

Conclusions. These findings provide supporting evidence for the role of HSP60 and TLR2 and 4 in vascular disease. Moreover, our data surpass the infection and autoimmunity based hypothesis of cardiovascular disease and suggests an additional HSP60-related autocrine process.

Keywords: Toll like receptor; heat shock protein; neointima 


\section{Introduction}

Intimal hyperplasia (IH), mainly characterized by venous smooth muscle cell (VSMC) migration and proliferation, contributes significantly to venous graft failure and atherosclerosis ${ }^{1}$. Although both processes have been studied extensively, the exact mechanisms are still unknown. Until the 1990s, most research focused on the role of various cytokines, growth factors and their cognate receptors. More recently, heat shock proteins (HSPs) emerged as possible culprits to cardiovascular disease ${ }^{2}$. Altered hemodynamic conditions, like those found in venous bypass grafts and atherosclerosis prone sites of the vascular tree, as well as high levels of oxidized low-density lipoproteins are possible causes of HSP induction ${ }^{3-4}$. In addition, microbial agents (eg Chlamydia pneumoniae) induce the production of bacterial as well as the endogenous HSP production by (vascular) host cells ${ }^{5,6}$. Indeed, Chlamydia HSP60 co-localizes with human HSP60 within atherosclerotic plaque macrophages $^{7}$. Initially, it was found that serum levels of antibodies against human and mycobacterial HSP60 markedly correlated with cardiovascular disease $^{8-9}$. Succeeding research showed that soluble HSP levels are associated with intima-media thickness and early atherosclerosis ${ }^{10}$. Kol and colleagues were the first to demonstrate that human HSP60 activates human endothelial cells, smooth muscle cells, and monocyte-derived macrophages ${ }^{11}$ thereby providing a potential link between HSP and vascular disease. Furthermore, endogenous as well as exogenous HSP60 have been implicated in vascular smooth muscle cell proliferation ${ }^{6,12}$. Most evidence suggests a central role for Toll-like receptors (TLRs) in HSP related cellular signaling. Like HSPs, TLRs are conserved through evolution. Of the 10 identified human TLRs, TLR2 and TLR4 are generally believed to be involved in the pathogenesis of cardiovascular disease ${ }^{13-14}$. TLR2 and 4 are expressed in most cardiovascular cells, like endothelial cells ${ }^{15}$, smooth muscle cells ${ }^{13}$ and macrophages ${ }^{16}$. Activation of these cells as a response to self and non-self ligands appears to be mediated by TLR2 and $4^{17-18}$.

However, human HSP60 induced VSMC proliferation, and the role of TLR2 and 4 herein, has not been investigated yet. In the present study, we first localized HSP60, TLR2 and TLR4 in venous neointimal lesions. In addition, we determined the effect of human HSP60 on VSMC proliferation and the mediating potency of TLR2 and TLR4 blockers in this process. Moreover, as a proof of concept, we determined whether HSP60 is able to enhance cell proliferation of HEK cells stably transfected with either TLR2 or TLR4/MD2. 


\section{Methods}

Reagents

Recombinant human HSP60 proteins were purchased from StressGen Biotechnologies Corp. (Victoria, British Columbia, Canada). This preparation (catalog no. ESP-540) was low in endotoxin as determined using Limulus Amebocyte Lysate (LAL) assay. Functional grade purified mouse-anti-human Toll-like receptor 2 and 4 (clone TL2.1 and HTA125 respectively) antibodies were obtained from eBioscience (San Diego, CA, USA). Monoclonal anti-Ki67 antibody was obtained from DakoCytomation, Denmark. Human embryonic kidney (HEK) cells stably transfected with human TLR2 or TLR4/MD-2 ${ }^{19}$ were kindly provided by Dr. Golenbock (Worcester, MA).

\section{Cell culture}

Venous smooth muscle cells were obtained from ATCC (Manassas, USA), and cultured in F-12K medium (Kaighn's Modification of Ham's F-12 Medium), supplemented with $0.1 \mathrm{mg} / \mathrm{ml}$ heparin, $0.03 \mathrm{mg} / \mathrm{ml}$ endothelial cell growth supplement (ECGS), and 10\% fetal calf serum. Passages 4-6 were used for experiments.

Transfected HEK cells were grown in Dulbecco's Modified Eagle Medium (Gibco, Grand Island, NY) with 10\% fetal calf serum (FCS). HEK cells stably transfected with the empty vector pcDNA were used as control cells.

\section{Immunohistochemistry}

Eight samples of failed venous grafts were obtained from patients undergoing arteriovenous fistula revision at the surgical department of the University Hospital Maastricht. During revision, the stenotic lesions were removed and fixed in $10 \%$ formalin for 4 hours, followed by 18 hours in $70 \%$ ethanol, and paraffin-embedded for immunocytochemistry. Paraffin sections were incubated in $2 \% \mathrm{BSA} / \mathrm{PBS} /$ tween for 20 minutes to block aspecific binding activity. TLR2, TLR4, and HSP60 antibodies were diluted in 2\% BSA/PBS and applied to the slides for 60 minutes at room temperature, followed by biotinylated goat anti-mouse IgG (HSP60) and swine anti-rabbit IgG (TLR2 and TLR4) (DakoCytomation, Denmark) incubation, followed by a steptavidin amplification reagent. Double staining visualization was finalized by fast red (TLR2 and TLR4) and fast blue (HSP60) application.

Vascular smooth muscle cell proliferation

VSMCs were seeded on glass coverslips (5000 cells/ $\left.\mathrm{cm}^{2}\right)$ in 24-well plates and 
synchronized for 24 hours in F-12K medium, supplemented with $2 \%$ fetal calf serum. In some experiments, VSMCs were incubated in different concentrations of recombinant human HSP60 for 48 hours. In others, TLR2 or TLR4 antibodies were added 30 minutes before exposure to HSP60. After 48 hours, cells were washed in PBS, fixed in formaldehyde, and permeabilized in MP-40 for 20 minutes. Nonspecific binding sites were blocked with $2 \%$ BSA. To determine VSMC proliferation, VSMCs were incubated with a mouse anti-human Ki67 antibody, followed by FITC-conjugated rabbit anti-mouse IgG (DakoCytomation, Denmark). Visualization was done by means of confocal fluorescence microscopy.

For each experimental group and control group, total nuclei and Ki67 positive nuclei were counted by an observer blinded to the specimen group. In total 4 experiments were done.

\section{HEK cell proliferation}

HEK cells, either transfected with TLR2 or TLR4/MD2 or with the empty vector pcDNA (control), were seeded at a density of $4 \times 106$ cells/flask and incubated with human HSP60 (1 or $20 \mathrm{mg} / \mathrm{ml}$ ) in DMEM/1\% FCS for 48 hours. The attached cells were harvested by trypsinization and cell number was determined using a hemocytometer.

\section{Statistics}

Data were expressed as mean \pm SE. Student's $t$ test was used for the comparison between the different groups. Differences were considered significant at $\mathrm{P}<0.05$.

\section{Results}

\section{Co-localization of HSP60 and Toll-like receptors}

We determined the expression of HSP60, TLR2, and TLR4 in neointimal lesions from failed arteriovenous fistulas. Since we hypothesized a direct stimulating role for human HSP60 in TLR2 and TLR4 mediated VSMC proliferation, we verified whether these mediators co-localized in (partially) occluded vascular segments. Immunohistochemical double-staining revealed a clear co-localization of TLR4 and HSP60 in venous neointimal lesions (Fig. 1A). TLR2 also co-localized with HSP60, albeit to a lesser extent than TLR4 (Fig. 1B). In contrast, control saphenous veins were deficient in TLRs and HSP60 (Fig. 1C and 1D). Negative controls, where the primary antibody was substituted with a non-immune $\lg G$ from the same species, confirmed specificity of the staining procedure (data not shown). 

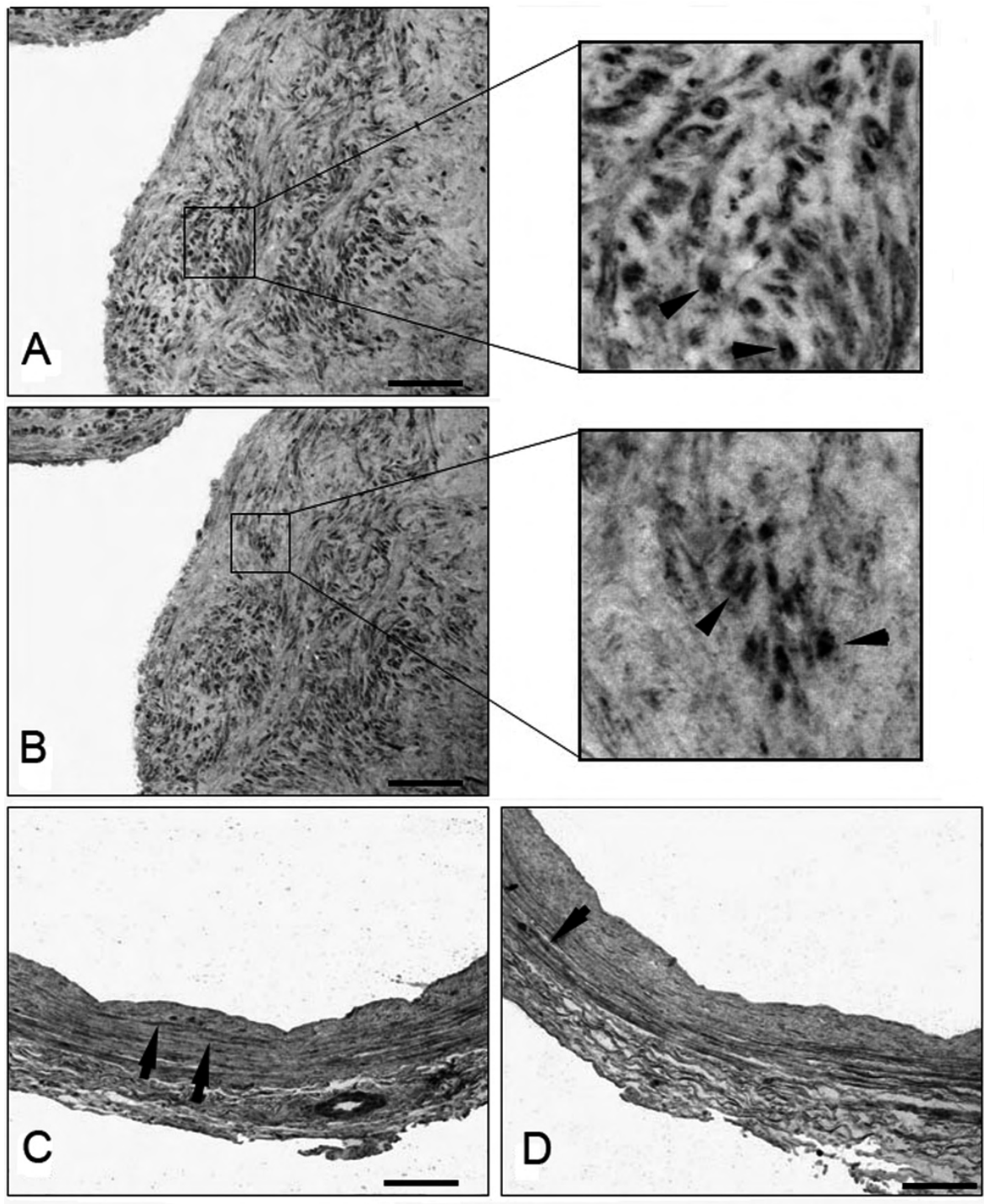

Figure 1.

Immunohistochemical analysis of TLR2, TLR4 and HSP60 proteins. A, doublestaining for TLR4 (red) and HSP60 (blue) in AVF neointimal lesion. Arrows indicate double-positive cells for TLR4 and HSP60 (detail). B, doublestaining for TLR2 (red) and HSP60 (blue). Arrows indicate double-positive cells for TLR2 and HSP60 (detail). C and D, Doublestaining for TLR2 or TLR4 (red) respectively and HSP60 (blue) in control venous segments. Arrows indicate diffuse TLR2 and TLR4 staining in medial

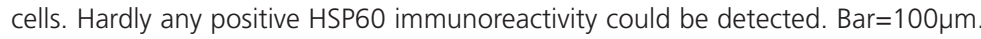



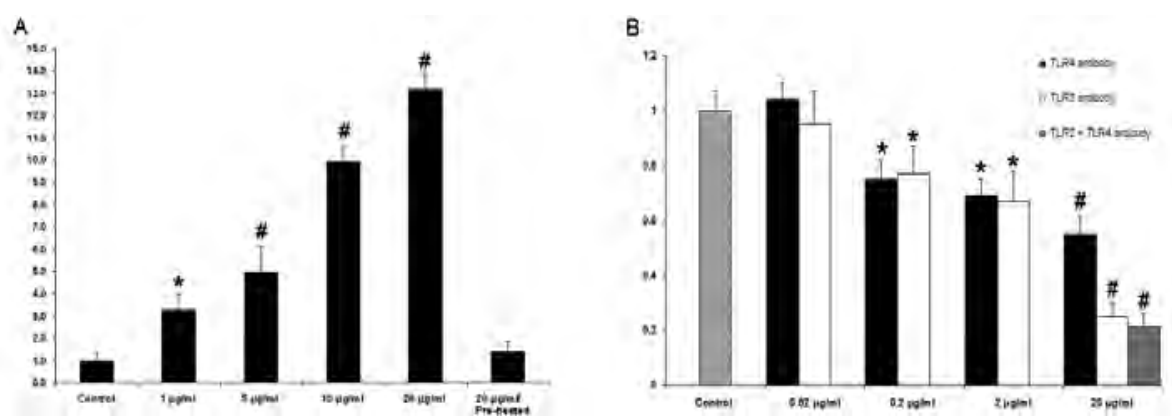

Figure 2.

Human heat shock protein 60 stimulates VSMC proliferation in a concentration and TLR2/4 dependent way. A, VSMCs were exposed to increasing concentrations of recombinant human HSP60 for 48 hours ( $n=4$ experiments). In the control group, VSMCs were exposed to medium containing $2 \%$ FCS. Pretreatment of the HSP60 preparations $(20 \mathrm{mg} / \mathrm{ml}, 20 \mathrm{~min} .100 \mathrm{oC})$ attenuated VSMC proliferation to control levels. B, anti-TLR2 and anti-TLR4 antibodies attenuated the mitogenic effect of $10 \mu \mathrm{g} / \mathrm{ml} \mathrm{HSP60}$ (control group) in a concentration dependent way ( $\mathrm{n}=4$ experiments). ${ }^{*} P<0.05$ and $\# P<0.01$, significantly different from control.

\section{Human HSP60 induces VSMC proliferation}

To investigate the mitogenic effect of human HSP60 on quiescent smooth muscle cells, we determined the percentage of Ki67 positive nuclei on a glass coverslip containing a total of $\sim 5000$ cells after 48 hours of human HSP60 stimulation (Fig. 2A). Exposure to HSP60 for 48 hours resulted in a concentration dependent increase in VSMC proliferation, with a maximum observed at $20 \mu \mathrm{g} / \mathrm{ml}$ recombinant HSP60 (Fig. 2A).

Induction of VSMC proliferation by human HSP6O is TLR2 and TLR 4 dependent To confirm that the effect of human HSP60 is mediated by stimulation of TLR2 or TLR4, we investigated the effect of TLR antibodies. We pre-incubated quiescent VSMCs for 30 minutes with either TLR2 or TLR4 antibodies, before adding $10 \mu \mathrm{g} / \mathrm{ml} \mathrm{HSP60}$ for $48 \mathrm{~h}$. Both TLR2 and TLR4 antibodies attenuated the stimulatory effect of HSP60 in a concentration dependent way (Fig. 2B).

\section{HSP6O induces proliferation of HEK cells transfected with human TLR2 or} TLR4/MD-2

HEK cells naturally lack TLR2 and TLR4, and genetic complementation with these receptors renders HEK cells responsive to their respective ligands. To 
further scrutinize the importance of TLR2 and TLR4 in mitogenic signaling, we compared the proliferative response of transfected and control HEK cells to human HSP60. When TLR2- and TLR4/MD2-expressing HEK cells were exposed to HSP60 $(20 \mathrm{mg} / \mathrm{ml}, 48 \mathrm{~h})$, total cell number increased 2.2 and 2.1fold, respectively $(p<0.05$ for both), when compared to control HEK cells, thereby providing further evidence that HSP60 invigorates cell proliferation by stimulating TLR2 as well as TLR4. Low $(1 \mu \mathrm{g} / \mathrm{ml})$ HSP60 concentration did not significantly induce HEK-TLR2 or HEK-TLR4/MD-2 cell proliferation.

Human HSP60-induced VSMC proliferation is not due to LPS contamination Bacterial products like lipopolysaccharide (LPS) are known to activate cells through TLR4 or even TLR2 ${ }^{7,20}$. Since Gao and $\operatorname{Tsan}^{21}$ recently demonstrated that contamination of commercially available recombinant human HSP60 preparations with LPS could be responsible for cellular activation, it was crucial to exclude that LPS contamination was responsible for the effects observed in the present study. Therefore, we determined the LPS content of the HSP60 preparations used in our experiments by LAL assay and found that the amount of LPS was $<0.2 \mathrm{pg} / \mathrm{ml}$ (below detection limits) This supports the concept that indeed HSP60, and not LPS, is responsible for the observed increase in cell proliferation which is in agreement with earlier data by Gao et al, who found comparable levels of endotoxin in their preparations, and demonstrated that these levels had no significant effect on cellular activity ${ }^{21}$.

To further exclude LPS involvement in our study, we pre-treated our HSP60 preparations for 20 minutes, $100^{\circ} \mathrm{C}^{22}$ prior to the $48 \mathrm{~h}$ incubation period. Heat pretreatment completely abolished the mitogenic effect of our preparation. Therefore, we are confident that the observed effects can be attributed to HSP60 stimulation and not to LPS contamination.

\section{Discussion}

In the present study we demonstrated that human HSP60 is a potent inducer of VSMC proliferation. Human HSP60 significantly augmented VSMC proliferation above control levels in a dose dependent fashion. Moreover, we showed that human HSP60 uses TLR2 as well as TLR4 to cause its mitogenic effect on VSMCs. Selective inhibition of TLR2 and 4 signaling attenuated HSP60-induced proliferation in a dose dependent way. Besides, HSP60 significantly stimulated the proliferation of HEK cells, expressing either TLR2 or TLR4/MD2, over control levels. Since we also demonstrated co-localization of HSP60 and TLR4 
and to a lesser extent TLR2 in venous neointimal lesions, a causative and interacting role for aforementioned proteins in cardiovascular disease seems even more likely. These results reinforce the data on HSP60, TLR2 and TLR4 involvement in cardiovascular disease.

Inappropriate flow conditions effectively induce $\mathrm{HSPs}^{3,10}$, which have been suspected to provoke autoimmune reactions resulting in atherogenesis ${ }^{2}$ and unbalanced neointimal formation ${ }^{23-24}$. Other studies showed HSP60 induction in monocytes/macrophages, SMCs, and endothelial cells in human atherosclerotic lesions. First prove of human HSP detection in diseased vascular tissue reverts to the early 90 's when Kleindienst et $\mathrm{al}^{25}$ demonstrated HSP60 expression in atherosclerotic lesions. However, data relating HSPs to vein graft disease are scarce. To our knowledge only one report demonstrated enhanced HSP60 and HSP70 expression in saphenous veins exposed to a hypoxic milieu $^{26}$. In the present paper, we demonstrate a marked up-regulation of endogenous HSP60 in failed arteriovenous fistulas. While positive immunostaining for HSP60 was almost absent in control veins, HSP60 immunoreactivity was prominently present in failed fistulas. As failure of such fistulas is mainly due to intemperate VSMC proliferation, we hypothesized that endogenous, 'self' HSP60 may contribute to VSMC proliferation.

Data from our in vitro experiments support this hypothesis. When VSMC were exposed to human HSP60, a dose dependent increase in Ki67 positive cells was observed, indicating that HSP60 indeed stimulates VSMC proliferation. Already $1 \mu \mathrm{g} / \mathrm{ml} \mathrm{HSP60} \mathrm{was} \mathrm{sufficient} \mathrm{to} \mathrm{induce} \mathrm{VSMC}$ proliferation above quiescent levels. Nonetheless, it remains to be questioned whether such concentrations are physiologically relevant. Interestingly, Pockley et $\mathrm{al}^{10}$ observed soluble HSP60 levels $>3 \mu \mathrm{g} / \mathrm{ml}$ in patients with borderline hypertension. As might be assumed that HSP60 levels within the vascular wall are even higher, a true physiological role for endogenous HSP60 is highly likely.

Evidence is mounting that TLR2 and TLR4 act as receptors for HSP60, thereby mediating its proliferating effects possibly by NF-kB activation and mitogen-activated protein kinase pathways with subsequent production of various proliferation-stimulating cytokines ${ }^{13}$. In particular, the recently suggested molecular link between TLR and the TGF- $\beta$ super family may be of interest ${ }^{27}$. Furthermore, the presence of TLR has been demonstrated not only on antigen presenting cells, such as macrophages and dendritic cells, but also on endothelial cells, adventitial fibroblasts and SMCs. Recently, a direct link between TLR4 and vascular remodeling has been demonstrated. In mouse models it has been shown that adventitial TLR4 activation by LPS augments the 
development of atherosclerotic lesions and stimulates neointima formation ${ }^{28}$. Moreover, flow-induced arterial remodeling, which is characterized by a significant increase in the arterial expression of HSP60 and TLR4 mRNA, is markedly diminished in mice lacking a functional TLR4 receptor, thereby strengthening the idea that both TLR4 and locally produced endogenous HSP60 contribute to the development of vascular disorders. In line with this is our observation that HSP60 and TLR4 antigens are far more present in the diseased vascular wall and are co-localized in venous neointima, which further nourishes the hypothesis of a HSP60/TLR4 interaction in the development and/or the progression of various cardiovascular diseases.

In contrast to TLR4, TLR2 has been paid less attention with respect to cardiovascular disease. Nevertheless, TLR2 is also expressed on human endothelial cells and monocyte derived macrophages. Also, in atherosclerotic plaques the expression of TLR2 has been demonstrated ${ }^{13}$. And although initially described as a receptor for peptidoglycans, HSP60 has also been described as a putative ligand for this receptor resulting in the activation of the Toll-like receptor/interleukin-1 receptor signaling pathway in innate immune cells ${ }^{29}$. When we examined the presence of TLR2 in failed arteriovenous fistulas, we found a marked up-regulation of TLR2 antigen expression in the venous neointima, although the up-regulation was not as pronounced as was found for the TLR4 receptor. Furthermore, HSP60 expression was found to co-localize also with TLR2 and in vitro experiments revealed that TLR2 receptor blockade was as effective as or even more effective at high concentrations in preventing VSMC proliferation than blockade of the TLR4 receptor. To stretch the role of TLR2 and 4 even further, we determined the effect of HSP60 on HEK cells transfected with human TLR2 or TLR4/MD-2. As expected, wild-type HEK cells which naturally lack TLRs were non-responsive to HSP60 while genetic complemented HEK cells showed a more than 2-fold increase in cell number after 48 hours of HSP60 exposure. As we found no difference between TLR2 and TLR4 transfected HEK cells, the seemingly more important role for TLR2 in HSP60 signaling as suggested in our blocking experiments in VSMC might be caused by an aspecific effect of the TLR2 receptor antibody at higher concentrations. Overall, these results demonstrate that both TLR2 and TLR4 might contribute significantly in HSP60 induced cell proliferation. Intriguingly, recent in vitro data suggest that stimulation of both TLR2 and 4 results in secretion of matrix metalloproteinases (MMP) by activated monocytes and mast cells $s^{30,31}$. Also, increased transcription of MMP-1 and MMP-3 by cervical smooth muscle following TLR4 stimulation has been demonstrated ${ }^{32}$. Since MMP production and activation are critical steps in vascular remodeling as they 
facilitate SMC proliferation and migration, TLR mediated stimulation of MMP activation may also significantly contribute to vascular remodeling and failure of arteriovenous fistulas.

As mentioned before, others already demonstrated a direct stimulatory effect of HSP60 on VSMCs via TLR4 signaling ${ }^{12}$. However, in this study Chlamydia pneumoniae HSP60 was used. Our results suggest that not only HSP60, derived from bacterial sources, but also human HSP60 stimulates VSMC proliferation, which raises the theory of an autocrine mechanism in venous neointimal formation. As altered hemodynamic conditions, such as at bifurcations or in venous bypass grafts, give rise to a marked up-regulation in HSP60 production, this may have serious consequences for the ultimate clinical outcome. Along the same line Hirono et $\mathrm{al}^{6}$ demonstrated that human HSP60, over-expressed in SMC, resulted in a small but significant increase in proliferation. However, in contrast to our and Sasu's data no effect was found on proliferation levels when chlamydial HSP60 was added exogenously. The reason for this discrepancy remains to be established.

There is one important issue that needs to be discussed. Previously, it has been suggested that the earlier reported activation of macrophages and SMCs by recombinant human HSP60 was due to LPS contamination ${ }^{21}$. However, we believe that contamination is not responsible for the noticed induction of VSMC proliferation in our study. First, we used commercially obtained, highly purified human HSP60, proven to have low endotoxin levels ${ }^{21}$. In agreement, we determined endotoxin levels in our HSP60 preparation by LAL assay, and could not find any significant amounts of endotoxin (detection level of the assay 0.2 $\mathrm{pg} / \mathrm{ml}$ ). Also, we preheated our preparations containing the highest HSP60 concentration before use. It is well established that such treatment eliminates the HSP60 but leaves LPS intact ${ }^{22}$. However, no effect on proliferation was observed when this pre-heated preparation was added to the VSMC culture. Therefore, we are convinced that our results truly represent HSP60-induced cell proliferation and not a concomitant effect of LPS contamination.

In summary, to our knowledge this is the first report demonstrating a stimulating effect of exogenously applied human 'self' HSP60 on VSMC proliferation. Hereby our results surpass the common notion of infection related vascular pathologies, and imply a possible HSP60-induced autocrine process. Furthermore, as HSP60 and both TLR receptor types were markedly up-regulated in the neointima of failed arteriovenous fistulas, this indicates a true physiological role for such autocrine mechanisms. Moreover, these data implicate TLR2 and 4 as possible targets for intervention to limit unfavorable neointimal formation. 
Chapter 3 


\section{References}

1. Ross R. Atherosclerosis--an inflammatory disease. N Engl J Med. 1999;340(2):115-126.

2. Wick G, Kleindienst R, Schett G, Amberger A, Xu Q. Role of heat shock protein 65/60 in the pathogenesis of atherosclerosis. Int Arch Allergy Immunol. 1995;107(1-3):130-131.

3. Hochleitner BW, Hochleitner EO, Obrist P, Eberl T, Amberger A, Xu Q, Margreiter R, Wick G. Fluid shear stress induces heat shock protein 60 expression in endothelial cells in vitro and in vivo. Arterioscler Thromb Vasc Biol. 2000;20(3):617-623.

4. Zhu W, Roma P, Pellegatta F, Catapano AL. Oxidized-LDL induce the expression of heat shock protein 70 in human endothelial cells. Biochem Biophys Res Commun. 1994;200(1):389-394.

5. Xu Q. Role of heat shock proteins in atherosclerosis. Arterioscler Thromb Vasc Biol. 2002;22(10):1547-1559.

6. Hirono S, Dibrov E, Hurtado C, Kostenuk A, Ducas R, Pierce GN. Chlamydia pneumoniae Stimulates Proliferation of Vascular Smooth Muscle Cells Through Induction of Endogenous Heat Shock Protein 60. Circ Res. 2003.

7. Kol A, Sukhova GK, Lichtman AH, Libby P. Chlamydial heat shock protein 60 localizes in human atheroma and regulates macrophage tumor necrosis factor-alpha and matrix metalloproteinase expression. Circulation. 1998;98(4):300-307.

8. Zhu J, Quyyumi AA, Rott D, Csako G, Wu H, Halcox J, Epstein SE. Antibodies to human heat-shock protein 60 are associated with the presence and severity of coronary artery disease: evidence for an autoimmune component of atherogenesis. Circulation. 2001;103(8):1071-1075.

9. Burian K, Kis Z, Virok D, Endresz V, Prohaszka Z, Duba J, Berencsi K, Boda K, Horvath L, Romics L, Fust G, Gonczol E. Independent and joint effects of antibodies to human heat-shock protein 60 and Chlamydia pneumoniae infection in the development of coronary atherosclerosis. Circulation. 2001;103(11):1503-1508.

10. Pockley AG, Wu R, Lemne C, Kiessling R, de Faire U, Frostegard J. Circulating heat shock protein 60 is associated with early cardiovascular disease. Hypertension. 2000;36(2):303-307.

11. Kol A, Bourcier T, Lichtman AH, Libby P. Chlamydial and human heat shock protein 60s activate human vascular endothelium, smooth muscle cells, and macrophages. I Clin Invest. 1999;103(4):571-577.

12. Sasu S, LaVerda D, Qureshi N, Golenbock DT, Beasley D. Chlamydia pneumoniae and chlamydial heat shock protein 60 stimulate proliferation of human vascular smooth muscle cells via toll-like receptor 4 and p44/p42 mitogen-activated protein kinase activation. Circ Res. 2001;89(3):244-250. 
13. Edfeldt K, Swedenborg J, Hansson GK, Yan ZQ. Expression of toll-like receptors in human atherosclerotic lesions: a possible pathway for plaque activation. Circulation. 2002;105(10):1158-1161.

14. Hollestelle SC, De Vries MR, Van Keulen JK, Schoneveld AH, Vink A, Strijder CF, Van Middelaar BJ, Pasterkamp G, Quax PH, De Kleijn DP. Toll-like receptor 4 is involved in outward arterial remodeling. Circulation. 2004;109(3):393-398.

15. Faure E, Equils O, Sieling PA, Thomas L, Zhang FX, Kirschning CJ, Polentarutti N, Muzio M, Arditi M. Bacterial lipopolysaccharide activates NF-kappaB through toll-like receptor 4 (TLR-4) in cultured human dermal endothelial cells. Differential expression of TLR-4 and TLR-2 in endothelial cells. J Biol Chem. 2000;275(15):11058-11063.

16. $\mathrm{Xu} \mathrm{XH}$, Shah PK, Faure E, Equils O, Thomas L, Fishbein MC, Luthringer D, Xu XP, Rajavashisth TB, Yano J, Kaul S, Arditi M. Toll-like receptor-4 is expressed by macrophages in murine and human lipid-rich atherosclerotic plaques and upregulated by oxidized LDL. Circulation. 2001;104(25):3103-3108.

17. Bulut Y, Faure E, Thomas L, Karahashi H, Michelsen KS, Equils O, Morrison SG, Morrison RP, Arditi M. Chlamydial heat shock protein 60 activates macrophages and endothelial cells through Toll-like receptor 4 and MD2 in a MyD88-dependent pathway. J Immunol. 2002;168(3):1435-1440.

18. Zanin-Zhorov A, Nussbaum G, Franitza S, Cohen IR, Lider O. T cells respond to heat shock protein 60 via TLR2: activation of adhesion and inhibition of chemokine receptors. Faseb J. 2003;17(11):1567-1569.

19. Latz E, Visintin A, Lien E, Fitzgerald KA, Monks BG, Kurt-Jones EA, Golenbock DT, Espevik T. Lipopolysaccharide rapidly traffics to and from the Golgi apparatus with the toll-like receptor 4-MD-2-CD14 complex in a process that is distinct from the initiation of signal transduction. J Biol Chem. 2002;277(49):47834-47843.

20. Ohashi K, Burkart V, Flohe S, Kolb H. Cutting edge: heat shock protein 60 is a putative endogenous ligand of the toll-like receptor-4 complex. J Immunol. 2000;164(2):558-561.

21. Gao B, Tsan MF. Recombinant human heat shock protein 60 does not induce the release of tumor necrosis factor alpha from murine macrophages. J Biol Chem. 2003;278(25):22523-22529.

22. Kol A, Lichtman AH, Finberg RW, Libby P, Kurt-Jones EA. Cutting edge: heat shock protein (HSP) 60 activates the innate immune response: CD14 is an essential receptor for HSP60 activation of mononuclear cells. J Immunol. 2000;164(1):13-17.

23. George J, Greenberg S, Barshack I, Singh M, Pri-Chen S, Laniado S, Keren G. Accelerated intimal thickening in carotid arteries of balloon-injured rats after immunization against heat shock protein 70. J Am Coll Cardiol. 2001;38(5):1564-1569.

24. George J, Greenberg S, Barshack I, Goldberg I, Keren G, Roth A. Immunity to heat shock protein 65-an additional determinant in intimal thickening. Atherosclerosis. 2003;168(1):33-38. 
25. Kleindienst R, Xu Q, Willeit J, Waldenberger FR, Weimann S, Wick G. Immunology of atherosclerosis. Demonstration of heat shock protein 60 expression and T lymphocytes bearing alpha/beta or gamma/delta receptor in human atherosclerotic lesions. Am J Pathol. 1993;142(6):1927-1937.

26. Hammerer-Lercher A, Mair J, Bonatti J, Watzka SB, Puschendorf B, Dirnhofer S. Hypoxia induces heat shock protein expression in human coronary artery bypass grafts. Cardiovasc Res. 2001;50(1):115-124.

27. Xiao C, Shim JH, Kluppel M, Zhang SS, Dong C, Flavell RA, Fu XY, Wrana JL, Hogan $\mathrm{BL}$, Ghosh S. Ecsit is required for Bmp signaling and mesoderm formation during mouse embryogenesis. Genes Dev. 2003;17(23):2933-2949.

28. Vink A, Schoneveld AH, van der Meer JJ, van Middelaar BJ, Sluijter JP, Smeets MB, Quax PH, Lim SK, Borst C, Pasterkamp G, de Kleijn DP. In vivo evidence for a role of toll-like receptor 4 in the development of intimal lesions. Circulation. 2002;106(15): 1985-1990.

29. Vabulas RM, Ahmad-Nejad P, da Costa C, Miethke T, Kirschning CJ, Hacker H, Wagner $\mathrm{H}$. Endocytosed HSP60s use toll-like receptor 2 (TLR2) and TLR4 to activate the toll/interleukin-1 receptor signaling pathway in innate immune cells. J Biol Chem. 2001;276(33):31332-31339.

30. Gebbia JA, Coleman JL, Benach JL. Selective induction of matrix metalloproteinases by Borrelia burgdorferi via toll-like receptor 2 in monocytes. J Infect Dis. 2004;189(1):113-119.

31. Ikeda T, Funaba M. Altered function of murine mast cells in response to lipopolysaccharide and peptidoglycan. Immunol Lett. 2003;88(1):21-26.

32. Watari M, Watari $\mathrm{H}$, Nachamkin I, Strauss JF. Lipopolysaccharide induces expression of genes encoding pro-inflammatory cytokines and the elastin-degrading enzyme, cathepsin S, in human cervical smooth-muscle cells. I Soc Gynecol Investig. 2000; 7(3):190-198. 



\section{Chapter 4}

$\mathrm{N}$-acetylcysteine attenuates hyperoxia induced venous smooth muscle cell proliferation and neointima formation in a rat venous graft model 


\section{Abstract}

Introduction. Neointima formation is an important cause of venous bypass graft failure. The significance of exposure of a vein to supra-physiological oxygen levels following implantation in the arterial circulation has not been addressed in the pathophysiology of smooth muscle cell proliferation that is characteristic of intimal hyperplasia. The aim of this study was to investigate whether hyperoxia triggers venous smooth muscle cell proliferation. Furthermore, we studied the therapeutic potential of the antioxidant $\mathrm{N}$-acetylcysteine to attenuate the detrimental effects of hyperoxia on smooth muscle cell proliferation and neointima formation in venous grafts.

Methods and Results. To investigate whether hyperoxia triggers venous smooth muscle cell (VSMC) proliferation, isolated human VSMCs were cultured under hyperoxic $\left(70 \% \mathrm{O}_{2}\right)$ or normoxic $\left(21 \% \mathrm{O}_{2}\right)$ conditions for 72 hours. Secretion of the mitogenic inflammatory cytokines IL-6 and IL-8 was 5-fold and 20-fold higher, respectively, in hyperoxic compared with normoxic VSMCs.

Subsequently, normoxic VSMCs were incubated with medium derived from hyperoxic VSMCs. This cytokine-rich medium induced proliferation of normoxic quiescent VSMCs as indicated by a 9-fold increase in the number of Ki-67 positive VSMC nuclei after a 72-h incubation period. Treatment of VSMCs with the antioxidant $\mathrm{N}$-acetylcysteine (NAC) prevented hyperoxia-induced cytokine production and VSMC proliferation. The therapeutic potential of NAC was further investigated in vivo using a rat venous graft model. Systemic administration of NAC significantly reduced smooth muscle cell proliferation at 7 days and attenuated neointima formation at 3 weeks in venous grafts.

Conclusions. Vein grafts endure hyperoxia following implantation in the arterial circulation. This potential stressor has as yet been disregarded in the pathogenesis of vein graft disease. The present study shows that hyperoxia induces VSMC proliferation. This effect is associated with a hyperoxia-induced increase in the secretion of mitogenic inflammatory cytokines by VSMCs. The antioxidant NAC prevents hyperoxia-induced cytokine production and VSMC proliferation, and attenuates neointima formation. The identification of hyperoxia as a novel element in the multifactorial process of neointima formation opens a window of opportunity by targeting oxidant-antioxidant mismatch to prevent venous bypass graft failure. 


\section{Introduction}

Implantation of autologous saphenous vein segments in the arterial circulation has been the treatment of choice for many years to bypass peripheral and coronary arterial obstructions. However, vein graft stenosis and occlusion due to neointima formation is a major problem resulting in unsatisfactory patency levels ${ }^{1}$. Intimal hyperplasia is characterized by medial smooth muscle cell proliferation and migration into the intima, increased extracellular matrix deposition, and formation of a thick neointima. Arterial bypass conduits exhibit superior patency rates as opposed to saphenous vein conduits. This disparity has been attributed to differences in the structural, cellular and molecular composition of arterial and venous walls, resulting in altered adaptation to arterial hemodynamics ${ }^{2,3}$, and different responses to atherogenic and mitogenic stimuli in arterial and venous grafts ${ }^{4}$. Recently, oxidative stress has also been related to differences in patency between vascular grafts ${ }^{5}$.

Oxidative stress, defined as an imbalance between reactive oxygen species (ROS) and endogenous antioxidants in the vascular tissue, is suggested to play an important role in the pathogenesis of cardiovascular diseases like atherosclerosis, hypertension and heart failure ${ }^{5-7}$. ROS, including $\mathrm{OH}, \mathrm{H}_{2} \mathrm{O}_{2}$, and $\mathrm{O}_{2}{ }^{-}$, are generated by virtually all types of vascular cells ${ }^{8}$. Excessive levels of these radicals have been shown to induce endothelial dysfunction with subsequent impairment of anticoagulant and anti-inflammatory properties and smooth muscle cell activation ${ }^{9}$.

Venous grafts exhibit higher oxidative stress than arterial grafts ${ }^{10}$. Thus far it is assumed that oxidative stress in venous grafts relates to vascular trauma, i.e. surgical injury and hemodynamic stress ${ }^{11-13}$. However, an obvious source of oxidative stress in venous grafts may be the exposure of the implanted venous segment to the high-oxygen environment of the arterial circulation. Detrimental effects of a hyperoxic environment have been well appreciated in pulmonary artery remodelling ${ }^{14,15}$ and in cardiac tissue injury following cardiac reoxygenation $^{16}$. Surprisingly, the effect of relative hyperoxia on venous smooth muscle cells (VSMCs) and its role in neointima formation in venous grafts have not been investigated.

The vasculature has adequate antioxidant reserves to cope with the production of ROS under physiological conditions. However, when ROS production is excessive, such as during prolonged stress, basal antioxidant mechanisms may be overwhelmed by ROS. Pioneering epidemiological research has suggested beneficial effects of antioxidant vitamin intake on cardiovascular risk profile ${ }^{17}$. Successive studies have attempted to boost 
antioxidant levels in the vasculature to preserve vascular function and reduce restenosis in experimental animal models. $\mathrm{N}$-acetylcysteine (NAC), a thiol, which for one is a strong scavenger of oxygen-free radicals, has been widely employed to counterbalance oxidative stress in vascular cells. It proved successful in preventing arterial restenosis by several proposed mechanisms like NF-KB inhibition ${ }^{18}$, reduction in platelet activity ${ }^{19}$ and interference with PDGF $\beta$-receptor signaling ${ }^{20}$. Thus far, no studies have been performed on the potency of NAC to interfere with neointima formation in venous bypass grafts.

We hypothesize that hyperoxia adds to oxidative stress, proinflammatory changes and subsequent neointima formation in venous bypass grafts and that treatment with NAC attenuates these processes. Therefore, in the present study the effects of hyperoxia on VSMC cytokine production and proliferation were investigated in vitro. Furthermore, we focussed on the therapeutic potential of NAC to restore the oxidant-antioxidant mismatch and decrease neointima formation in venous grafts in vivo.

\section{Methods}

In vitro

Cell culture

Human venous smooth muscle cells (VSMCs) were obtained from ATCC (Manassas, USA), and cultured in F-12K medium (Kaighn's Modification of Ham's F-12 Medium), supplemented with $0.1 \mathrm{mg} / \mathrm{mL}$ heparin, $0.03 \mathrm{mg} / \mathrm{mL}$ endothelial cell growth supplement, and $10 \%$ fetal calf serum. Cells were grown under normoxic $\left(21 \% \mathrm{O}_{2}-5 \% \mathrm{CO}_{2}\right)$ conditions. Passages 4-6 were used for experiments.

\section{Cytokine analysis}

Cells were seeded at a density of $5 \times 10^{5}$ cells $/ \mathrm{mL}$ in 24-well cell culture plates and synchronized for $24 \mathrm{~h}$ in $\mathrm{F}-12 \mathrm{~K}$ medium supplemented with $2 \%$ fetal calf serum under normoxic $\left(21 \% \mathrm{O}_{2}-5 \% \mathrm{CO}_{2}\right)$ conditions. Subsequently, quiescent VSMCs were placed in an incubator under hyperoxic $\left(70 \% \mathrm{O}_{2}-5 \% \mathrm{CO}_{2}\right)$ or normoxic $\left(21 \% \mathrm{O}_{2}-5 \% \mathrm{CO}_{2}\right)$ conditions. $\mathrm{PO}_{2}$ and $\mathrm{PCO}_{2}$ in the medium were measured in preliminary experiments with a blood gas analyzer. Mean $\mathrm{Po}_{2}$ was $714 \mathrm{mmHg}$ and $173 \mathrm{mmHg}$ under hyperoxic and normoxic conditions, respectively. The $\mathrm{PCO}_{2}$ and $\mathrm{pH}$ values of the culture medium were similar under normoxic and hyperoxic conditions. Medium and cells were collected following 12, 24, 48 and $72 \mathrm{~h}$ of incubation under either hyperoxic or normoxic conditions. Viability of the cells was determined by trypan blue staining. Conditioned medium was immediately 
analyzed for cytokine concentration. The human inflammation Cytometric Bead Array kit (BD Biosciences, NJ, USA) was used to quantitatively measure cytokine (IL-1ß, IL-6, IL-8, IL-10, TNF- $\alpha$, IL-12p70) expression levels in VSMC culture media. Fifty microlitres of conditioned medium were used and the assay was performed according to the manufacturer's instructions and analyzed on the FACSCalibur ${ }^{\circledR}$ flow cytometer (BD Biosciences, NJ, USA).

\section{Cell proliferation assay}

VSMCs were seeded on glass coverslips $\left(5000 \mathrm{cells} / \mathrm{cm}^{2}\right)$ in 24 -well plates and synchronized for $24 \mathrm{~h}$ in F-12K medium, supplemented with $2 \%$ fetal calf serum under normoxic conditions. Again, conditioned medium from VSMCs was collected following incubation for 12, 24, 48 and $72 \mathrm{~h}$ under either hyperoxic or normoxic conditions and transferred immediately to quiescent normoxic VSMCs, which were subsequently placed in an incubator under normoxic conditions for $48 \mathrm{~h}$. After $48 \mathrm{~h}$, cells were washed in PBS, fixed in formaldehyde, and permeabilized in NP-40 for 20 minutes. Nonspecific binding sites were blocked with $2 \%$ BSA. VSMCs were incubated with mouse anti-human Ki-67 (DakoCytomation, Denmark) antibody, followed by a secondary antibody (goat anti-mouse; DakoCytomation). Finally, VSMCs were incubated with horseradish peroxidase-coupled streptavidin (Vector Laboratories, CA, USA), followed by immunodetection using DAB as a substrate, and counterstaining with haematoxylin. For each experimental group and control group, total nuclei and Ki-67 positive nuclei were counted by an observer blinded to the specimen group. Proliferation index was calculated as the amount of positive cells divided by total cell count.

Effect of NAC on hyperoxia-induced cytokine production and VSMC proliferation It has been suggested that intracellular changes induced by oxidative stress might be attenuated by the antioxidant agent NAC. To examine the effect of NAC on hyperoxia-induced cytokine production in VSMCs, NAC (Sigma-Aldich Sweden AB, Stockholm, Sweden) was added to F-12K medium to a final concentration of $2 \mathrm{mmol} / \mathrm{L}$. VSMCs were incubated with NAC-enriched medium under hyperoxic conditions $\left(70 \% \mathrm{O}_{2}-5 \% \mathrm{CO}_{2}\right)$. At $12,24,48$, and $72 \mathrm{~h}$ after exposure to hyperoxia, $2 \mathrm{~mL}$ of conditioned medium was removed and transferred immediately onto quiescent normoxic VSMCs which were further incubated under normoxic conditions. After $48 \mathrm{~h}$ a proliferation assay was performed on these cells as described above. An additional $2 \mathrm{~mL}$ of conditioned medium was used for cytokine quantification by means of a Cytometric Bead Array kit as described above. 
In vivo

Animals

Male inbred specific pathogen free (SPF) Lewis rats were obtained from the Department of Experimental Animal service of the University of Maastricht, the Netherlands. Experiments were performed in animals aged 12 weeks weighing 300-400 gram. Housing and care of the animals, and all the procedures used in this study were approved by the Ethical Committee for the Use of Experimental Animals of the institution, and were in accordance with the Guide for the Care and the Use of Laboratory Animals, published by the US National Institute of Health (NIH Publication No. 85-23, revised 1985). Rats were fed standard rat chow and tap water at libitum. All surgical procedures were performed under general anesthesia and using sterile techniques.

\section{Rat venous graft model and drug treatment protocol}

Autologous epigastric vein-to-common femoral artery interposition grafts were placed in rats as previously described ${ }^{21}$. Briefly, each animal was anesthetized with an intraperitoneal injection of pentobarbital sodium (60 $\mathrm{mg} / \mathrm{kg}$ ). An $8-\mathrm{mm}$ segment of the relaxed ipsilateral epigastric vein was carefully harvested, gently irrigated with heparinized saline solution (100 $\mathrm{U} / \mathrm{mL}$ ), and placed as reverse interposition graft into a segmental 3-mm defect of the common femoral artery with 8 to 10 interrupted sutures of 11 0 nylon (Ethicon). The entire procedure was carried out with standard microsurgical techniques. The total ischemic time was kept to less than 30 min. Patency was verified by visual inspection. In total 28 rats were recovered from anaesthesia. Animals were randomized to either NAC treatment $(n=14)$ or saline control group $(n=14)$. The respective groups received either $2 \mathrm{~mL}$ NAC solution $(150 \mathrm{mg} / \mathrm{kg}$ bodyweight $\mathrm{NAC}$ in $\mathrm{NaCl}$ $0.9 \%$ ) or $2 \mathrm{~mL}$ saline once a day via oral gavage. Drug treatment was started at 2 days prior to surgery and continued until sacrifice. Rats were sacrificed 7 days (NAC $n=7$, control $n=7$ ) or 3 weeks (NAC $n=7$, control $n=7$ ) after vein graft surgery. To determine proliferation rates in vein graft segments at 7 days of surgery, bromodeoxyuridine (BrdU, $30 \mathrm{mg} / \mathrm{kg}$ ip) was administered at 18 $\mathrm{h}$ and $12 \mathrm{~h}$ prior to euthanasia. Rats were anaesthetized, the chest and abdominal cavities were opened, and a catheter was inserted into the apex of the heart. Blood vessels were initially flushed with physiological salt solution and then perfusion fixed with $3.7 \%$ formaldehyde in phosphatebuffered saline, $\mathrm{pH} 7.4$, at physiological pressure $(100 \mathrm{~mm} \mathrm{Hg})$. Vein grafts were removed, fixed overnight in the same fixative, routinely processed and paraffin embedded. 


\section{Histomorphometric analysis}

Cross-sections $(4 \mu \mathrm{m})$ were taken for morphometrical analysis at 200- $\mu \mathrm{m}$ intervals and mounted on glass slides for haematoxylin-eosin (HE) and elastin (Lawson) staining. VSMCs were detected by a monoclonal anti-smooth muscle actin antibody (DakoCytomatic, Denmark), endothelial cells were identified by a monoclonal rat endothelial cell antibody (RECA-1, Abcam). Medial thickness, neointimal area (area between the internal elastic lamina and endothelium) and percentage of stenosis (area within the endothelium divided by the area within the internal elastic lamina) were determined on two mid-graft sections, using a computer-assisted morphometry system (analySIS ${ }^{\circledR}$, Soft Imaging System, Munster, Germany).

BrdU immunoreactivity was detected in vein graft segments by a specific monoclonal anti-BrdU antibody (1/500 dilution, DakoCytomatic, Denmark). After DNA denaturation with $2 \mathrm{~N} \mathrm{HCl}$ and enzymatic pretreatment with pepsin, BrdU immunohistochemistry was performed with biotinylated goat anti-mouse IgG (DakoCytomation, Denmark) and the ABC-AP kit with Fast Red and counterstaining with haematoxylin for quantification. Presence of VSMCs in neointimal lesions was determined by a monoclonal anti- $\alpha$ smooth muscle actin antibody (DakoCytomatic, Denmark).

\section{Statistics}

Data are expressed as mean \pm SE. Differences between the experimental and control groups for cytokine analysis and comparisons between groups for morphometric analyses were made using the Mann-Whitney $U$ test. Differences were considered significant at a value of $\mathrm{P}<.05$.

\section{Results}

Hyperoxia induces cytokine production by VSMCs

Viability of cells was $>95 \%$ at $0 \mathrm{~h}$, and $>80 \%$ at $72 \mathrm{~h}$ of hyperoxia treatment as determined by trypan blue staining. VSMCs exposed to $70 \% \mathrm{O}_{2}$ showed a timedependent increase in the production of IL-8 and IL-6 as compared with VSMCs incubated at $21 \% \mathrm{O}_{2}$ (Figure 1). In contrast, IL-10 levels in medium were on average below the detection limit of the assay $(3.3 \mathrm{pg} / \mathrm{mL})$. No significant increase from baseline concentration of IL-1 $\beta, \mathrm{IL}-12 \mathrm{p} 70$ or TNF- $\alpha$ was found in both hyperoxic and normoxic cells (Table 1 ).

Medium from hyperoxic VSMCs induces proliferation of normoxic VSMCs Quiescent VSMCs incubated under normoxic conditions were exposed for $48 \mathrm{~h}$ 

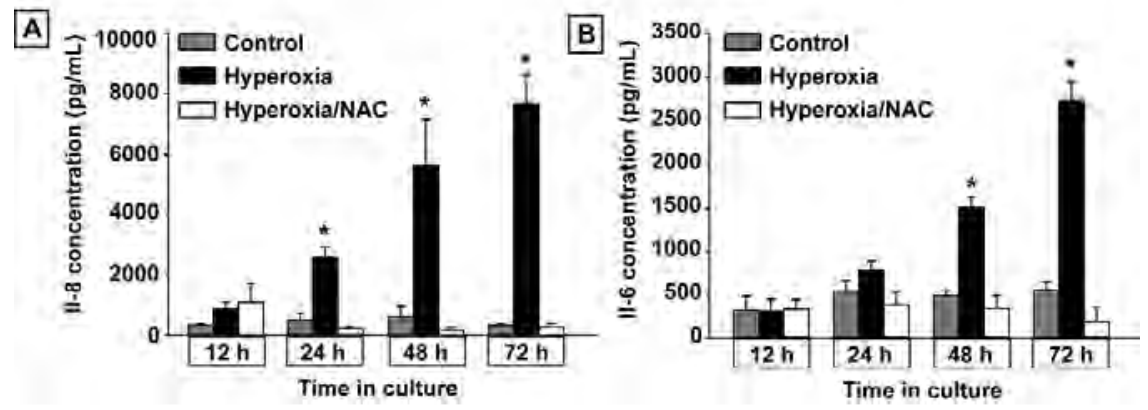

\section{Figure 1.}

Culturing of venous smooth muscle cells under hyperoxic conditions induces increased secretion of mitogenic cytokines. Both IL-8 (A) and IL-6 (B) levels in the culture medium, as determined by Cytometric Beads Array assay, significantly increased during exposure to $70 \% \mathrm{O}_{2}$ (hyperoxia, black bars) as compared with exposure to $21 \% \mathrm{O}_{2}$ (control, grey bars). Concomitant administration of the antioxidant NAC (hyperoxia/NAC, white bars) completely abolished hyperoxia-induced cytokine expression. Data represent the mean \pm SE of four experiments. ${ }^{*} P<.01$ versus control

Table 1. Effects of hyperoxia and NAC on cytokine secretion by VSMCs

\begin{tabular}{|c|c|c|c|c|c|c|}
\hline & IL-1 $1 \beta$ & IL-8 & IL-10 & IL-12p70 & TNF- $\alpha$ & \\
\hline O h control & ND & $30 \pm 12$ & $186 \pm 80$ & ND & ND & ND \\
\hline $12 \mathrm{~h}$ control & $35 \pm 10.6$ & $315 \pm 163$ & $323 \pm 49$ & ND & $3.1 \pm 1.2$ & $2.7 \pm 1.0$ \\
\hline $12 \mathrm{~h} \mathrm{O}_{2}-\mathrm{NAC}$ & $34 \pm 16.4$ & $309 \pm 134$ & $874 \pm 200$ & ND & $4.2 \pm 2.1$ & $2.4 \pm 0.9$ \\
\hline $12 \mathrm{~h} \mathrm{O}_{2}+\mathrm{NAC}$ & $31 \pm 9.6$ & $330 \pm 106$ & $1078 \pm 632$ & ND & $3.7 \pm 2.1$ & $2.2 \pm 1.0$ \\
\hline 24 h control & $30 \pm 9.5$ & $536 \pm 119$ & $485 \pm 234$ & ND & $5.0 \pm 2.8$ & $3.4 \pm 1.6$ \\
\hline $24 \mathrm{~h} \mathrm{O}_{2}-\mathrm{NAC}$ & $22 \pm 10.6$ & $780 \pm 100$ & $2560 \pm 351$ * & ND & $7.3 \pm 4.3$ & $2.4 \pm 1.1$ \\
\hline $24 \mathrm{hO}_{2}+\mathrm{NAC}$ & $31 \pm 8.7$ & $380 \pm 151$ & $209 \pm 67$ & ND & $5.5 \pm 2.7$ & $1.9 \pm 0.5$ \\
\hline $48 \mathrm{~h}$ control & $27 \pm 12.1$ & $485 \pm 49$ & $631 \pm 336$ & ND & $3.3 \pm 2.3$ & $2.3 \pm 0.8$ \\
\hline $48 \mathrm{~h} \mathrm{O}_{2}-\mathrm{NAC}$ & $26 \pm 12.5$ & $1503 \pm 120$ * & $5470 \pm 1509 \dagger$ & ND & $5.9 \pm 4.1$ & $2.5 \pm 0.9$ \\
\hline $48 \mathrm{~h} \mathrm{O}_{2}+\mathrm{NAC}$ & $26 \pm 11.3$ & $340 \pm 149$ & $210 \pm 90$ & ND & $3.8 \pm 2.4$ & $2.9 \pm 1.3$ \\
\hline 72 h control & $32 \pm 9.9$ & $546 \pm 94$ & $360 \pm 37$ & ND & $3.6 \pm 2.4$ & $2.3 \pm 0.2$ \\
\hline $72 \mathrm{~h} \mathrm{O}_{2}-\mathrm{NAC}$ & $34 \pm 11.3$ & $2729 \pm 223$ * & $7614 \pm 731$ * & ND & $9.3 \pm 3.9$ & $3.4 \pm 1.7$ \\
\hline $72 \mathrm{~h} \mathrm{O}_{2}+\mathrm{NAC}$ & $32 \pm 9.3$ & $187 \pm 164$ & $315 \pm 121$ & ND & $6.5 \pm 2.9$ & $2.1 \pm 0.8$ \\
\hline
\end{tabular}

Values represent mean \pm SE of four experiments and all values are expressed in $\mathrm{pg} / \mathrm{mL}$.

Control, exposure to $21 \% \mathrm{O}_{2}$

$\mathrm{O}_{2}$ - NAC, exposure to $70 \% \mathrm{O}_{2}$ without NAC

$\mathrm{O}_{2}+\mathrm{NAC}$, exposure to $70 \% \mathrm{O}_{2}$ with $\mathrm{NAC}$

${ }^{*} \mathrm{P}<.01, \dagger \mathrm{P}<.05$ versus control; ND: not detectable 
to medium retrieved from hyperoxia-exposed VSMCs. Direct cell counting revealed a significant increase in the number of Ki-67 positive VSMC nuclei incubated with conditioned medium as compared with VSMCs incubated with control medium (Figure 2). Incubation with conditioned medium obtained after 24, 48 and $72 \mathrm{~h}$ of hyperoxia induced a 4, 6, and 9-fold increase of Ki-67 positive cells, respectively.

\section{NAC prevents hyperoxia-induced cytokine production and VSMC proliferation}

To determine the effects of NAC treatment on proinflammatory cytokine secretion from VSMCs, $2 \mathrm{mmol} / \mathrm{L}$ NAC was added to the culture medium and quiescent VSMCs were subsequently exposed to hyperoxia. Treatment with NAC prevented the increase in IL-8 and IL-6 levels after 24, 48 and 72 h of hyperoxia (Figure 1),

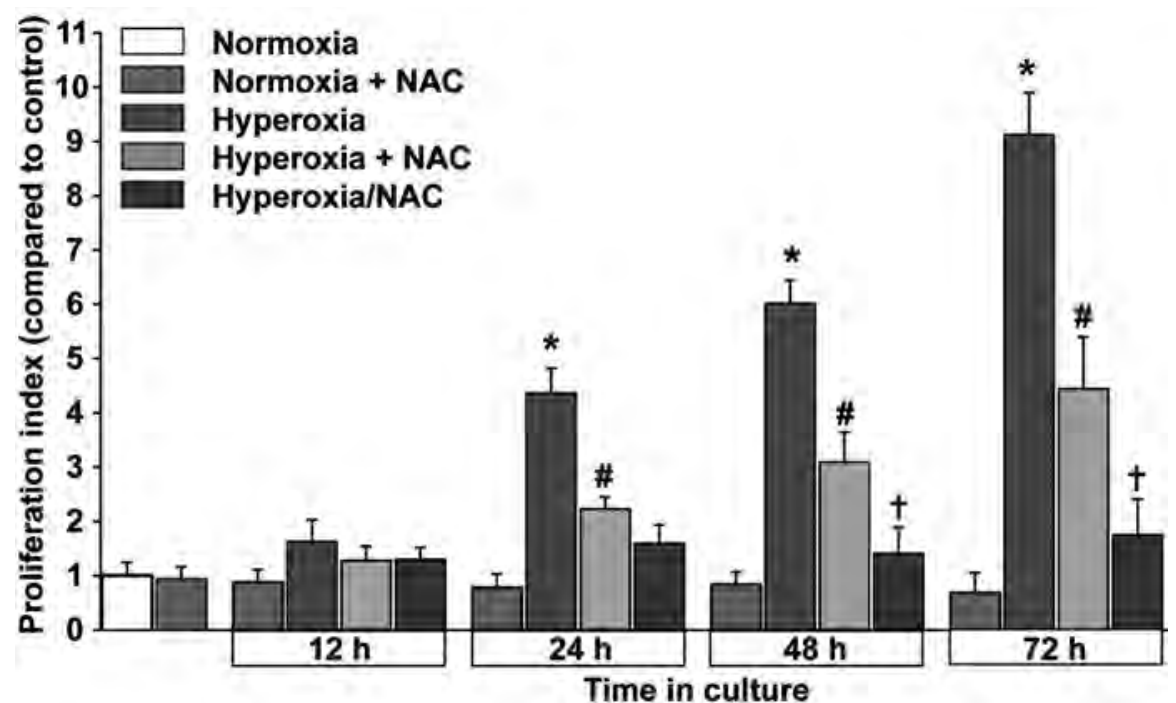

Figure 2.

Medium from hyperoxic VSMCs induces proliferation of quiescent normoxic VSMCs, which is prevented by NAC. Proliferation indices in normoxic VSMCs after 48-h incubation with conditioned medium retrieved from VSMCS after 24-72 $\mathrm{h}$ of hyperoxia induced a significant increase in the number of Ki-67 positive cells (red bars, ${ }^{*} \mathrm{P}<.01$ versus incubation with control medium). Administration of NAC to quiescent VSMCs reduced the proliferative effect of medium from hyperoxic VSMCs (yellow bars, \# P $<.05$ versus medium from hyperoxic VSMCs, ie versus red bars). The proliferative response of quiescent VSMCs was completely abolished by conditioned medium from hyperoxic NAC-treated VSMCs (blue bars, $+\mathrm{P}<.05$ versus medium from hyperoxic VSMCs that had not been treated with NAC, ie versus yellow bars). Data are expressed as mean \pm SE of four experiments. 
but did not affect the secretion of other measured cytokines (Table 1). These data show that exposure of VSMCs to hyperoxia leads to secretion of mitogenic cytokines II-6 and II-8 and proliferation of quiescent VSMCs.

Since NAC attenuated the secretion of IL-6 and IL-8, we next determined the mitogenic effects of conditioned medium retrieved from VSMCs which received NAC throughout exposure to hyperoxia. Proliferation rates of normoxic VSMCs after 48-h incubation with conditioned medium from hyperoxic NAC-treated VSMCs were significantly reduced to quiescent normoxic levels as compared to incubation with medium from hyperoxic VSMCs that had not been treated with NAC (Figure 2). These data indicate that medium retrieved from hyperoxia-exposed and NAC-treated VSMCs lost its mitogenic potential.

Since NAC has been suggested to cause growth-arrest of $\mathrm{SMCs}^{22}$, we also determined the direct effects of NAC on VSMCs stimulated by conditioned medium. Quiescent VSMCs were incubated with conditioned medium retrieved from hyperoxia-exposed VSMCs with the addition of $2 \mathrm{mmol} / \mathrm{L}$ NAC. Proliferation rates were determined after 48-h culture under normoxic conditions. NAC treatment of quiescent normoxic VSMCs reduced the proliferative response of these cells to medium from hyperoxia-exposed VSMCs, supporting a direct inhibitory effect of NAC on VSMC proliferation. However, this direct antiproliferative effect of NAC on normoxic VSMCs was significantly smaller than the aforementioned inhibitory effect of NAC treatment of hyperoxic VSMCs on subsequent normoxic VSMC proliferation (Figure 2).

\section{NAC inhibits neointima formation in rat venous grafts}

At 7 days of surgery, one vein graft in the control group was occluded by thrombosis and excluded from analysis. None of the vein grafts in the NAC-treated group exhibited thrombosis. Anti-BrdU staining was performed in all remaining vein graft segments (control $n=6, N A C n=7$; Figure 3). A scale between 1 (few) and 4 (abundant) was used to obtain a semi-quantitative index of the number of proliferating cells in the media and neointima of experimental vein grafts. Proliferation scores were significantly lower in the NAC-treated compared with the control group $(1.5 \pm 0.2$ versus $3.1 \pm 0.2, \mathrm{P}=.004)$. The majority of cells in the vein segments were qualified as VSMCs, as determined by anti- $\alpha$ smooth muscle actin staining.

At 3 weeks of surgery, thrombosis was seen in 1 segment from the control group and 1 from the treatment group. Morphologic measurements were performed on the remaining vein graft segments (control $n=6, N A C n=6$ ). Neointimal area in the NAC-treated group was significantly reduced compared with the control group (Figure 4a, Figure 5). Furthermore, the stenosis rate in 


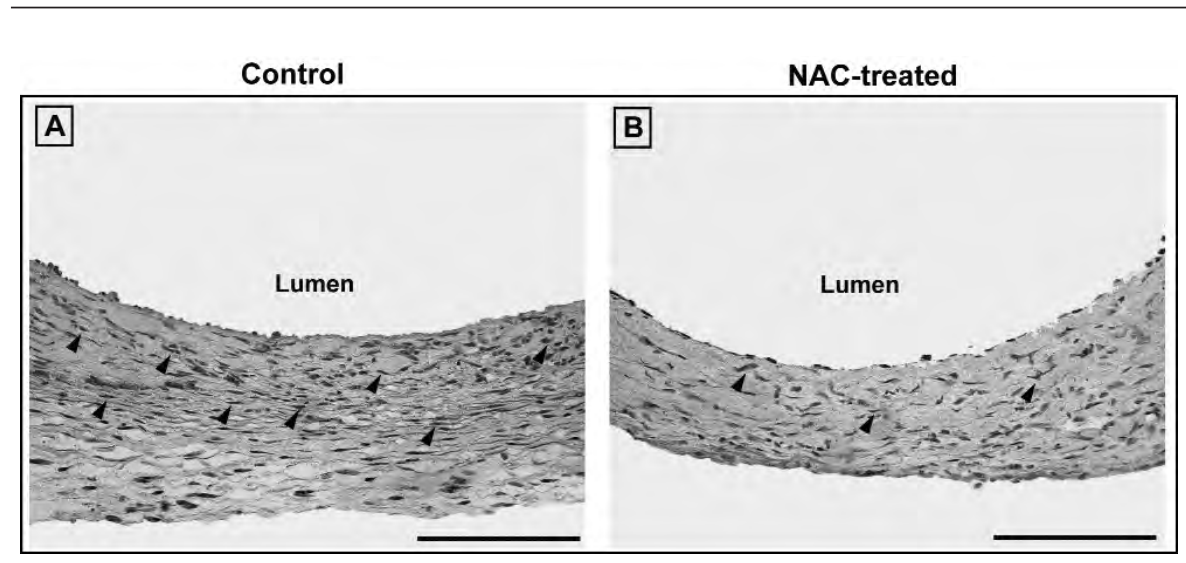

\section{Figure 3.}

Systemic treatment with NAC reduces VSMC proliferation in rat venous grafts. VSMC proliferation is significantly lower in vein grafts of NAC-treated $(B ; 150 \mathrm{mg} / \mathrm{kg} / \mathrm{d}$ orally; $\mathrm{n}=7)$ compared with control rats $(A ; n=6)$ at 7 days of surgery, as demonstrated by BrdU immunohistochemistry (arrowheads). Scale bars represent $100 \mu \mathrm{m}$.

grafted veins in the NAC-treated group was 6-fold lower compared with the control group (Figure 4c). In contrast, media thickness did not differ between treatment and control groups (Figure $4 \mathrm{~b}$ ). Taken together, these results demonstrate that NAC inhibits neointima formation in experimental vein grafts, through reduction of VSMC proliferation.
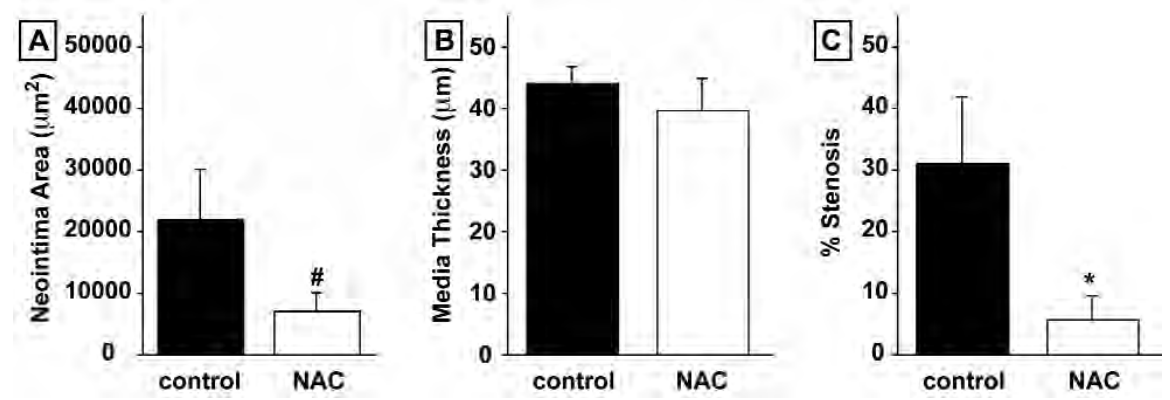

\section{Figure 4.}

Systemic treatment with NAC inhibits neointima formation in rat vein grafts. A. Neointimal area in venous grafts at 3 weeks of surgery was significantly reduced in NAC-treated $(150 \mathrm{mg} / \mathrm{kg} / \mathrm{d}$ orally; $n=6)$ compared with control $(n=6)$ rats. B. Medial thickness of grafted veins was not significantly different between NAC-treated and control groups. C. Percentage stenosis was significantly lower in the NAC-treated compared with the control group. Data are expressed as mean $\pm \mathrm{SE}$. \# $\mathrm{P}<.05$, $* \mathrm{P}<.01$ versus control. 


\section{Control}

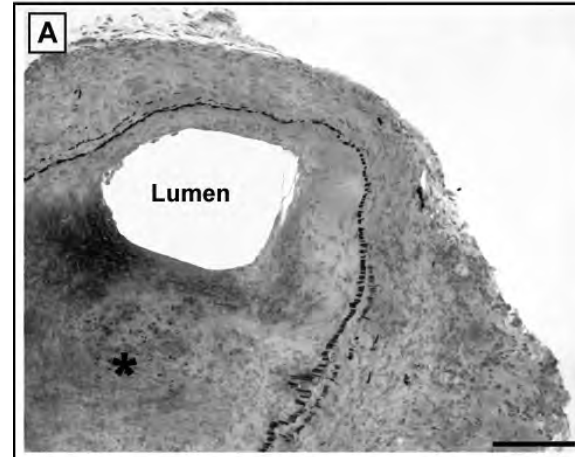

NAC-treated

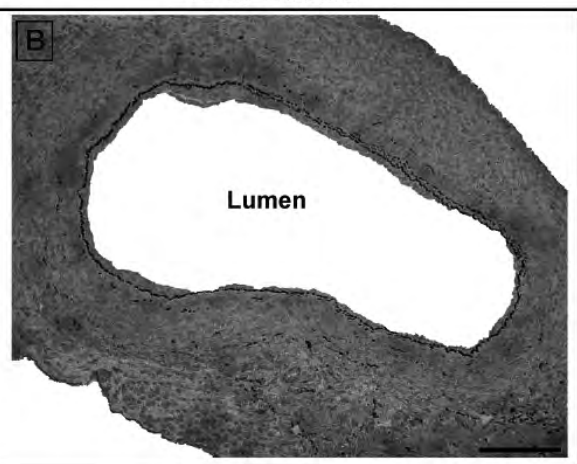

Figure 5.

Abundant neointima formation $\left(^{*}\right)$ is present in a vein graft segment from a control animal at 3 weeks of surgery (A). Treatment with NAC prevents neointima formation (B), as shown by Lawson elastin staining. Scale bars represent $100 \mu \mathrm{m}$.

\section{Discussion}

Neointima formation is a complex process of multifactorial origin. What does actually happen when a vein is implanted into the arterial circulation? Two major changes in the venous environment occur. First, the vein is exposed to the high blood pressure of the arterial tree. Second, the vein is exposed to the oxygen-rich blood of the arterial circulation. The influence of mechanical factors on the integrity of the venous wall is subject of extensive research. For example, cyclic high pressure stretching has been shown to trigger a cascade of molecular events in endothelial and smooth muscle cells which have been linked to the development of thrombosis, neointima formation and atherosclerosis $^{23}$. Surprisingly, no attention has been paid to the effects of hyperoxia on the vein wall. This was the subject of the current study. We demonstrate that hyperoxia initiates a proinflammatory response in VSMCs resulting in VSMC proliferation. Treatment with the antioxidant NAC inhibits this process, and prevents neointima formation and vein graft stenosis.

The potential effects of hyperoxia on the vein wall were investigated in smooth muscle cells, not in endothelial cells, since vein grafts are rapidly denuded from their endothelium by surgical manipulation and hemodynamic stress. We found that exposure of isolated human VSMCs to $70 \% \mathrm{O}_{2}$ induced a marked increase in IL- 6 and IL- 8 secretion, whereas the levels of IL-1 $\beta$, TNF- $\alpha$, and IL-10 remained unaffected. Induction of IL-6 and IL-8 secretion under 
hyperoxic conditions has previously been shown in macrophages ${ }^{24,25}$. Furthermore, the only study thus far that examined effects of hyperoxia on vascular wall cells found an increase in IL-8 mRNA levels in human umbilical vein endothelial cells ${ }^{26}$. Reports on the expression of other inflammatory cytokines, including IL-1 $\beta$, are conflicting, since both increased and decreased expression have been reported in response to hyperoxia ${ }^{24,26,27}$. To investigate the mitogenic potential of hyperoxia-induced secretion of IL-6 and IL-8, we transferred medium retrieved from hyperoxic VSMCs onto quiescent VSMCs and noticed significant proliferation. These findings are in line with previous studies which identified the mitogenic properties of proinflammatory cytokines IL-6 and IL-8 in smooth muscle cells ${ }^{28,29,30}$.

In contrast to the cytokine-mediated proliferative effect of hyperoxia, direct exposure of VSMCs to hyperoxia did not lead to proliferation (data not shown). Congruent with these findings, previous studies demonstrated that in vitro hyperoxia induces growth arrest in the S-phase of the cell cycle ${ }^{31}$. In vivo, however, hyperoxia has been shown to induce smooth muscle cell proliferation in pulmonary arteries in a rat model ${ }^{32}$. This discrepancy between in vitro and in vivo effects of hyperoxia on smooth muscle cell proliferation may relate to the position of the smooth muscle cell within the vascular wall. Arterial partial oxygen pressure decreases from $90 \mathrm{mmHg}$ to $35 \mathrm{mmHg}$ within a $1 \mathrm{~mm}$ distance in the vessel wall as measured from the lumen ${ }^{33}$. We suggest that although high luminal oxygen concentration might lead to growth arrest in the first cell layers, paracrine stimulation by high levels of IL- 6 and IL-8 secreted by the hyperoxic cells may well induce smooth muscle cell proliferation in the medial cell layers.

Our data suggest that oxidative stress is implied in the origin of vein graft disease. Hyperoxia is a well-known potent inducer of ROS. An imbalance between the production and degradation of ROS induces oxidative damage. Previous studies demonstrated that the antioxidant NAC may reduce arterial stenosis in experimental models of balloon-induced arterial injury ${ }^{18,19,34}$. Therefore, we examined the therapeutic potential of NAC to prevent vein graft stenosis. We show that NAC prevented the hyperoxia-induced increase in secretion of the mitogenic cytokines IL- 6 and IL-8 by VSMCs. Consequently, treatment with NAC abolished the proliferative response of VSMCs to medium retrieved from hyperoxic VSMCs in vitro. The potential of NAC to inhibit VSCM proliferation was confirmed in vivo. We found that NAC strongly attenuated neointima formation and vein graft stenosis in a rat venous bypass graft model by reducing VSMC proliferation. These findings provide experimental evidence for a promising novel role for NAC. The antioxidant properties of NAC have 
been shown to be of benefit in many clinical conditions, including sepsis, respiratoy failure, hepatic failure, and prevention of radiographic contrast nephropathy ${ }^{35}$. Further clinical studies are required before it can be recommended for the routine management of venous bypass grafts and, potentially, arteriovenous hemodialysis fistulas.

In summary, these data indicate that the antioxidant $\mathrm{N}$-acetylcysteine can prevent hyperoxia-induced venous smooth muscle cell proliferation. Our study presents a novel concept in the pathophysiology of neointima formation and provides a potential therapy for venous graft stenosis.

\section{Acknowledgments}

Support from the Netherlands Heart Foundation to E.R. and A.T. (grant number 2002T011) is greatly acknowledged. 


\section{References}

1. Motwani JG, Topol EJ. Aortocoronary saphenous vein graft disease: pathogenesis, predisposition, and prevention. Circulation 1998;97:916-931.

2. Cox JL, Chiasson DA, Gotlieb Al. Stranger in a strange land: the pathogenesis of saphenous vein graft stenosis with emphasis on structural and functional differences between veins and arteries. Prog CardiovasC Dis 1991;34:45-68.

3. Deng DX, Spin JM, Tsalenko A, Vailaya A, Ben-Dor A, Yakhini Z, et al. Molecular signatures determining coronary artery and saphenous vein smooth muscle cell phenotypes: distinct responses to stimuli. Arterioscler Thromb Vasc Biol 2006;26:1058-1065.

4. Yang Z, Oemar BS, Carrel T, Kipfer B, Julmy F, Luscher TF. Different proliferative properties of smooth muscle cells of human arterial and venous bypass vessels: role of PDGF receptors, mitogen-activated protein kinase, and cyclin-dependent kinase inhibitors. Circulation 1998;97:181-187.

5. Heistad DD. Oxidative stress and vascular disease: 2005 Duff lecture. Arterioscler Thromb Vasc Biol 2006;26:689-695.

6. Griendling KK, FitzGerald GA. Oxidative stress and cardiovascular injury: Part II: animal and human studies. Circulation 2003;108:2034-2040.

7. Madamanchi NR, Vendrov A, Runge MS. Oxidative stress and vascular disease. Arterioscler Thromb Vasc Biol 2005;25:29-38.

8. Griendling KK, Sorescu D, Ushio-Fukai M. NAD(P)H oxidase: role in cardiovascular biology and disease. Circ Res 2000;86:494-501.

9. Cai H, Harrison DG. Endothelial dysfunction in cardiovascular diseases: the role of oxidant stress. Circ Res 2000;87:840-844.

10. Shi Y, Niculescu R, Wang D, Patel S, Davenpeck KL, Zalewski A. Increased NAD(P)H oxidase and reactive oxygen species in coronary arteries after balloon injury. Arterioscler Thromb Vasc Biol 2001;21:739-745.

11. Hishikawa K, Oemar BS, Yang Z, Luscher TF. Pulsatile stretch stimulates superoxide production and activates nuclear factor-kappa B in human coronary smooth muscle. Circ Res 1997;81:797-803.

12. O'Brien JE Jr, Ormont ML, Shi Y, Wang D, Zalewski A, Mannion JD. Early injury to the media after saphenous vein grafting. Ann Thorac Surg 1998;65:1273-1278.

13. Nunes GL, Robinson K, Kalynych A, King SB 3rd, Sgoutas DS, Berk BC. Vitamins C and E inhibit $\mathrm{O}_{2}{ }^{-}$production in the pig coronary artery. Circulation 1997;96:3593-3601.

14. Jones R, Zapol WM, Reid L. Pulmonary artery remodeling and pulmonary hypertension after exposure to hyperoxia for 7 days. A morphometric and hemodynamic study. Am J Pathol 1984;117:273-285. 
15. Coflesky JT, Jones RC, Reid LM, Evans JN. Mechanical properties and structure of isolated pulmonary arteries remodeled by chronic hyperoxia. Am Rev Respir Dis 1987;136:388-394.

16. Roy S, Khanna S, Wallace WA, Lappalainen J, Rink C, Cardounel AJ, et al. Characterization of perceived hyperoxia in isolated primary cardiac fibroblasts and in the reoxygenated heart. J Biol Chem 2003;278:47129-47135.

17. Rimm EB, Stampfer MJ, Ascherio A, Giovannucci E, Colditz GA, Willett WC. Vitamin E consumption and the risk of coronary heart disease in men. N Engl / Med 1993;328: 1450-1456.

18. Hayashi K, Takahata H, Kitagawa N, Kitange G, Kaminogo M, Shibata S. N-acetylcysteine inhibited nuclear factor-kappaB expression and the intimal hyperplasia in rat carotid arterial injury. Neurol Res 2001;23:731-738.

19. Ghigliotti G, Mereto E, Eisenberg PR, Martelli A, Orsi P, Sini D, et al. N-acetyl-cysteine reduces neointimal thickening and procoagulant activity after balloon-induced injury in abdominal aortae of New Zealand white rabbits. Thromb Haemost 2001;85:724-729.

20. Kappert K, Sparwel J, Sandin A, Seiler A, Siebolts U, Leppanen O, et al. Antioxidants relieve phosphatase inhibition and reduce PDGF signaling in cultured VSMCs and in restenosis. Arterioscler Thromb Vasc Biol 2006;26:2644-2651.

21. Hoch JR, Stark VK, Hullett DA, Turnipseed WD. Vein graft intimal hyperplasia: leukocytes and cytokine gene expression. Surgery 1994;116:463-470.

22. Lee JS, Kypreos KE, Sonenshein GE. Synchronization of cultured vascular smooth muscle cells following reversal of quiescence induced by treatment with the antioxidant N-acetylcysteine. Exp Cell Res 1998;239:447-453.

23. Shuhaiber JH, Evans AN, Massad MG, Geha AS. Mechanisms and future directions for prevention of vein graft failure in coronary bypass surgery. Eur I Cardiothorac Surg 2002;22:387-396.

24. Desmarquest P, Chadelat K, Corroyer S, Cazals V, Clement A. Effect of hyperoxia on human macrophage cytokine response. Respir Med 1998;92:951-960.

25. Hjort MR, Brenyo AJ, Finkelstein JN, Frampton MW, LoMonaco MB, Stewart JC, et al. Alveolar epithelial cell-macrophage interactions affect oxygen-stimulated interleukin-8 release. Inflammation 2003;27:137-145.

26. Park MS, Wallace HM. Hyperoxia influences mRNA expression of cytokines in cultured human umbilical vein endothelial cells. Yonsei Med / 1998;39:1-12.

27. Bhandari V, Elias JA. Cytokines in tolerance to hyperoxia-induced injury in the developing and adult lung. Free Radic Biol Med 2006;41:4-18.

28. Christiansen JF, Hartwig D, Bechtel JF, Kluter H, Sievers H, Schonbeck U, et al. Diseased vein grafts express elevated inflammatory cytokine levels compared with atherosclerotic coronary arteries. Ann Thorac Surg 2004;77:1575-1579. 
29. Ross R. Atherosclerosis--an inflammatory disease. N Engl J Med 1999;340:115-126.

30. Yue TL, Wang X, Sung CP, Olson B, McKenna PJ, Gu JL, et al. Interleukin-8. A mitogen and chemoattractant for vascular smooth muscle cells. Circ Res 1994;75:1-7.

31. Shenberger JS, Dixon PS. Oxygen induces S-phase growth arrest and increases p53 and p21(WAF1/CIP1) expression in human bronchial smooth-muscle cells. Am / Respir Cell Mol Biol 1999;21:395-402.

32. Coflesky JT, Adler KB, Woodcock-Mitchell J, Mitchell J, Evans JN. Proliferative changes in the pulmonary arterial wall during short-term hyperoxic injury to the lung. Am J Pathol 1988; 132:563-573.

33. Santilli SM, Wernsing SE, Lee ES. The effect of supplemental oxygen on the transarterial wall oxygen gradients at a prosthetic vascular graft to artery anastomosis in the rabbit. Ann Vasc Surg 2001;15:435-442.

34. Jeremias A, Dusa C, Forudi F, Jacobsen DW, Vince DG, Nissen SE, et al. N-acetylcysteine in the prevention of vascular restenosis after percutaneous balloon angioplasty. Int J Cardiol 2004;95:255-260.

35. Atkinson MC. The use of $\mathrm{N}$-acetylcysteine in intensive care. Crit Care ResusC 2002;4:21-27. 



\section{Chapter 5}

Detection of cell-cycle regulators in failed arteriovenous fistulas

for hemodialysis 


\section{Abstract}

Background. Renal failure (RF) patients rely on arteriovenous fistulas (AVFs) for hemodialysis vascular access. Intimal hyperplastic stenoses result in failure of AVFs and frequent interventions are required to maintain vascular access. The extent of intimal hyperplasia ( $\mathrm{IH}$ ) depends on the interplay between cyclins and cyclin dependent kinases (e.g. cdk2), positively regulating cell cycle progression. Cdk activity is negatively modulated by the interaction with cdk inhibitory proteins, such as $\mathrm{p} 21^{\text {Waf1 }}$ and $\mathrm{p} 27^{\mathrm{Kip} 1}$. Little is known about the expression of these proteins in the development of $\mathrm{IH}$ in AVFs.

Methods and Results. p2 $1^{\text {Waf1 }}, \mathrm{p} 27^{\mathrm{Kip} 1}, \mathrm{cdk} 2$, and PCNA immunoreactivity was determined in 18 failed AVFs from 16 RF patients and 10 non-diseased vessels (5 arteries and 5 veins). The percentage p $21^{\text {Waf } 1}$ positive cells was significantly lower in AVFs $(3 \pm 1 \%$ ), compared to normal veins and arteries (62 $\pm 4 \%$ and $63 \pm 4 \%$, respectively; $p<0.001)$. Cdk2 positive cells were significantly higher in AVFs (40.7 $\pm 3.7 \%)$ than in normal veins and arteries $(2 \pm 1 \%$ and $0 \pm 0 \%$, respectively; $p<0.001)$. Although no difference in $\mathrm{p} 27^{\mathrm{Kip} 1}$ immunoreactivity was found between AVFs $(37 \pm 17 \%)$ and veins $(23 \pm 8 \% ; p=0.208)$, it was lower in healthy arteries $(17 \pm 11 \% ; p=0.037)$.

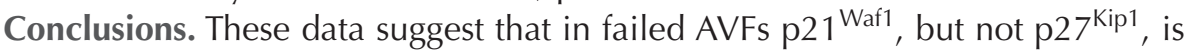
related to $\mathrm{IH}$. This is the first report to show involvement of cell cycle regulators in AVF-related human intimal hyperplasia. 


\section{Introduction}

Intimal hyperplastic stenoses in surgically created arteriovenous fistulas (AVFs) for hemodialysis remain a serious problem in maintaining vascular access. One-year primary patency rates vary from 53-88\% for autogenous radiocephalic wrist fistulas to $37-70 \%$ when prosthetic grafts are used ${ }^{1}$. Pathological proliferation and migration of vascular smooth muscle cells (VSMC) resulting in intimal thickening is the main cause of graft stenosis and occlusion within the first year after AVF construction ${ }^{2,3}$. In normal vascular tissue, quiescent VSMCs are found in the $\mathrm{G}_{0}$ phase of the cell cycle and VSMCs proliferate at a low rate. However, on stimulation VSMCs can exit their quiescent state and progress through the $\mathrm{G}_{1}$ and $\mathrm{G}_{1} / \mathrm{S}$ transition of the cell cycle ${ }^{4,5}$.

Cell cycle progression is positively regulated by the formation of complexes comprised of cyclin-dependent kinases (CDK) and their activating subunits, the cyclins. Cdk activity is, in turn, negatively modulated by the interaction with cdk inhibitory proteins (CKIs), resulting in cell cycle arrest ${ }^{6}$. Progression through the first gap $\left(\mathrm{G}_{1}\right)$ phase requires both cyclin D-cdk $4 / 6$ (early $\mathrm{G}_{1}$ ) and cyclin E-cdk2 (late $\left.\mathrm{G}_{1}\right)^{5}$. Specific CKIs (p21 Waf1 and p2 ${ }^{\text {Kip1 }}$ ) are capable of blocking cell cycle progression by inhibiting cyclin E-associated cdk complexes ${ }^{7}$.

Expression of these CDKs and CKIs in arterial balloon injury models and the role of these cell cycle proteins in VSMC proliferation have been investigated in cultured bovine, porcine, and human endothelial and smooth muscle cells as well as in human atherosclerotic lesions and normal porcine arteries $^{8,9}$. However, it is not known how the expression of these cell cycle regulators relate to venous intimal hyperplasia as a result of hemodynamic forces which are relevant in AVFs. Therefore, we investigated the expression of p2 $1^{\text {Waf1 }}$, p2 $7^{\text {Kip1 }}$, cdk2, and Proliferating Cell Nuclear Antigen (PCNA) in AVFs and non-diseased vascular tissue.

\section{Material and methods}

\section{Tissue Specimens}

Eighteen specimens of stenotic AVFs were obtained from 16 patients (8 men and 8 women; age: $59.8 \pm 3.4$ year) undergoing AVF revision at the surgical department of the University Hospital Maastricht. Hypertension was diagnosed in 12 patients $(75 \%)$ and only one patient presented with non-insulin dependent diabetes. The diagnosis of stenosis was based on generally accepted 
Duplex ultrasound criteria and confirmed by angiography ${ }^{10}$. The study was approved by the joint Medical Ethical Committee of the Maastricht University and the University Hospital Maastricht and the patients were included after written informed consent.

AVF revision was performed 27 months (range 1-80 months) after primary access creation. In 14 of 18 AVFs vascular access was created through a prosthetic brachial-anticubital forearm loop access, while in the 4 other cases, an autogenous radial-cephalic direct wrist fistula was constructed. During revision, the stenotic lesions were obtained and fixed in 10\% formalin for 4 hours, followed by 18 hours in $70 \%$ ethanol, and paraffin-embedded for immunocytochemistry. Sections (4 $\mu \mathrm{m}$ thick) were stained with haematoxylin and eosin, and immunostained with p21 Waf1, p2 $7^{\text {Kip1 }}, \mathrm{cdk} 2$, and PCNA antibodies.

Five normal arteries were obtained during obduction from patients who died of non-cardiovascular cause. Remnants of vein grafts used for arterial revascularization were obtained $(n=5)$. Both non-diseased arteries and veins were formalin fixed, paraffin-embedded and stained with afore mentioned antibodies.

\section{Immunocytochemistry}

Serial sections of the tissues were incubated with the following primary antibodies: a mouse monoclonal anti-human p2 $1^{\text {Waf1 }}$ antibody, 1:50 dilution (NeoMarkers, Inc. Fremont, CA, USA); a mouse monoclonal anti-human p2 $7^{\text {Kip1 }}$ antibody, 1:50 dilution (NeoMarkers); a mouse monoclonal anti-human cdk2 antibody, 1:50 dilution (NeoMarkers); and a mouse monoclonal antihuman PCNA antibody, 1:30 dilution (NeoMarkers). Sections (4 $\mu \mathrm{m}$ thick) were deparaffinized in three changes of xylene, and rehydrated in $90 \%, 70 \%$, and $50 \%$ ethanol. Slides were boiled in citrate buffer for $20 \mathrm{~min}$, and incubated in $2 \%$ BSA/PBS/tween for 20 minutes to block aspecific binding activity. Primary antibodies were diluted in TBS and applied to the slides for 60 minutes at room temperature. After 3 washes with TBS for 5 minutes, a biotinylated horse antimouse secondary antibody (1:400 dilution, Dako) was applied for 30 minutes at room temperature, followed by a steptavidin amplification reagent (Dako) for 30 minutes at room temperature. Finally, Fast Red was used for 10 minutes at room temperature, yielding a red reaction product. Visualization of all nuclei in the tissue sections was realized with a haematoxylin counterstain.

Total nuclei, and positive nuclei were counted in the (neo-)intima of the different vascular segments by means of a microscope-based video image analysing system (Analysis ${ }^{\circledR}$, Soft Imaging System, Münster, Germany). Four random high-power fields of each specimen were analysed. 


\section{Statistical analysis}

Data management and statistical analysis were performed with the SPSS 10.0 package for Windows (SPSS, Chicago, III., USA). Data are presented as mean values and standard errors of the mean (SEM). Mean percentages in the patient group and control tissues were compared by means of ANOVA with Bonferroni correction. Simple linear regression analysis was performed to correlate patient characteristics (such as sex, age, and present cardiovascular risk factors ) and graft survival to cell cycle regulating proteins.

\section{Results}

Cell cycle regulators in AVFs and non-diseased vascular tissue

All vascular segments were stained with p2 $1^{\text {Waf1 }}, \mathrm{p} 27^{\text {Kip } 1}, \mathrm{cdk} 2$, and PCNA antibodies and total nucleic, and immunoreactive nucleic count was determined in 4 random high-power fields. The average number of nuclei counted was 4,416 in AVFs, 1,363 in non-diseased veins, and 1,262 in non-diseased arteries.

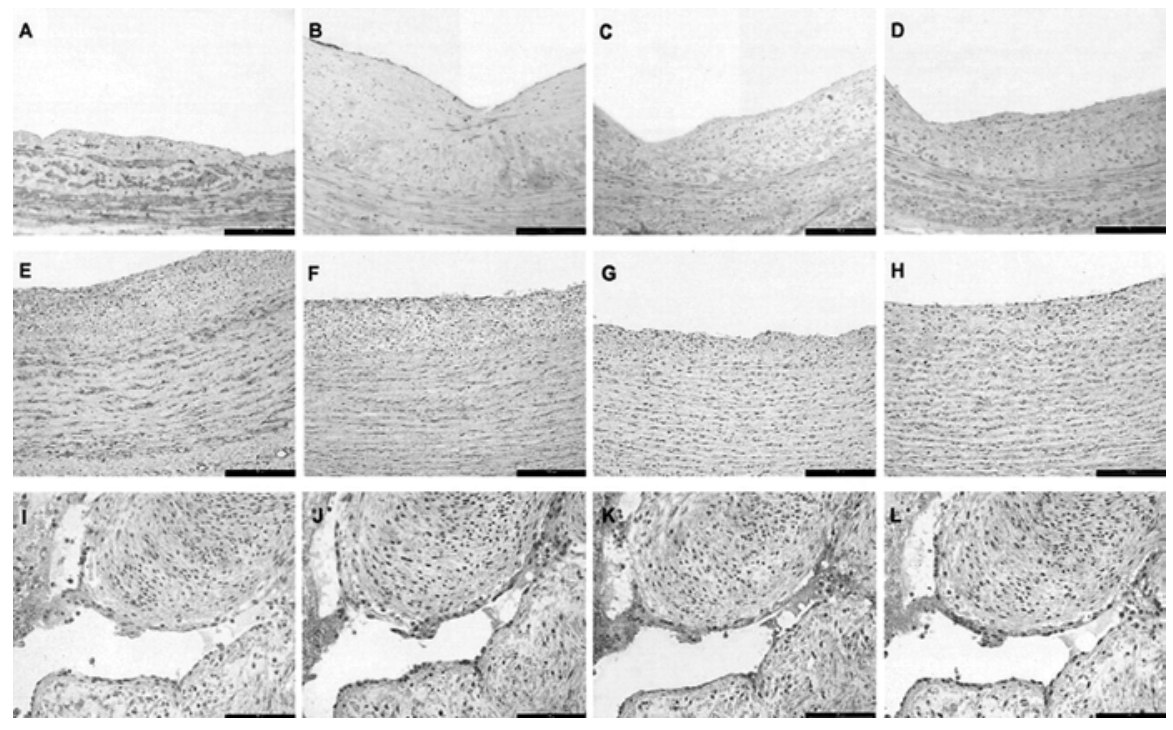

Figure 1.

Immunocytochemical staining of healthy and intimal hyperplastic vascular segments. Shown are Fast Red-stained nuclei in normal veins: (A) p21Waf1, (B) p27Kip1, (C) cdk2, and (D) PCNA; normal arteries: (E) p21Waf1, (F) p27Kip1, (G) cdk2, and (H) PCNA; AVFs: (I) p21Waf1, (J) p27Kip1, (K) cdk2, and (L) PCNA expression. Bar, $100 \mu \mathrm{m}$. 
Whereas $\mathrm{p} 21^{\text {Waf1 }}$ was clearly expressed to a greater extent in non-diseased veins and arteries, cdk2 and PCNA positive cells were more frequently detected in failed AVFs (figure 1). p2 $7^{\text {Kip1 }}$ immunoreactivity was observed both in nondiseased and stenotic tissue (figure 1). Figure 2 shows the percentage of positively stained cells for $\mathrm{p} 21^{\text {Waf1 }}, \mathrm{p} 27^{\mathrm{Kip} 1}, \mathrm{cdk} 2$, and PCNA, respectively. The percentage p $21^{\text {Waf1 }}$ positive cells was significantly lower in AVFs $(3 \pm 1 \%)$ compared to nondiseased veins and arteries $(62 \pm 9 \%$ and $63 \pm 8 \%$, resp.; $p<0.001)$. In contrast, cdk2 and PCNA positive cells were abundantly present in AVFs $(41 \pm 16 \%$ and $37 \pm 15 \%$, respectively) while immunopositive cells were almost absent in nondiseased veins $(0 \pm 0 \%$, and $0 \pm 0 \%$, resp.; $p<0.001)$ and arteries $(2 \pm 2 \%$, and $1 \pm 0.4 \%$, resp.; $\mathrm{p}<0.001)$. p $27^{\text {Kip } 1}$ immunoreactivity was lower in arteries compared to failed AVFs $(17 \pm 11 \%$ and $37 \pm 14 \%$, resp.; $p=0.037)$.

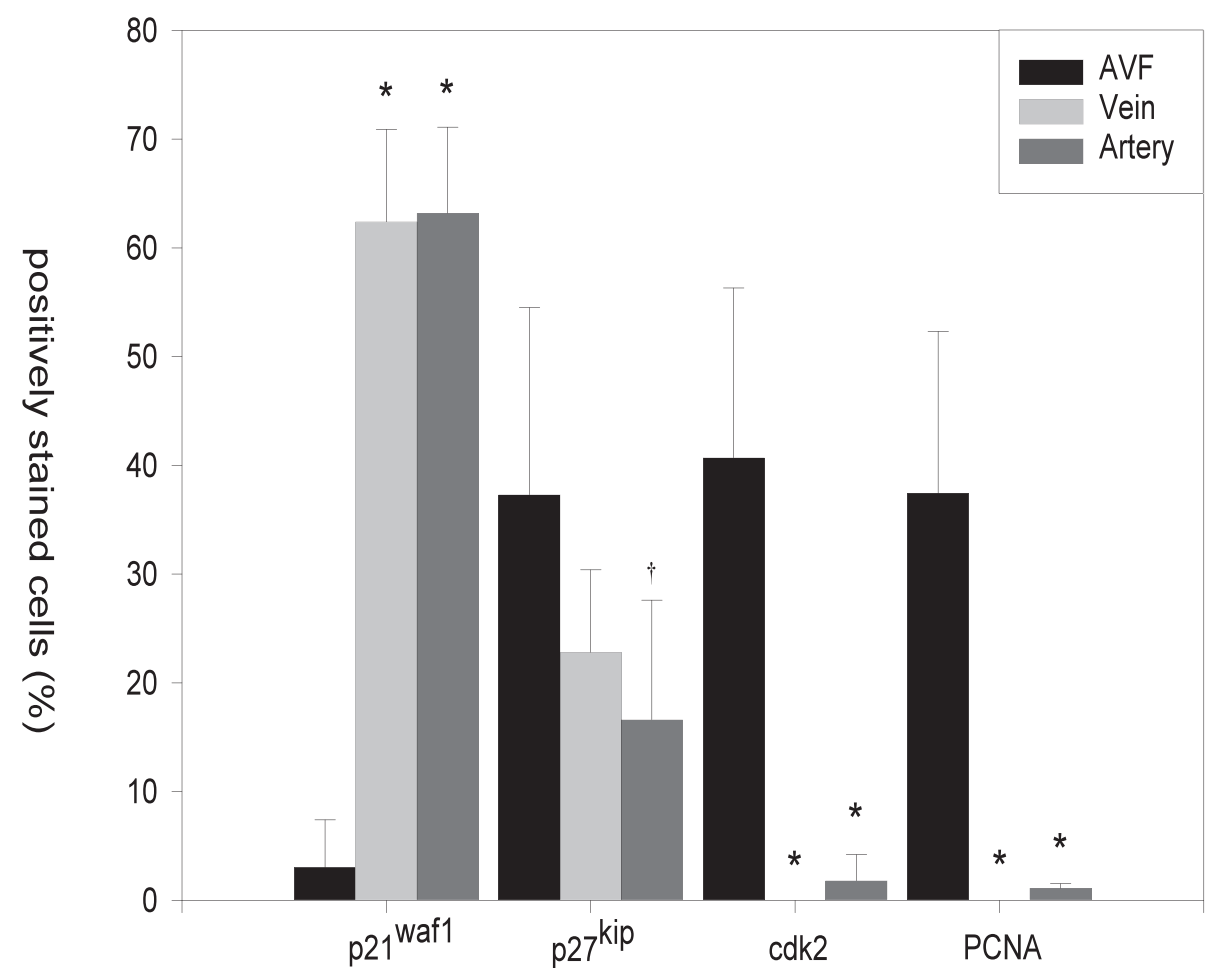

\section{Figure 2.}

Expression of p21Waf1, p27Kip1, cdk2, and PCNA in arteriovenous fistulas for hemodialysis, normal veins and arteries. Data are presented as mean percentages \pm standard error of the means. ${ }^{*}=p$ $<0.001$ compared to expression in AVFs; \# $=p<0.05$ compared to expression in AVFs. 
However, between veins and AVFs no difference was found in $\mathrm{p} 27^{\mathrm{Kip} 1}$ immunoreactivity $(23 \pm 8 \% ; p=0.208)$. Correction for the variables age, sex, and cardiovascular risk factors had no influence on the level of significance. No relation was found between the different cell cycle regulating proteins and patient history of former AVFs or the number of revisions.

\section{Discussion}

Although cell cycle regulator expression in normal, balloon-injured, and atherosclerotic vascular tissue has been described ${ }^{8,9}$, this has not yet been reported in human intimal hyperplastic lesions.

Normal human arteries and veins are mainly characterized by the presence of quiescent VSMCs in the media. This is supported by our finding that $\mathrm{p} 21^{\text {Waf1 }}$ and $\mathrm{p} 27^{\mathrm{Kip} 1}$ are abundantly expressed in non-diseased human arteries and veins. In contrast, cdk2 expression was absent in veins and minimally expressed in arteries. Considering the afore mentioned characteristics of the cell cycle machinery, these results agree with earlier studies, showing a correlation between CKI (p2 $1^{\text {Waf1 }}$, p2 $7^{\text {Kip } 1}$ ) expression and VSMC quiescence ${ }^{8,11,12}$.

Intimal hyperplasia $(\mathrm{IH})$, ensuing stenosis is characterized by an increased VSMC proliferation and migration from the media to the intima. $227^{\text {kip } 1}$ and p $21^{\text {waf1 }}$ expression might be expected to be reduced in $\mathrm{IH}$. However, in the present study $\mathrm{p} 27^{\mathrm{kip} 1}$ does not seem to play a significant role. In contrast, p2 $1^{\text {waf1 }}$ expression was considerably lower in stenotic AVFs. These findings collaborate the notion that $\mathrm{p} 21^{\text {Waf1 }}$ is a negative regulator of VSMC proliferation and thus $\mathrm{IH}$ in $\mathrm{AVFs}^{8,11,12}$. The prevailing theory of $\mathrm{p} 21^{\text {Waf1 }}$ negatively modulating cdk2 expression is reflected by our finding that cdk2 is profusely expressed in intimal hyperplastic lesions.

Wei et al have shown a temporally and spatially coordinated expression of cdk2, cyclins E and A, and PCNA in a rat balloon-injury model ${ }^{13}$. Unfortunately, we were not able to examine cell cycle protein expression through time due to the retrospective nature of the study. Further investigations in time-dependent cell cycle protein expression are needed to elucidate cell cycle protein function in intimal hyperplasia and eventually providing a site for intervention.

Recently, there has been a growing interest in the role of therapeutical means in preventing restenosis after vascular reconstruction. For example, rapamycin has been shown to inhibit VSMC proliferation and migration in vitro and arterial intimal thickening after balloon injury in vivo by a stabilizing effect on $\mathrm{p} 27^{\mathrm{Kip} 1} \cdot{ }^{14}$ In addition, Tranilast has been found to inhibit proliferation and 
migration of VSMCs and collagen synthesis ${ }^{15}$ by induction of $\mathrm{p} 21^{\text {Waf1 }}$ and $\mathrm{p} 53$, preventing restenosis after PTCA $^{16}$. In the present paper, we demonstrated dramatic reduction of $21^{\text {Waf1 }}$ levels in occluded AVFs. It might be anticipated that an imposed stabilisation or even up-regulation of $\mathrm{p} 21^{\text {Waf1 }}$ might inhibit VSMC proliferation, thereby preventing AVF stenosis.

The altered expression of several cell cycle proteins in failed AVFs contributes to intimal hyperplasia. Since the cell cycle machinery is accessible for therapeutic intervention, it is our opinion that it might be an attractive target to prevent intimal hyperplasia in AVFs. Large randomised placebo-controlled intervention studies are required to prove noteworthy reduction in intimal hyperplasia after AVF construction. 


\section{References}

1. Burger H, Kluchert BA, Kootstra G, et al. Survival of arteriovenous fistulas and shunts for haemodialysis. Eur J Surg. 1995;161:327-34.

2. Chan P, Munro E, Patel M, et al. Cellular biology of human intimal hyperplastic stenosis. Eur J Vasc Surg. 1993;7:129-35.

3. Ross R. Atherosclerosis--an inflammatory disease. N Engl J Med. 1999;340:115-26.

4. Sanz-Gonzalez SM, Poch E, Perez-Roger I, et al. Control of vascular smooth muscle cell growth by cyclin-dependent kinase inhibitory proteins and its implication in cardiovascular disease. Front Biosci. 2000;5:D619-28.

5. Sherr CJ. G1 phase progression: cycling on cue. Cell. 1994;79:551-5.

6. Morgan DO. Principles of CDK regulation. Nature. 1995;374:131-4.

7. Serrano M, Hannon GJ, Beach D. A new regulatory motif in cell-cycle control causing specific inhibition of cyclin D/CDK4. Nature. 1993;366:704-7.

8. Tanner FC, Yang ZY, Duckers E, et al. Expression of cyclin-dependent kinase inhibitors in vascular disease. Circ Res. 1998;82:396-403.

9. Yang ZY, Simari RD, Perkins ND, et al. Role of the p21 cyclin-dependent kinase inhibitor in limiting intimal cell proliferation in response to arterial injury. Proc Natl Acad Sci U S A. 1996;93:7905-10.

10. Sidawy AN, Gray R, Besarab A, et al. Recommended standards for reports dealing with arteriovenous hemodialysis accesses. J VasC Surg. 2002;35:603-10.

11. Tanner FC, Boehm M, Akyurek LM, et al. Differential effects of the cyclin-dependent kinase inhibitors p27(Kip1), p21(Cip1), and p16(Ink4) on vascular smooth muscle cell proliferation. Circulation. 2000;101:2022-5.

12. Xiong $\mathrm{Y}$, Hannon GJ, Zhang $\mathrm{H}$, et al. p21 is a universal inhibitor of cyclin kinases. Nature. 1993;366:701-4.

13. Wei GL, Krasinski K, Kearney M, et al. Temporally and spatially coordinated expression of cell cycle regulatory factors after angioplasty. Circ Res. 1997;80:418-26.

14. Gallo R, Padurean A, Jayaraman T, et al. Inhibition of intimal thickening after balloon angioplasty in porcine coronary arteries by targeting regulators of the cell cycle. Circulation. 1999;99:2164-70.

15. Fukuyama J, Miyazawa K, Hamano S, et al. Inhibitory effects of tranilast on proliferation, migration, and collagen synthesis of human vascular smooth muscle cells. Can J Physiol Pharmacol. 1996;74:80-4.

16. Takahashi A, Taniguchi T, Ishikawa Y, et al. Tranilast inhibits vascular smooth muscle cell growth and intimal hyperplasia by induction of p21(waf1/cip1/sdi1) and p53. Circ Res. 1999;84:543-50. 



\section{Chapter 6}

The new immunosuppressive agent FK778 attenuates neointima formation in an experimental bypass model 


\begin{abstract}
Introduction. Neointimal formation, characterized by proliferation and migration of smooth muscle cells, plays a central role in the pathogenesis of vein graft disease. In this whole process, intemperate cell cycle progression is an unfavourable factor and might be a promising target for intervention. We examined the potency of the immunosuppressive agent FK778 to interfere with smooth muscle cell cycle progression and inhibition of vein graft neointimal formation.
\end{abstract}

Material and methods. Quiescent venous smooth muscle cells were incubated for 48 hours with $10 \%$ FCS and different concentrations of FK778. Cell proliferation was measured by means of Ki-67 immunostaining. Uridine was added to reverse FK778 induced pyrimidine synthesis blockade. A rat venous bypass model was used to evaluate the effect of $15 \mathrm{mg} / \mathrm{kg}$ FK778 on neointimal area, percentages of stenosis and medial thickness. Sixteen male inbred specific pathogen free Lewis rats were used to perform femoral artery interposition graft surgery.

Results. FK778 inhibited venous SMC proliferation in a dose dependent manner, while this effect was reversed by addition of uridine. Furthermore, FK778 significantly reduced neointimal formation and percentage of stenosis in experimental vein grafts.

Conclusions. FK778 is a potent inhibitor of venous smooth muscle cell proliferation and neointimal formation in experimental vein grafts. Thus, FK778 might provide a new pharmacological therapy to interfere with unfavourable neointimal formation in vein grafts. 


\section{Introduction}

Although minimal invasive procedures like subintimal recanalisation, balloon dilatation and arterial stenting have been introduced to overcome peripheral atherosclerotic obstructive disease, venous bypass grafting often remains the treatment of choice. However, venous graft patency is hampered by hemodynamically-induced attrition, and subsequent failure of bypass grafts. Over recent years, many, mainly pharmacological therapies have been introduced to increase venous graft patency rates. For example, early graft failure has been reduced by anti-platelet agents ${ }^{12}$, and late atherosclerosis related graft failure prevented by aggressive lipid lowering therapies ${ }^{3}$. Although these strategies had some success, neointimal formation, as a result of intemperate smooth muscle cell (SMC) proliferation, still contributes significantly to venous bypass failure. Several mechanisms implicated in unfavorable intimal thickening have been targeted by means of pharmacological agents like MMP inhibitors ${ }^{4}$ and angiotensin-converting enzyme (ACE) inhibitors ${ }^{5}$, but also genetic manipulation of distinct mechanisms has proven efficacy ${ }^{6}$. Although promising, theses types of therapy remained largely experimental and as yet are not proven feasible in the clinical setting. Furthermore, due to the multifactorial nature of intimal thickening, inhibition of an individual stimulus is unlikely to be effective and advocates targeting of downstream events.

Since SMC proliferation may be seen as the hallmark of neointimal formation, and the final common pathway of SMC proliferation relies on cell cycle progression, this pathway emerged as a prosperous target for intervention. Accordingly, direct inhibition of SMC proliferation by blockage of the cell cycle has recently been investigated and generated several drugs found to prevent (re-) stenosis. Especially local drug release has been successful, which is emphasized by excellent patency results of sirolimus-coated stents in the prevention of secondary coronary artery and saphenous vein graft stenosis after percutaneous transluminal angioplasty (PTA $)^{7}$. Alternatively, oral administration of anti-proliferative drugs may also be used to prevent excessive intimal thickening, which is underscored by reduced in-stent restenosis after oral immunosuppressive therapy ${ }^{9}{ }^{10}$. However, conflicting data question the potency of oral sirolimus to prevent restenosis in coronary stents ${ }^{11}$ and adverse effects like dyslipidemia hamper the therapy's efficacy ${ }^{12}$. Therefore, there is a need to discover drugs with anti-proliferative potency and minimal side effects.

The synthetic malononitrilamide (MNA) FK778 is a new immunosuppressive agent structurally similar to A77 1726, the active metabolite of leflunomide, 
which proved to be beneficial in several autoimmune and inflammatory diseases. Also, it has recently been shown that FK778 exerts antiproliferative effects similar to leflunomide. In contrast, FK778 lacks the adverse aspects of leflunomide (half life of 15-18 days) thus emerging as an interesting candidate for in vivo intervention of SMC proliferation and vein graft neointima formation.

The present study was designed to examine the inhibitory potential of FK778 on venous SMC proliferation and neointima formation in venous bypass grafts in an experimental animal model.

\section{Methods}

Reagents

FK778 (2-cyano-3-oxo-N-[4-(trifluoromethyl)phenyl]-6-heptanoic acid amide) was a generous gift from Fujisawa Healthcare Inc. (Osaka, Japan). Uridine (Sigma, St Louis, MO, USA) was prepared as a $10 \mathrm{mM}$ stock solution in cell culture medium. Monoclonal anti-Ki67 antibody was obtained from DakoCytomation, Denmark. For oral administration, FK778 powder was mixed with 1\% carboxymethylcellulose in water until a final concentration of $5 \mathrm{mg} / \mathrm{ml}$ was obtained.

\section{Cell culture}

Human venous smooth muscle cells were obtained from ATCC (Manassas, USA), and cultured in F-12K medium (Kaighn's Modification of Ham's F-12 Medium), supplemented with $0.1 \mathrm{mg} / \mathrm{ml}$ heparin, $0.03 \mathrm{mg} / \mathrm{ml}$ endothelial cell growth supplement (ECGS), and 10\% fetal calf serum (FCS). Passages $4-6$ were used for experiments.

Subsequently SMCs were seeded in 24-wells plate (5000 cells/well) and synchronized for 24 hours in F-12K medium, supplemented with $2 \%$ fetal calf serum. Then the incubation medium was replaced by growth factor supplemented F-12K medium containing different concentrations of FK778 (1-30 $\mu \mathrm{M})$ and 10\% FCS. In additional experiments, uridine was also added to the incubation medium at a concentration of $1 \mathrm{mM}$. After 48 hours, cells were washed in PBS, fixed in formaldehyde, and permeabilized in NP-40 for 20 minutes. To determine SMC proliferation, SMCs were incubated with a mouse anti-human Ki67 antibody, followed by FITC-conjugated rabbit anti-mouse IgG (DakoCytomation, Denmark). Visualization was done by means of fluorescence microscopy.

\section{Animal conditions}

Sixteen male inbred specific pathogen free (SPF) Lewis (LEW) rats were 
obtained from the Department of Experimental Animal service of the University of Maastricht, the Netherlands. Experiments were carried out on animals aged 12 weeks weighing 300-400 gram. Housing and care of the animals, and all the procedures used in this study were approved by the Ethical Committee for the Use of Experimental Animals of the institution, and conformed to the Guide for the Care and the Use of Laboratory Animals, published by the US National Institute of Health (NIH Publication No. 85-23, revised 1996). Rats were fed standard rat chow and tap water at libitum. All surgical procedures were performed under general anesthesia and using sterile techniques.

\section{Experimental design}

Autologous epigastric vein-to-common femoral artery interposition grafts were placed in 16 rats by the use of a method similar to that described earlier by Hoch et al. ${ }^{13}$. Briefly, each animal was anesthetized with an intraperitoneal (i.p.) injection of pentobarbital sodium $(60 \mathrm{mg} / \mathrm{kg})$. An $\sim 8 \mathrm{~mm}$ segment of the relaxed ipsilateral epigastric vein was carefully harvested, gently irrigated with heparinized saline solution $(100 \mathrm{U} / \mathrm{ml})$, and placed as reverse interposition graft into a segmental $3 \mathrm{~mm}$ defect of the common femoral artery with 8 to 10 interrupted sutures of 11-0 nylon (Ethicon). The entire procedure was carried out with standard microsurgical techniques. The total ischemic time was kept to less than 30min. Patency was verified by visual inspection.

Eight animals received daily an oral dose of $15 \mathrm{mg} / \mathrm{kg}$ body weight starting 1 day prior to the operation until the day of sacrifice. Eight control rats received $3 \mathrm{ml}$ of $1 \%$ carboxymethylcellulose solution only.

Three weeks after surgery, rats were anaesthetised, the chest and abdominal cavities were opened, and a catheter was inserted into the apex of the heart. Vessels were initially flushed with physiological salt solution and then perfusion fixed with $3.7 \%$ formaldehyde in phosphate-buffered saline, $\mathrm{pH} 7.4$, at physiological pressure $(100 \mathrm{mmHg})$. Vein grafts were removed and fixed overnight in the same fixative. The fixed vein grafts were routinely processed and paraffin embedded. Cross-sections $(4 \mu \mathrm{m})$ were taken for morphometrical analysis at $200-\mu \mathrm{m}$ intervals and mounted on glass slides for haematoxylin-eosin (HE) and Lawson staining. Medial thickness, neointimal area and percentage of stenosis were determined by using a computer-assisted morphometry system (analySIS ${ }^{\circledR}$, Soft Imaging System, GmbH).

\section{Statistics}

Data were expressed as mean \pm SE. Student's $t$ test was used for the comparison between the different cell culture groups. Comparisons between groups for 
morphometric analyses were made using the two-sample Wilcoxon rank-sum (Mann-Whitney) test. Differences were considered significant at $\mathrm{P}<0.05$.

\section{Results}

Serum induced venous SMC proliferation is inhibited by FK778

The anti-proliferative potency of FK778 was studied on serum stimulated venous smooth muscle cells. Ki-67 immunoreactive cells were counted 48 hours following stimulation with $10 \%$ FCS in the presence of increasing concentrations of FK778. FK778 inhibited the proliferation of venous SMCs in a dose dependent manner (Figure 1). Reduction of SMC proliferation was already significant at a concentration of $3 \mu \mathrm{M}$ and maximum inhibition was obtained at $30 \mu \mathrm{M}$. Although it has been suggested that FK778 may exert

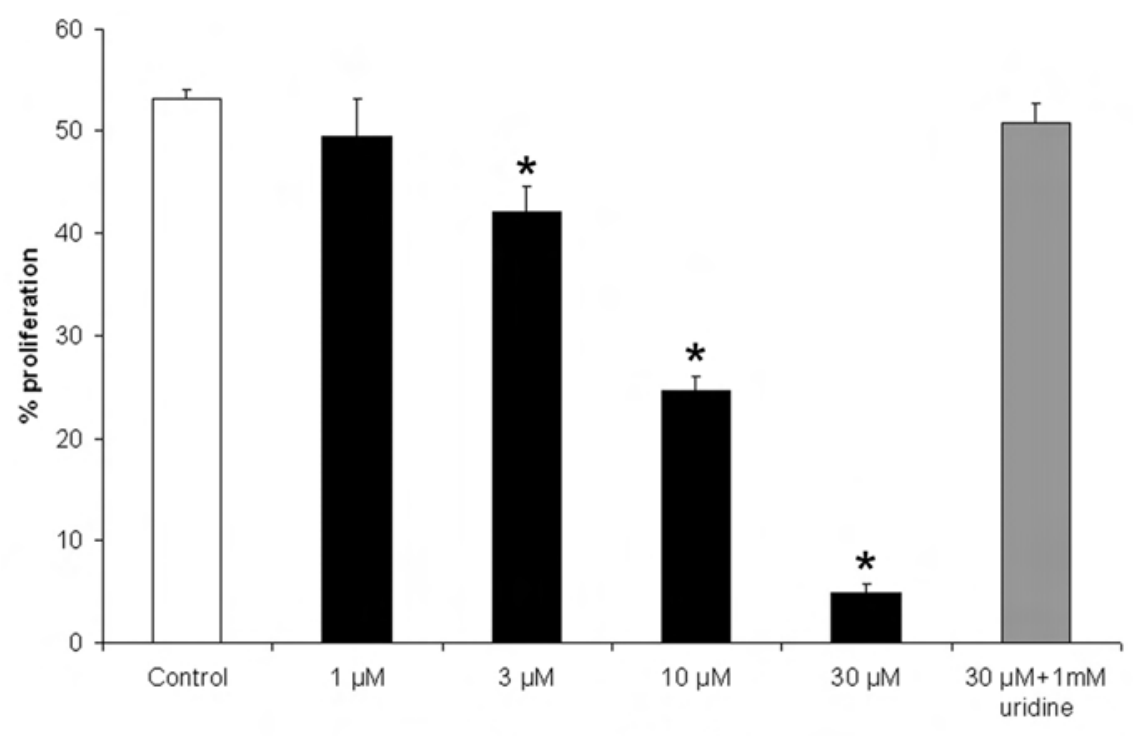

Concentration FK778

\section{Figure 1.}

FK778 dose-dependently inhibits Ki-67 immunoreactivity in 10\% FCS stimulated smooth muscle cells, while uridine $(1 \mathrm{mM})$ reverses the inhibitory effect of FK778 on smooth muscle cell proliferation. The values are plotted as a percentage of proliferating smooth muscle cells to the total amount of cells. Data points are expressed as mean \pm SEM of four different cultures tested. ${ }^{*} \mathrm{P}<0.01$, significantly different from control. 
cytotoxic effects when used in high $(>100 \mu \mathrm{M})$ concentrations $^{14}$, in our hands no signs of cell death were seen, even at the highest concentration of FK778 used, indicated by the absence of a positive trypan blue staining. To demonstrate that the observed inhibition of proliferation was due to FK778, uridine was added to the culture medium. For all FK778 concentrations used, the addition of $1 \mathrm{mM}$ uridine returned proliferation rates to control values (Figure 1).

\section{FK778 attenuates neointimal formation in experimental vein grafts}

No apparent clinical signs of illness were observed in any of the animals during the follow-up period. Starting body weight ranged from $300 \mathrm{~g}$ to $400 \mathrm{~g}$; at the end of the experiments animal weight ranged from $350 \mathrm{~g}$ to $450 \mathrm{~g}$. Body weight did not differ between the experimental group and the control group. (data not shown).

The mean medial thickness of native veins was $10 \pm 2 \mu \mathrm{m}$. Three weeks after bypass grafting, media thickness increased significantly in all veins irrespective whether rats were FK778 or sham treated. Nevertheless, no differences were observed between both groups (sham: 36.0 $\pm 2.3 \mu \mathrm{m}$ versus FK778 42.3 $\pm 4.2 \mu \mathrm{m}$, fig $2 \mathrm{~A}$ ). Also, neointimal thickening was observed in all graft but marked
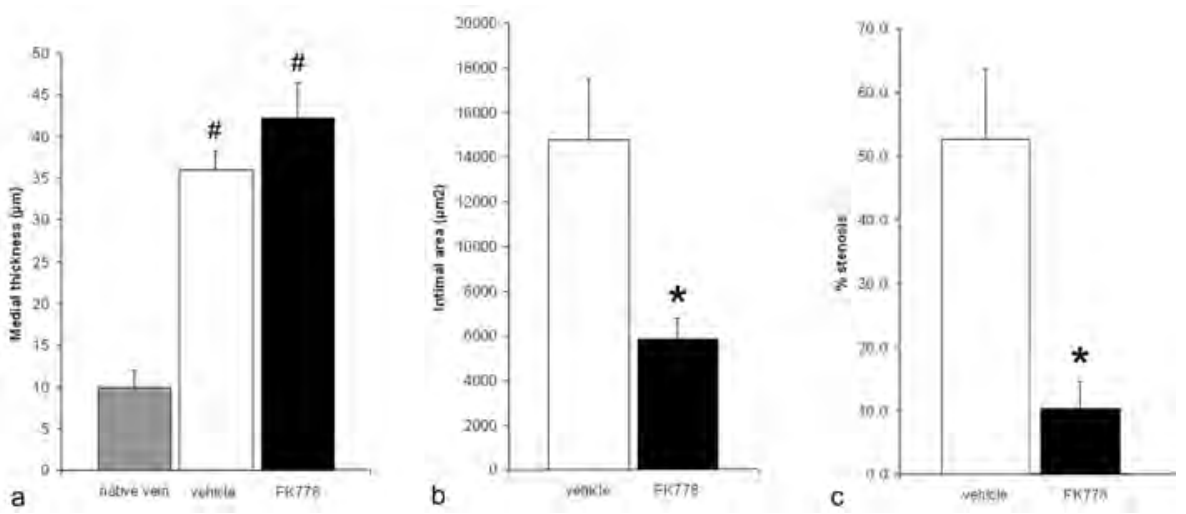

Figure 2.

A-C: FK778 (15 mg/kg) treated animals versus controls. A. medial thickness of grafted veins does not differ between experimental and control groups. B. Neointimal area is significantly reduced in the FK778 treated group compared to the control group. C. Percentage of stenosis is significantly lower in the FK778 treated group. Data points are expressed as mean \pm SEM. ${ }^{*} P<0.01$, significantly different from control. \#P<0.01, significant different from native vein. 


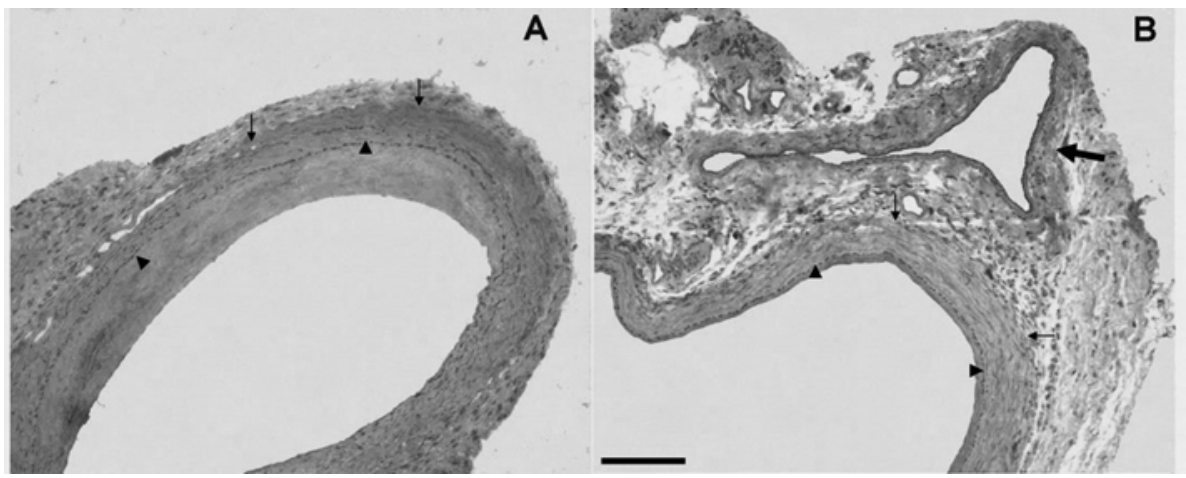

\section{Figure 3.}

Three weeks after vein grafting. Representative images after Lawson staining of a control vein graft (A) and FK778 treated vein graft (B). Arrowheads represent the lamina elastica interna. The media-aventitia border is indicated by small arrows. The large arrow indicates the native vein in situ adjacent to the grafted vein, which shows normal intimal and medial thickness. Notice the marked increase in medial thickness of both control and FK778 treated vein grafts compared to the native vein. Moreover, medial thickness is similar in both vein grafts. Scale bar: $100 \mu \mathrm{m}$.

differences were observed between control and FK778-treated rats (figure 3). Morphometric analyses revealed a significant reduction in the neointimal area following FK778 treatment compared to the control group $\left(5852 \pm 934 \mu \mathrm{m}^{2}\right.$ versus $14747.5 \pm 2750 \mu \mathrm{m}^{2}$ ) (Figure $2 \mathrm{~B}$ ). Furthermore, the stenosis rate in grafted veins in the FK778 treated group was approximately 6-times lower compared to the control group $(8.8 \pm 3.6 \%$ versus $52.6 \pm 11.1 \%$, $p<0.01$, fig $2 \mathrm{C}$, data are expressed as mean percentages of the lumen size to the area inside the internal elastic lamina).

\section{Discussion}

In the present study, we demonstrated that FK778 is a potent inhibitor of venous SMC proliferation. Moreover, oral treatment with FK778 attenuated neointimal formation in a rat epigastric-to-common femoral artery interposition graft model.

FK778 has been developed as an alternative for leflunomide, of which its active metabolite A77 1726 shares structural similarities with FK778 and proved beneficial in the treatment of various diseases. Initially, leflunomide was successfully applied in the treatment of rheumatoid arthritis, but was also used 
to treat autoimmune diseases and graft rejection ${ }^{15}$. Successive research showed that leflunomide is also effective in attenuating rat aortic smooth muscle proliferation ${ }^{16}$. This raised the question whether leflunomide could be used as an anti-proliferative drug to prevent vein graft failure. However, due to the long half-life and gastrointestinal toxicity of leflunomide ${ }^{17}$, applicability in clinical practice is hampered. In contrast, FK778 provides a more favorable pharmacologic profile in that it shares the same therapeutic efficacy without the extended halflife of leflunomide.

This triggered us to examine if FK778 could be applied to restrain venous SMC proliferation and prevent vein graft stenosis. Indeed, we were able to demonstrate that FK778 has the potency to inhibit serum dependent human venous SMC proliferation in a dose dependent manner. Earlier, others have attributed the anti-proliferative effect of malononitrilamides to inhibition of the de novo pyrimidine biosynthesis ${ }^{16}{ }^{18}$. As proliferative responses to $10 \%$ FCS could be restored completely by the addition of uridine, this suggests that SMC proliferation likewise depends on de novo synthesis of pyrimidine. Some cell types with high turn over rates, like the gastrointestinal lining cells, have previously been shown to be rather insensitive to the anti-proliferative effects of FK778, probably because they use salvage pathways for pyrimidine ribonucleotide synthesis ${ }^{19}$. Our results now suggest that proliferating vascular smooth muscle cells, as can be found in vein grafts or balloon-injured arterial segments, seem in short supply of pyrimidine, and are therefore obliged to synthesize pyrimidine de novo during the initial stages of neointimal formation. This suggests that proliferating smooth muscle cells might be potential targets for therapeutic interventions with FK778.

To test this and to verify our in vitro data, we used an experimental venous bypass graft model. Here, we demonstrate for the first time that FK778 effectively reduces neointimal formation in a rat epigastric vein-to-common femoral artery interposition graft model of intimal hyperplasia ${ }^{13}$. A similar vasculoprotective potency of FK778 to reduce neointimal formation, most likely independent of its immunosuppressive effects, has recently been shown in rat aorta injury models ${ }^{20}$. In agreement with these data, our results similarly showed a significant decrease in neointimal area after oral treatment with 15 $\mathrm{mg} / \mathrm{kg}$ FK778. Next to its anti-proliferative effect, it has also been suggested that FK778 directly reduces the up-regulation of endothelial adhesion molecules and attenuates lymphocyte-endothelium interaction in a transplantation model ${ }^{21}$. Although we did not scrutinize this possibility, this effect may have also aided in reducing the neointimal formation found in our model.

In addition to the neointimal area, we determined the percentage of stenosis in 
vein grafts. In our opinion, this parameter is of clinical significance, because it better resembles the functionality of the vein graft than the area of neointimal formation. Our data show that FK778 treatment not only prevented the hyperplastic response but also reduced the percentage of stenosis in the graft. Nevertheless, maturation of the graft was not impaired as the increase in medial thickness was comparable between groups. Interestingly, this increase in medial thickness does not seem to result from an increase in cell number, but appears to be dependent on extracellular matrix deposition, as revealed by HE staining (data not shown).

Several animal studies examined the characteristics of FK778 and its efficacy to prevent allograft rejection, and determined the nature and incidence of adverse side effects. Depending on the different mechanisms studied, variable drug doses were used, ranging from $5 \mathrm{mg} / \mathrm{kg} /$ day to $25 \mathrm{mg} / \mathrm{kg} /$ day. Even with the highest concentrations used no deaths have been reported so far, although some adverse effects were seen in animal groups treated with 25 $\mathrm{mg} / \mathrm{kg} /$ day. However, at efficacious doses hardly any complications have been reported. Accordingly, in the present study the effective dose of $15 \mathrm{mg} / \mathrm{kg} /$ day did not result in any deaths among the treated animals, nor was any discomfort noticed. Additionally, and in agreement with the present and other animal studies, recent clinical trials evaluated the safety of FK778 and its predecessor leflunomide and found few adverse events like diarrhea, increased liver functions and anemia ${ }^{22}$. In contrast, FK778 may even decrease total cholesterol and LDL-cholesterol levels, thus establishing a favorable cardiovascular risk profile ${ }^{22}$. Obviously, it is rather enticing to integrate this suggested attractive characteristic into the already favorable outcome prospect of FK778 in vein graft disease as we present in the current study. Taken together, it is of interest to commence clinical studies to investigate the potency of FK778 to interfere with vein graft neointimal formation and arterial restenosis after PTA.

Yet, some limitations of the present study should also be noted. It still needs to be clarified which dose of FK778 is most efficacious without causing adverse side effects. In contrast to long term periods as suggested for the treatment of diseases like rheumatoid arthritis, a relatively short treatment period might suffice for the prevention of intimal hyperplasia in vein graft as we observed a marked reduction in both neointimal formation as well as percentage of stenosis after only a 3 week treatment period. Furthermore, since it has been suggested that the starting time of treatment is more important than the duration of treatment ${ }^{23,24}$, we initiated the treatment period already at 1 day prior to surgery. Nevertheless, it needs further clarification which treatment strategy leads to the most favorable outcome in preventing graft failure. 
Furthermore, the present study did not make it indisputable that the inhibition of neointimal formation was merely the result of anti-proliferative effects of FK778. The family of MNAs exhibit anti-inflammatory effects as well, which might very well add to the control of neointimal formation. It has been shown that MNAs inhibit the expression of pro-inflammatory cytokines and adhesion molecules, thereby attenuating injury response and the process of neointimal formation ${ }^{25}$.

With the introduction of immunosuppressive drugs with anti-proliferative potential a new era has begun in the treatment of cardiovascular diseases. However, obviously developed to target other disease patterns, the balance between positive and adverse effects should continually be evaluated for every field of application. Evidently, the present study shows that the immunosuppressive agent FK778 has great potential to inhibit venous SMC proliferation in vitro and prevent venous neointima formation in vivo, without causing adverse side effects. The latter has been vastly supported by recent patient studies reporting few complications and even a possible favorable cardiovascular risk profile, which solicits confirmation of our findings in a clinical setting. 
Chapter 6

114 


\section{References}

1. Chesebro JH, Clements IP, Fuster V, Elveback LR, Smith HC, Bardsley WT, Frye RL, Holmes DR, Jr., Vlietstra RE, Pluth JR, Wallace RB, Puga FJ, Orszulak TA, Piehler JM, Schaff HV, Danielson GK. A platelet-inhibitor-drug trial in coronary-artery bypass operations: benefit of perioperative dipyridamole and aspirin therapy on early postoperative vein-graft patency. N Engl / Med. 1982;307(2):73-78.

2. Tangelder MJ, Lawson JA, Algra A, Eikelboom BC. Systematic review of randomized controlled trials of aspirin and oral anticoagulants in the prevention of graft occlusion and ischemic events after infrainguinal bypass surgery. J Vasc Surg. 1999;30(4):701-709.

3. Campeau L, Hunninghake DB, Knatterud GL, White CW, Domanski M, Forman SA, Forrester JS, Geller NL, Gobel FL, Herd JA, Hoogwerf BJ, Rosenberg Y. Aggressive cholesterol lowering delays saphenous vein graft atherosclerosis in women, the elderly, and patients with associated risk factors. NHLBI post coronary artery bypass graft clinical trial. Post CABG Trial Investigators. Circulation. 1999;99(25):3241-3247.

4. Porter KE, Thompson MM, Loftus IM, McDermott E, Jones L, Crowther M, Bell PR, London NJ. Production and inhibition of the gelatinolytic matrix metalloproteinases in a human model of vein graft stenosis. Eur J Vasc Endovasc Surg. 1999;17(5):404-412.

5. O'Donohoe MK, Schwartz LB, Radic ZS, Mikat EM, McCann RL, Hagen PO. Chronic ACE inhibition reduces intimal hyperplasia in experimental vein grafts. Ann Surg. 1991;214(6):727-732.

6. Conte MS, Mann MJ, Simosa HF, Rhynhart KK, Mulligan RC. Genetic interventions for vein bypass graft disease: a review. J Vasc Surg. 2002;36(5):1040-1052.

7. Windecker S, Remondino A, Eberli FR, Juni P, Raber L, Wenaweser P, Togni M, Billinger M, Tuller D, Seiler C, Roffi M, Corti R, Sutsch G, Maier W, Luscher T, Hess OM, Egger M, Meier B. Sirolimus-eluting and paclitaxel-eluting stents for coronary revascularization. N Engl J Med. 2005;353(7):653-662.

8. Ge L, lakovou I, Sangiorgi GM, Chieffo A, Melzi G, Cosgrave J, Montorfano M, Michev I, Airoldi F, Carlino M, Corvaja N, Colombo A. Treatment of saphenous vein graft lesions with drug-eluting stents: immediate and midterm outcome. I Am Coll Cardiol. 2005;45(7):989-994.

9. Farb A, John M, Acampado E, Kolodgie FD, Prescott MF, Virmani R. Oral everolimus inhibits in-stent neointimal growth. Circulation. 2002;106(18):2379-2384.

10. Hausleiter J, Kastrati A, Mehilli J, Vogeser M, Zohlnhofer D, Schuhlen H, Goos C, Pache J, Dotzer F, Pogatsa-Murray G, Dirschinger J, Heemann U, Schomig A. Randomized, double-blind, placebo-controlled trial of oral sirolimus for restenosis prevention in patients with in-stent restenosis: the Oral Sirolimus to Inhibit Recurrent In-stent Stenosis (OSIRIS) trial. Circulation. 2004;110(7):790-795. 
11. Guarda E, Marchant E, Fajuri A, Martinez A, Moran S, Mendez M, Uriarte P, Valenzuela E, Lazen R. Oral rapamycin to prevent human coronary stent restenosis: a pilot study. Am Heart J. 2004;148(2):e9.

12. Kahan BD, Van Buren CT, Weinman EJ, Sandler CM, Maddox AM, Van Horn G. Management of end-stage renal disease by transplantation: the use and limitations of cyclosporine. Tex Med. 1985;81(8):32-43.

13. Hoch JR, Stark VK, Hullett DA, Turnipseed WD. Vein graft intimal hyperplasia: leukocytes and cytokine gene expression. Surgery. 1994;116(2):463-470; discussion 470-461.

14. Evers DL, Wang X, Huong SM, Andreoni KA, Huang ES. Inhibition of human cytomegalovirus signaling and replication by the immunosuppressant FK778. Antiviral Res. 2005;65(1):1-12.

15. Bartlett RR, Dimitrijevic M, Mattar T, Zielinski T, Germann T, Rude E, Thoenes GH, Kuchle CC, Schorlemmer HU, Bremer E, et al. Leflunomide (HWA 486), a novel immunomodulating compound for the treatment of autoimmune disorders and reactions leading to transplantation rejection. Agents Actions. 1991;32(1-2):10-21.

16. Czech J, Kurrle R, Schorlemmer HU. The antiproliferative effect of malononitrilamides (MNAs) on vascular smooth muscle cells is antagonized by exogenous uridine. Inflamm Res. 1999;48 Suppl 2:S128-129.

17. Cherwinski HM, McCarley D, Schatzman R, Devens B, Ransom JT. The immunosuppressant leflunomide inhibits lymphocyte progression through cell cycle by a novel mechanism. J Pharmacol Exp Ther. 1995;272(1):460-468.

18. Nair RV, Cao W, Morris RE. Inhibition of smooth muscle cell proliferation in vitro by leflunomide, a new immunosuppressant, is antagonized by uridine. Immunol Lett. 1995;47(3):171-174.

19. Linke SP, Clarkin KC, Di Leonardo A, Tsou A, Wahl GM. A reversible, p53-dependent G0/G1 cell cycle arrest induced by ribonucleotide depletion in the absence of detectable DNA damage. Genes Dev. 1996;10(8):934-947.

20. Savikko J, Von Willebrand E, Hayry P. Leflunomide analogue FK778 is vasculoprotective independent of its immunosuppressive effect: potential applications for restenosis and chronic rejection. Transplantation. 2003;76(3):455-458; discussion 471-453.

21. Deuse T, Schrepfer S, Schafer H, Koch-Nolte F, Schwedhelm E, Boger RH, Reichenspurner H. FK778 attenuates lymphocyte-endothelium interaction after cardiac transplantation: in vivo and in vitro studies. Transplantation. 2004;78(1):71-77.

22. Vanrenterghem $Y$, van Hooff JP, Klinger M, Wlodarczyk Z, Squifflet JP, Mourad G, Neuhaus P, Jurewicz A, Rostaing L, Charpentier B, Paczek L, Kreis H, Chang R, Paul LC, Grinyo JM, Short C. The effects of FK778 in combination with tacrolimus and steroids: a phase II multicenter study in renal transplant patients. Transplantation. 2004;78(1): 9-14. 
23. Uchimura N, Perera GB, Fujitani RM, Tobis JM, Ishimaru S, Wilson SE, Gordon IL. Dose-dependent inhibition of myointimal hyperplasia by orally administered rapamycin. Ann Vasc Surg. 2004;18(2):172-177.

24. Jahnke T, Schafer FK, Bolte H, Rector L, Schafer PJ, Brossmann J, Fandrich F, Hedderich J, Heller M, Muller-Hulsbeck S. 2005 Dr. Gary J. Becker Young Investigator Award: periprocedural oral administration of the leflunomide analogue FK778 inhibits neointima formation in a double-injury rat model of restenosis. J Vasc Interv Radiol. 2005;16(7):903-910.

25. Crews GM, Erickson L, Pan F, Fisniku O, Jang MS, Wynn C, Benediktsson H, Kobayashi M, Jiang H. Down-regulation of TGF-beta and VCAM-1 is associated with successful treatment of chronic rejection in rats. Transplant Proc. 2005;37(4):1926-1928. 



\section{Chapter 7}

\section{General discussion}


Failure of venous bypass grafts and subsequent intervention weighs heavily on today's patient's quality of life and healthcare capacity. Despite extensive research into the mechanisms leading to graft failure and the development of multiple pharmacological agents and surgical techniques to prevent disproportionate remodeling, currently no effective strategy has emerged. The main goal of the present thesis was to expose unknown culprits that serve the development of venous intimal thickening and further, judge the potential of pharmacological agents to inhibit the harmful effects of these mediators. Furthermore, we tried to discover a prognostic method to determine the risk of future vein graft failure, by examining morphologic aspects of the autologous vein at the time of implantation.

Inflammation, smooth muscle cell proliferation and vein graft neointima formation Numerous studies have been conducted to discover mechanisms and pathways involved in venous intimal thickening and several emerged in recent years. Accordingly, the process of neointimal formation in vein grafts should be considered multifactorial. Therefore, it would be utopian to assume that treatments targeting an individual mechanism or pathway would be feasible or even adequate to prevent excessive intimal thickening. Nevertheless, discovery of unknown mediators might increase our knowledge regarding neointimal formation in vein grafts and lead us in the right way to further reduce the number of bypass failures.

The majority of previous research addressing the etiology of neointimal formation has been done in arterial injury models. In line with ample evidence demonstrating a prominent role for inflammation-dependent mechanisms in arterial neointima formation, recently a relation between inflammation and the venous wall response to injury has been presented ${ }^{1,2}$. Thus, pro-inflammatory cytokines and growth factors appear to be an important link between the altered hemodynamic milieu and ultimate SMC proliferation/migration in vein grafts. Endothelial cells sense hemodynamic alterations and are known to react by secreting several vasoprotective and pro-inflammatory agents, that in turn activate SMCs to migrate and proliferate. Furthermore, hemodynamic stress induces up-regulation of monocyte chemoattractant protein (MCP)-1, which is closely followed by monocyte/macrophage infiltration and neointimal formation $^{3,4}$. In addition, cell-mediated damage of vein grafts induces upregulation of adhesion molecules, which increases the affinity for circulating inflammatory cells and platelets ${ }^{5}$. On activation, these cell types both secrete pro-inflammatory cytokines with high mitogenic potential for SMCs. In experimental animal models it has previously been shown that 
monocytes/macrophages and T-cells infiltrate vein grafts after implantation ${ }^{6}$. In chapter 2 we confirmed these findings when we demonstrated significant higher levels of macrophages and T-cells in venous neointimal lesions, compared to control veins. Moreover, we immunohistochemically evaluated small sections from veins predestined for venous bypass graft surgery, and correlated this with clinical outcome one year post-surgery. Interestingly, we observed a significant larger number of macrophages and T-cells in veins which failed in the following year. Predisposing factors for vein graft failure have been recognized earlier, as general cardiovascular risk factors like smoking, dyslipidemia, hypertension and diabetes all showed to hamper long term patency. However, there was no instrument available that could indicate which vein grafts were prone to fail in the future. With our results we were the first to present a possible prognostic method to predict future venous bypass failure. Also, our findings underscore the inflammatory nature of venous intimal thickening. Furthermore, immune-mediated mechanisms known to be involved in the pathogenesis of atherosclerosis ${ }^{7}$ now are stronger implicated in venous intimal hyperplasia.

T-lymphocytes, like macrophages produce many different cytokines that stimulate growth, differentiation and chemotaxis. A primary role of immune reactions in venous intimal hyperplasia was underscored by Cherian et al who found colocalization of T-cells and dendritic cells in intimal hyperplastic lesions, indicating an antigen presenting relationship ${ }^{8}$. Candidate antigens that may lead to a humoral and/or cellular immune response include modified lipoproteins, intracellular antigens exposed through cytolysis or necrosis and antigens of infectious organisms such as cytomegalovirus, and Chlamydia pneumoniae. Heat shock proteins (HSP) assemble another very interesting group of antigens. HSPs have been implicated in the maintenance of the inflammatory/immunologic response observed in atherosclerotic lesions, and the expression of human HSP60 correlates positively with the severity of atherosclerotic lesions ${ }^{9}$. HSPs or "stress proteins" comprise a family of proteins demonstrating highly homologous sequences between various species, from bacteria to humans. This high degree of amino acid sequence homology between human and microbial HSP60 (antigen mimicry) has been the foundation for the autoimmune hypothesis in atherosclerotic disease ${ }^{7}$. Specifically, infection of vascular cells with Chlamydia pneumoniae for instance causes an increase in both Chlamydial and human HSP60, and crossreaction with both HSPs might thus lead to an (auto) immune response to vascular cells ${ }^{10}$. However, several entities other than infection have been shown to induce HSP production by vascular cells, like oxidative stress, 
cytokine stimulation, and mechanical stress ${ }^{11}$. Of interest is the substantial production of HSP60 by endothelial cells in response to hemodynamic stress ${ }^{12}$.

HSP60 has also been suggested to incorporate inflammatory qualities, epitomized by HSP60 induced triggering of signal transduction via the proinflammatory MAPK pathway ${ }^{13}$. Furthermore, HSP60 has been shown to induce the production of pro-inflammatory cytokines such as tumor necrosis factor (TNF)- $\alpha$, interleukin (IL)-1, IL-6, and IL-12 ${ }^{14}$, and in turn, is up-regulated by pro-inflammatory cytokines itself. Thus, potential paracrine and autocrine mechanisms by which endogenous HSP60 might be involved in the process of neointima formation are abundant. In chapter 3 we found that autogenous HSP60 features yet another cytokine function in that it directly stimulates human venous SMC proliferation, and that this mitogenic effect could be inhibited by blocking Toll like receptors (TLR) 2 and 4, which are the suggested receptors for HSP60. TLRs however are known to recognize lipopolysaccharide (LPS) which induces cellular responses similar to those suggested for HSP60. Therefore, we were very meticulous to exclude the danger of contamination with LPS in our preparations used to examine HSP60 induced SMC proliferation. Both Limulus amebocyte lysate (LAL) assay and heat inactivation of our preparations were used, and convinced us that the mitogenic effect of HSP60 was not due to contamination with LPS. In order to make a more practical interpretation of our findings we studied venous neointima lesions and healthy veins by immunohistochemistry. Evidently, both TLR2 and TLR4 COlocalized with HSP60 in venous neointima lesions, and visibly to a larger extent then in healthy veins. Although HSP60 is originally a mitochondrial protein that can be translocated into the cytoplasm under stress conditions, it is well understood that HSPs can be released in the extracellular compartment independent of cell death, but in response to a number of stressful conditions ${ }^{15}$. Furthermore, circulating HSP60 reside in healthy individuals and elevated HSP60 levels relate to pathological conditions, like hypertension and atherosclerosis ${ }^{16,17,18}$. Because of the high levels and different types of stress, particularly in vein grafts just after implantation, it is conceivable that local extracellular HSP60 reaches high levels and thus contributes significantly to SMC proliferation. Whether autogenous HSP60 indeed plays a significant role in neointima formation in vivo should be further investigated in animal models.

In chapter $\mathbf{4}$ we presented an additional mechanism that as yet has not been considered to be involved in venous intimal thickening. We hypothesized that venous wall injury after implantation in the arterial circulation is not only induced by hemodynamic stress, but also by supra-physiological oxygen levels leading to oxidative stress. Accumulating evidence indicates that oxidative 
stress is an important modulator of vascular cell functions and that it plays a major role in several cardiovascular diseases. In venous bypass grafts, two mechanisms might hamper the functionality of the conduit. First, when excessive ROS overpower the endogenous antioxidant systems, impaired endothelial cell function leads to decreased nitric oxide (NO) bioavailability. Consequently, endothelium-mediated vasodilatation is impaired which contributes to the risk of thrombosis related early graft failure. Secondly, it has been shown that ROS induce several processes related to vascular remodeling and inflammation, like NF-kB activation, MMP expression, and SMC proliferation/migration ${ }^{19}$. Furthermore, research from the field of pulmonary physiology has already demonstrated that human umbilical vein endothelial cells (HUVEC) induce pro-inflammatory responses when exposed to hyperoxia ${ }^{20}$. Finally, it has been demonstrated that elevations in ROS are related to neointimal hyperplasia after vascular injury in experimental animal models ${ }^{21}$. The origin of ROS in vein grafts and the relation with neointimal hyperplasia development was not yet investigated. We found that supraphysiological oxygen levels induced pro-inflammatory cytokine secretion in VSMCs, which initiated quiescent venous SMC proliferation in vitro. We further found that $\mathrm{N}$-acetyl-L-cysteine (NAC) reduced cytokine levels in conditioned medium from the hyperoxic VSMC culture. In agreement, the conditioned medium no longer showed mitogenic potential in SMC culture. This finding was supported by our experimental vein graft studies. First we found a significant reduction in proliferating VSMCs in vein graft 1 week after implantation in the NAC treated group in comparison to the control group. Second, at 3 weeks post surgery it was shown that NAC treatment significantly reduced neointima formation and stenosis in experimental vein grafts. We were not the first group to show that NAC exerts vasculoprotective qualities and attenuates neointima formation. However, these investigations were all performed in arterial models. Moreover, we were the first to implicate supra-physiological oxygen levels in the pathogenesis of vein graft disease. Although we do not neglect the importance of hemodynamic stress in the development of venous neointima formation, our findings might certainly add to the knowledge of vein graft disease and offer new implementations for the prevention of venous neointima formation.

Prevention of venous neointimal hyperplasia

With the presentation of aforementioned results we underscored the inflammatory nature of venous neointimal hyperplasia, and supplemented the current hypothesis of neointimal formation with novel culprit mediators. 
Moreover, we introduced possible intervention methods to inhibit the adverse effects of these mediators. For many years efforts have been made to prevent early and late venous graft failure. First, vascular interventionists stressed the importance of risk factor reduction by introducing anti-thrombotic agents to target early graft failure, and lipid lowering drugs to prevent late graft failure. Second, the problem of venous neointimal hyperplasia was targeted by introducing alternative conduits, like the internal mammary artery and synthetic grafts. However, unidentified mediators continued to hamper the patency of bypass grafts. Following the inflammation hypothesis of atherosclerosis, venous neointimal hyperplasia was also thought to be mediated by inflammatory processes. The role of pro-inflammatory and mitogenic cytokines has been investigated extensively and several intervention methods have been designed to target these growth factors. Both in vitro and in vivo, antibodies against inflammatory cytokines proved efficient to inhibit SMC proliferation and neointimal thickening ${ }^{22,23}$. Furthermore, gene therapy targeting distinct growth factors still is a promising technique with adequate results in experimental models ${ }^{24,25,26}$. However, up till now none of these intervention techniques proved to be feasible in the clinical setting. First and foremost, the multifactorial nature of neointimal hyperplasia is a plausible reason for the incomplete inhibition of neointimal thickening, because several growth factor related mechanisms occur simultaneously and cumulative. Thus, blocking or elimination of distinct cytokines and growth factors will probably not adequately reduce neointimal formation, and therefore request simultaneous targeting of multiple growth factors at the same time. However, it seems laborious to target all possible mediators of neointima thickening by antibody treatment. The transcription factor nuclear factor-kappaB (NF-kB) plays a pivotal role in the coordinated transactivation of cytokine and adhesion molecule genes involved in neointimal formation. Therefore, direct inhibition of NF-kB activation would be a promising alternative for generalized cytokine inhibition in order to prevent inflammation related neointimal formation. In fact, encouraging results were recently published showing that injury induced intimal hyperplasia was inhibited using a 'decoy' cis element that blocked NF-kB gene activation ${ }^{27}$. Subsequent inflammatory responses as adhesion molecule expression and inflammatory cell influx were also significantly inhibited. As mentioned before, in chapter $\mathbf{4}$ we showed that NAC significantly reduced proinflammatory cytokine levels in SMCs and reduced neointimal thickening in experimental vein grafts. NAC is known to be a potent inhibitor of NF-kB activation $^{28}$, thus might inhibit intimal hyperplasia through a NF-kB mediated pathway. Although interesting, since NF-KB gene activation is the basis for 
numerous downstream cell processes, blocking NF-kB gene activation might also lead to inhibition of protective (e.g. anti-inflammatory) processes that counteract inflammation induced neointimal thickening. Furthermore, several pro-inflammatory cytokines have been shown to exert contradictory effects on SMCs (mitogenic versus inhibitory) ${ }^{29,30}$, and bifunctional responses during the development of neointima formation ${ }^{31}$. However, it seems that the favorable effect of NF-kB inhibition overrule the adverse effects.

Inflammatory processes play a significant role in venous neointimal formation and one of the most prominent and detrimental consequences is the increase in SMC number within the inner layers of the vessel wall, mainly caused by proliferation of locally residing SMCs. The final common pathway of $\mathrm{SMC}$ proliferation composes the progression through the different phases of the cell cycle, which comprises the Gap (G)1, DNA synthesis (S), G2, and mitosis (M) phase. The cell cycle of the SMC could suffice as an attractive target for intervention if it would be accessible for pharmacological agents. Cell cycle progression, leading to cell proliferation is tightly regulated by the sequential formation, activation and inactivation of a group of nuclear proteins ${ }^{32}$. Briefly, complexes between cyclins and cyclin dependent kinases (CDK) that stimulate cell cycle progression continually compete with cyclin dependent kinase inhibitors (CKI) that impede cell cycling, which in turn is dependent on the balance between pro- and anti-mitogenic signaling. During SMC quiescence, the key CKIs p21, p27, and p57 inactivate cyclin-CDK complexes thus preventing G1-S transition. After mitogenic signaling, proteolysis of CKIs result in phosphorylation of retinoblastoma protein that subsequently evades its inhibitory control over the transcription factor E2F leading to cell cycle progression. To find out if the cell cycle machinery might be a functional target for intervention, we examined if cells in venous neointimal lesions express distinct patterns of cell cycle proteins. In chapter $\mathbf{5}$ we immunohistochemically studied venous intimal hyperplasic lesions from arteriovenous fistulas (AVF) and found typical expression of cell cycle promoters and inhibitors. We compared the expression of cell cycle regulators cdk2, p21, p27, and proliferating cell nuclear antigen (pcna) between healthy control veins and stenosed AVF lesions and showed that venous neointimal lesions of AVFs express low p21 levels versus high cdk2 and pcna levels. p27 levels did not differ significantly, which is in agreement with previous reports suggesting that p27 is up-regulated at the later phases of vascular response to injury ${ }^{33,34}$. Since the vascular specimens used in our study were removed at the time of failure, we suggest that the acute moment in the response to injury was captured and p27 upregulation was still awaited. Also, it implies that boosting the levels of p27 in the venous wall might 
block unfavorable neointima formation. However, the first studies focused on the genetic manipulation of p21 to reduce neointima lesions size ${ }^{35,36}$. Besides genetic manipulation by means of adenoviruses, pharmacological agents have been shown to influence cell proliferation by manipulating cell cycle regulating proteins. Tranilast, an anti-allergic drug, was originally suggested to suppress intimal hyperplasia after angioplasty ${ }^{37}$, which was elaborated later by Takahashi et al who found Tranilast induced inhibition of SMC proliferation via upregulation of $\mathrm{p} 21^{38}$. However, in a multicenter, randomized clinical trial, administration of Tranilast did not improve either angiographic or clinical restenosis compared with administration of placebo alone ${ }^{39}$. Around the same time, the immunosuppressive agent Rapamycin was introduced because of its suggested anti-proliferative potential, which is mediated by the effect on the cell cycle regulator p27 by Rapamycin. In contrast to Tranilast, Rapamycin not only proved to inhibit intimal hyperplasia after coronary angioplasty in a pig model $^{40}$, but in recent years consistently showed beneficial in prevention of restenosis after stent placement in randomized controlled trials ${ }^{41-43}$. Moreover, local application of Rapamycin substantially inhibited neointimal hyperplasia of vein grafts in a mouse model, suggesting that Rapamycin may have therapeutic potential for the treatment of vein graft disease ${ }^{44}$. Recently, Murphy et al published optimistic results showing reduced neointima after pretreatment of saphenous veins with Rapamycin ${ }^{45}$. Clinical studies should now point out if similar outcomes can be achieved in humans.

In chapter $\mathbf{6}$ we examined the potency of another immunosuppressive agent, FK778 to inhibit SMC proliferation and neointima formation in vein grafts. Former research already suggested a favorable result of orally administered FK778 on neointima formation in a double-injury rat model of restenosis. The foundation for this promising outcome was previously created by Czech et al who proved that the family of malononitrilamides to which FK778 belongs, exerts an anti-proliferative effect on vascular SMCs ${ }^{46}$. We found that FK778 inhibited venous SMC proliferation in a dose dependent fashion in vitro. In addition, neointima hyperplasia was significantly reduced by oral administration of FK778 in a rat experimental vein graft model. All together, it seems that FK778 treatment is a promising drug to enhance patency in venous bypass grafts. However, up till now it remains obscure which molecular mechanisms underlie the potency of FK778. Both inhibition of receptor tyrosine kinase (RTK) activity and blocking of the pyrimidine synthesis pathway have been suggested to reduce cell cycle progression ${ }^{47,48}$. Up till now however, it is mainly believed that suppression of the novo pyrimidine biosynthesis is the key mechanisms in SMC proliferation. This is supported by our study in which we 
found that addition of uridine, a nucleoside that can be utilized via the salvage pathway to maintain the intracellular pool of pyrimidine nucleotides abolished the effects of FK778.

As mentioned above Ross suggested that the immune system mediates the inflammatory response within the vessel wall ${ }^{49}$. T-cell activation might considerably enhance the initiating stages in neointima formation. FK778 has been shown to block cellular (ie, T-cell) and humoral immune responses, and by this an alternative method of action to prevent intima hyperplasia might be proposed.

We conclude that cell cycle interference either by genetic manipulation or pharmacological intervention is a promising method to attenuate unfavorable intima hyperplasia and warrants further clinical investigation.

\section{Suggestions for clinical trials}

In addition to established treatments proven to be beneficial in most patients receiving venous bypass grafts, several (pharmacological) intervention methods could be considered. Beside the stipulation that potential drugs should be feasible as well as effective to prevent bypass failure, evaluation of adverse side effects is necessary before these drugs can be introduced in clinical practice. NAC has proven to be efficient in our and other experimental animal model to reduce neointimal formation possibly by inhibiting NF-kB activity as well as scavenging free oxygen radicals. Since NAC has been used in several clinical trials and no adverse effects were seen up to doses of $6000 \mathrm{mg}$ it seems acceptable to conclude that NAC can be administered safely.

FK778 is still under development, but a recently completed clinical trial did not show significant adverse effects ${ }^{50}$, thus it seems unlikely that the positive effects on patency rates of vein grafts noticed in our study will be hampered by side effects.

Our finding that pre-existence of inflammatory cells in saphenous veins destined to be implanted as vein grafts might predict vein graft occlusion might help to discriminate between patients needing additional therapy and patients for whom conservative treatment would suffice.

\section{Conclusions}

The pathogenesis of neointimal hyperplasia in vein grafts is of multifactorial origin; therefore a wide range of potential interventions is conceivable. However, the predominant morphological feature of $\mathrm{IH}$ is smooth muscle proliferation putting exacerbated cell cycle progression in the center of its development and in the scope of promising interventions. 


\section{References}

1. Crook MF, Newby AC, Southgate KM. Expression of intercellular adhesion molecules in human saphenous veins: effects of inflammatory cytokines and neointima formation in culture. Atherosclerosis. 2000;150(1):33-41.

2. Christiansen JF, Hartwig D, Bechtel JF, Kluter H, Sievers H, Schonbeck U, Bartels C. Diseased vein grafts express elevated inflammatory cytokine levels compared with atherosclerotic coronary arteries. Ann Thorac Surg. 2004;77(5):1575-1579.

3. Wung BS, Cheng JJ, Hsieh HJ, Shyy YJ, Wang DL. Cyclic strain-induced monocyte chemotactic protein-1 gene expression in endothelial cells involves reactive oxygen species activation of activator protein 1. Circ Res. 1997;81(1):1-7.

4. Stark VK, Hoch JR, Warner TF, Hullett DA. Monocyte chemotactic protein-1 expression is associated with the development of vein graft intimal hyperplasia. Arterioscler Thromb Vasc Biol. 1997;17(8):1614-1621.

5. Chester $\mathrm{AH}$, Morrison KJ, Yacoub MH. Expression of vascular adhesion molecules in saphenous vein coronary bypass grafts. Ann Thorac Surg. 1998;65(6):1685-1689.

6. Hoch JR, Stark VK, Hullett DA, Turnipseed WD. Vein graft intimal hyperplasia: leukocytes and cytokine gene expression. Surgery. 1994;116(2):463-470; discussion 470-461.

7. Wick G, Romen M, Amberger A, Metzler B, Mayr M, Falkensammer G, Xu Q. Atherosclerosis, autoimmunity, and vascular-associated lymphoid tissue. Faseb /. 1997;11(13):1199-1207.

8. Cherian SM, Bobryshev YV, Liang H, Inder SJ, Wang AY, Lord RS, Tran D, Pandey P, Halasz P, Farnsworth AE. Immunohistochemical and ultrastructural evidence that dendritic cells infiltrate stenotic aortocoronary saphenous vein bypass grafts. Cardiovasc Surg. 2001;9(2):194-200.

9. Kleindienst R, Xu Q, Willeit J, Waldenberger FR, Weimann S, Wick G. Immunology of atherosclerosis. Demonstration of heat shock protein 60 expression and T lymphocytes bearing alpha/beta or gamma/delta receptor in human atherosclerotic lesions. Am J Pathol. 1993;142(6):1927-1937.

10. Mayr M, Metzler B, Kiechl S, Willeit J, Schett G, Xu Q, Wick G. Endothelial cytotoxicity mediated by serum antibodies to heat shock proteins of Escherichia coli and Chlamydia pneumoniae: immune reactions to heat shock proteins as a possible link between infection and atherosclerosis. Circulation. 1999;99(12):1560-1566.

11. Xu Q, Wick $\mathrm{G}$. The role of heat shock proteins in protection and pathophysiology of the arterial wall. Mol Med Today. 1996;2(9):372-379.

12. Hochleitner BW, Hochleitner EO, Obrist P, Eberl T, Amberger A, Xu Q, Margreiter R, Wick G. Fluid shear stress induces heat shock protein 60 expression in endothelial cells in vitro and in vivo. Arterioscler Thromb Vasc Biol. 2000;20(3):617-623. 
13. Wick G, Knoflach M, Xu Q. Autoimmune and inflammatory mechanisms in atherosclerosis. Annu Rev Immunol. 2004;22:361-403.

14. Tsan MF, Gao B. Cytokine function of heat shock proteins. Am J Physiol Cell Physiol. 2004;286(4):C739-744.

15. Liao DF, Jin ZG, Baas AS, Daum G, Gygi SP, Aebersold R, Berk BC. Purification and identification of secreted oxidative stress-induced factors from vascular smooth muscle cells. J Biol Chem. 2000;275(1):189-196.

16. Pockley AG, Wu R, Lemne C, Kiessling R, de Faire U, Frostegard J. Circulating heat shock protein 60 is associated with early cardiovascular disease. Hypertension. 2000;36(2):303-307.

17. Pockley AG, Bulmer J, Hanks BM, Wright BH. Identification of human heat shock protein 60 (Hsp60) and anti-Hsp60 antibodies in the peripheral circulation of normal individuals. Cell Stress Chaperones. 1999;4(1):29-35.

18. Xu Q, Schett G, Perschinka H, Mayr M, Egger G, Oberhollenzer F, Willeit J, Kiechl S, Wick G. Serum soluble heat shock protein 60 is elevated in subjects with atherosclerosis in a general population. Circulation. 2000;102(1):14-20.

19. Touyz RM, Schiffrin EL. Reactive oxygen species in vascular biology: implications in hypertension. Histochem Cell Biol. 2004;122(4):339-352.

20. Suzuki Y, Aoki T, Takeuchi O, Nishio K, Suzuki K, Miyata A, Oyamada Y, Takasugi T, Mori M, Fujita H, Yamaguchi K. Effect of hyperoxia on adhesion molecule expression in human endothelial cells and neutrophils. Am J Physiol. 1997;272(3 Pt 1):L418-425.

21. Shi Y, Niculescu R, Wang D, Patel S, Davenpeck KL, Zalewski A. Increased NAD(P)H oxidase and reactive oxygen species in coronary arteries after balloon injury. Arterioscler Thromb Vasc Biol. 2001;21(5):739-745.

22. Rutherford C, Martin W, Salame M, Carrier M, Anggard E, Ferns G. Substantial inhibition of neo-intimal response to balloon injury in the rat carotid artery using a combination of antibodies to platelet-derived growth factor-BB and basic fibroblast growth factor. Atherosclerosis. 1997;130(1-2):45-51.

23. Wolf YG, Rasmussen LM, Ruoslahti E. Antibodies against transforming growth factorbeta 1 suppress intimal hyperplasia in a rat model. J Clin Invest. 1994;93(3):1172-1178.

24. Hanna AK, Fox JC, Neschis DG, Safford SD, Swain JL, Golden MA. Antisense basic fibroblast growth factor gene transfer reduces neointimal thickening after arterial injury. J Vasc Surg. 1997;25(2):320-325.

25. Kotani M, Fukuda N, Ando H, Hu WY, Kunimoto S, Saito S, Kanmatsuse K. Chimeric DNA-RNA hammerhead ribozyme targeting PDGF A-chain mRNA specifically inhibits neointima formation in rat carotid artery after balloon injury. Cardiovasc Res. 2003;57(1):265-276. 
26. Ando H, Fukuda N, Kotani M, Yokoyama S, Kunimoto S, Matsumoto K, Saito S, Kanmatsuse K, Mugishima H. Chimeric DNA-RNA hammerhead ribozyme targeting transforming growth factor-beta $1 \mathrm{mRNA}$ inhibits neointima formation in rat carotid artery after balloon injury. Eur J Pharmacol. 2004;483(2-3):207-214.

27. Miyake T, Aoki M, Shiraya S, Tanemoto K, Ogihara T, Kaneda Y, Morishita R. Inhibitory effects of NFkappaB decoy oligodeoxynucleotides on neointimal hyperplasia in a rabbit vein graft model. J Mol Cell Cardiol. 2006;41(3):431-440.

28. Hayashi K, Takahata H, Kitagawa N, Kitange G, Kaminogo M, Shibata S. Nacetylcysteine inhibited nuclear factor-kappaB expression and the intimal hyperplasia in rat carotid arterial injury. Neurol Res. 2001;23(7):731-738.

29. Mii S, Ware JA, Kent KC. Transforming growth factor-beta inhibits human vascular smooth muscle cell growth and migration. Surgery. 1993;114(2):464-470.

30. Battegay EJ, Raines EW, Seifert RA, Bowen-Pope DF, Ross R. TGF-beta induces bimodal proliferation of connective tissue cells via complex control of an autocrine PDGF loop. Cell. 1990;63(3):515-524.

31. Koyama N, Koshikawa T, Morisaki N, Saito Y, Yoshida S. Bifunctional effects of transforming growth factor-beta on migration of cultured rat aortic smooth muscle cells. Biochem Biophys Res Commun. 1990;169(2):725-729.

32. Li JM, Brooks G. Cell cycle regulatory molecules (cyclins, cyclin-dependent kinases and cyclin-dependent kinase inhibitors) and the cardiovascular system; potential targets for therapy? Eur Heart J. 1999;20(6):406-420.

33. Tanner FC, Yang ZY, Duckers E, Gordon D, Nabel GJ, Nabel EG. Expression of cyclindependent kinase inhibitors in vascular disease. Circ Res. 1998;82(3):396-403.

34. Chung JK, Lee T, Jung IM, Kim YK, Min SK, Suh JW, Kim SJ. Expression of cell cycle regulators during smooth muscle cell proliferation after balloon catheter injury of rat artery. J Korean Med Sci. 2004;19(3):327-332.

35. Chang MW, Barr E, Lu MM, Barton K, Leiden JM. Adenovirus-mediated over-expression of the cyclin/cyclin-dependent kinase inhibitor, p21 inhibits vascular smooth muscle cell proliferation and neointima formation in the rat carotid artery model of balloon angioplasty. J Clin Invest. 1995;96(5):2260-2268.

36. Yang ZY, Simari RD, Perkins ND, San H, Gordon D, Nabel GJ, Nabel EG. Role of the p21 cyclin-dependent kinase inhibitor in limiting intimal cell proliferation in response to arterial injury. Proc Natl Acad Sci U S A. 1996;93(15):7905-7910.

37. Fukuyama J, Ichikawa K, Hamano S, Shibata N. Tranilast suppresses the vascular intimal hyperplasia after balloon injury in rabbits fed on a high-cholesterol diet. Eur J Pharmacol. 1996;318(2-3):327-332.

38. Takahashi A, Taniguchi T, Ishikawa Y, Yokoyama M. Tranilast inhibits vascular smooth muscle cell growth and intimal hyperplasia by induction of p21(waf1/cip1/sdi1) and p53. Circ Res. 1999;84(5):543-550. 
39. Holmes DR, Jr., Savage M, LaBlanche JM, Grip L, Serruys PW, Fitzgerald P, Fischman D, Goldberg S, Brinker JA, Zeiher AM, Shapiro LM, Willerson J, Davis BR, Ferguson JJ, Popma J, King SB, 3rd, Lincoff AM, Tcheng JE, Chan R, Granett JR, Poland M. Results of Prevention of REStenosis with Tranilast and its Outcomes (PRESTO) trial. Circulation. 2002;106(10):1243-1250.

40. Gallo R, Padurean A, Jayaraman T, Marx S, Roque M, Adelman S, Chesebro J, Fallon J, Fuster V, Marks A, Badimon JJ. Inhibition of intimal thickening after balloon angioplasty in porcine coronary arteries by targeting regulators of the cell cycle. Circulation. 1999;99(16):2164-2170.

41. Petronio AS, De Carlo M, Branchitta G, Papini B, Ciabatti N, Gistri R, Cortese B, Gherarducci G, Barsotti A. Randomized comparison of sirolimus and paclitaxel drugeluting stents for long lesions in the left anterior descending artery: an intravascular ultrasound study. J Am Coll Cardiol. 2007;49(5):539-546.

42. Morice MC, Serruys PW, Sousa JE, Fajadet J, Ban Hayashi E, Perin M, Colombo A, Schuler G, Barragan P, Guagliumi G, Molnar F, Falotico R. A randomized comparison of a sirolimus-eluting stent with a standard stent for coronary revascularization. N Engl J Med. 2002;346(23):1773-1780.

43. Hausleiter J, Kastrati A, Mehilli J, Vogeser M, Zohlnhofer D, Schuhlen H, Goos C, Pache J, Dotzer F, Pogatsa-Murray G, Dirschinger J, Heemann U, Schomig A. Randomized, double-blind, placebo-controlled trial of oral sirolimus for restenosis prevention in patients with in-stent restenosis: the Oral Sirolimus to Inhibit Recurrent In-stent Stenosis (OSIRIS) trial. Circulation. 2004;110(7):790-795.

44. Schachner T, Zou Y, Oberhuber A, Tzankov A, Mairinger T, Laufer G, Bonatti JO. Local application of rapamycin inhibits neointimal hyperplasia in experimental vein grafts. Ann Thorac Surg. 2004;77(5):1580-1585.

45. Murphy GJ, Johnson TW, Chamberlain MH, Rizvi SI, Wyatt M, George SJ, Angelini GD, Karsch KR, Oberhoff M, Newby AC. Short- and long-term effects of cytochalasin D, paclitaxel and rapamycin on wall thickening in experimental porcine vein grafts. Cardiovasc Res. 2007;73(3):607-617.

46. Czech J, Kurrle R, Schorlemmer HU. The antiproliferative effect of malononitrilamides (MNAs) on vascular smooth muscle cells is antagonized by exogenous uridine. Inflamm Res. 1999;48 Suppl 2:S128-129.

47. Williamson RA, Yea CM, Robson PA, Curnock AP, Gadher S, Hambleton AB, Woodward K, Bruneau JM, Hambleton P, Moss D, et al. Dihydroorotate dehydrogenase is a high affinity binding protein for A77 1726 and mediator of a range of biological effects of the immunomodulatory compound. I Biol Chem. 1995;270(38): 22467-22472. 
48. Xu X, Williams JW, Gong H, Finnegan A, Chong AS. Two activities of the immunosuppressive metabolite of leflunomide, A77 1726. Inhibition of pyrimidine nucleotide synthesis and protein tyrosine phosphorylation. Biochem Pharmacol. 1996;52(4):527-534.

49. Ross R. Atherosclerosis--an inflammatory disease. N Engl J Med. 1999;340(2):115-126.

50. Vanrenterghem Y, van Hooff JP, Klinger M, Wlodarczyk Z, Squifflet JP, Mourad G, Neuhaus P, Jurewicz A, Rostaing L, Charpentier B, Paczek L, Kreis H, Chang R, Paul LC, Grinyo JM, Short C. The effects of FK778 in combination with tacrolimus and steroids: a phase II multicenter study in renal transplant patients. Transplantation. 2004;78(1):9-14. 

Summary 
In this thesis some novel mechanisms that might lead to intimal hyperplasia and subsequent venous graft failure are highlighted and potential intervention possibilities are suggested. Chapter 1 presents a comprehensive overview of the pathogenesis of intimal hyperplasia with special emphasis on the role of SMC proliferation herein. Also, attention is given to currently employed intervention methods, in particular by pharmaceutical interference. In chapter $\mathbf{2}$ the inflammatory nature of venous intimal hyperplasia is underscored by the observation that macrophages and $\mathrm{T}$ lymphocytes co-localize with in intimal hyperplastic lesions of failed bypass grafts as correlates to earlier reports in the literature. Of more importance however is the finding that both macrophages and $\mathrm{T}$ lymphocytes are detectable at higher levels in veins found to fail in the year following bypass surgery, than in veins surviving this one year follow-up period. Obviously, this implicates that immunohistochemical evaluation of veins at the time of implantation as bypass grafts could be a prognostic tool and might help to individualize medical treatment. Chapter 3 puts forward a novel mechanism by which HSP60, a protein recently discovered to play a role in vascular disease might induce venous intimal hyperplasia. Originally considered responsible for intracellular protective processes, and lately implicated in the auto-immune response hypothesis of cardiovascular disease, e.g. atherosclerosis, we reported the direct mitogenic aspect of autologous HSP60. Furthermore, we emphasized the earlier suggested affiliation between HSP60 and TLRs since we presented TLR2 and TLR4 as receptors by which HSP60 mediates its mitogenic effects. First, we hereby suggest a novel autocrine mechanism in the development of intimal hyperplasia and second we propose a possible target for intervention. In chapter $\mathbf{4}$ we questioned whether hyperoxia is a significant factor in the pathogenesis of venous bypass intimal hyperplasia. Since arterial oxygen levels might be stressful to venous cells, we proposed that relative hyperoxia might be an additional factor in the inflammatory cascade leading to intimal hyperplasia. We found hyperoxia to induce the release of pro-inflammatory and mitogenic cytokines by venous SMCs. Since free oxygen radicals seem to be intermediaries between hyperoxia and the subsequent intracellular inflammatory process, we tried to scavenge these culprit factors by antioxidant treatment. N-acetyl cysteine, a strong scavenger of free radicals proved to counteract the detrimental effect of hyperoxia in venous SMCs. Furthermore, we showed that $\mathrm{N}$-acetyl cysteine is a potent inhibitor of neointima formation in a venous graft bypass model in the rat, which advocates future application of this pharmacological agent in clinical trials. In chapter 5 we addressed the final common pathway of intimal hyperplasia. We examined the expression of cell cycle proteins in normal veins 
and intimal hyperplastic lesions. The high proliferation rate of venous SMCs within these lesions correlated well to the expression profile of cell cycle proteins. Since blocking cell cycle progression has proven efficient to restrain cell proliferation, we suggested pharmacological manipulation of cell cycle protein expression to interfere with venous neointima formation. Chapter $\mathbf{6}$ elaborates on the prevention of neointima formation by investigating the antiproliferative qualities of FK778, a better tolerated derivate of the known immune-suppressive drug Leflunomide. First, we showed that FK778 inhibits venous SMC proliferation in vitro. We substantiated our in vitro results by showing that oral FK778 inhibited neointima formation in a rat venous bypass model. In conclusion, the data presented in this thesis underscore the inflammatory nature of neointima formation. Also, the role of two as yet underestimated mediators in the development of neointima formation, autologous HSP60 and supra-physiological oxygen, has been analyzed in more detail and related to the pro-inflammatory profile within the venous graft wall. Furthermore, our data suggest that pharmaceutical treatment might be applicable to abolish the negative effects of these mediators or to intervene with their down-stream pathways. 

Samenvatting 
Aderverkalking in de slagaders van de benen is een veel voorkomende cardiovasculaire aandoening die nog te vaak tot ernstige invaliditeit leidt. Gelukkig kan de vaatchirurg in veel gevallen een ader gebruiken om het bloed om te leiden tot in het onderbeen. Helaas gaat deze "veneuze graft" in circa de helft van de gevallen na verloop van tijd dichtzitten door "intima hyperplasie." Veneuze intima hyperplasie $(\mathrm{IH})$ is het verdikken van de vaatwand door uitbundig vermenigvuldigen van gladde spiercellen waaruit de normale vaatwand grotendeels is opgebouwd. Dit kan dermate ernstige vormen aannemen dat een veneuze graft faalt. In het huidige proefschrift worden tot dusver onbekende mechanismen beschreven welke zouden kunnen bijdragen tot het ontstaan van intima hyperplasie in veneuze grafts. Verder worden therapeutische mogelijkheden aangedragen ter voorkoming van dit proces. In hoofdstuk 1 wordt een uitvoerig overzicht verstrekt aangaande het ontstaan van intima hyperplasie, waarbij vooral wordt ingegaan op de rol van de gladde spiercel. Tevens worden de vooral medicamenteuze interventie mogelijkheden belicht welke momenteel vaak worden toegepast. In hoofdstuk 2 wordt het inflammatoire karakter van intima hyperplasie benadrukt. Hierin wordt beschreven dat macrofagen en T-lymfocyten aantoonbaar zijn in veneuze intima hyperplasie laesies, maar ook in venen voordat deze geïmplanteerd worden als veneuze bypass. Deze ontstekingcellen zijn echter in grotere aantallen detecteerbaar in venen welke falen binnen een jaar na implantatie in vergelijking met venen welke langer dan 1 jaar open blijven. Deze bevinding impliceert dat het kwantificeren van ontstekingscellen in natieve venen het lot van de veneuze bypass voorspelt en daarmee gerichte therapie mogelijk maakt. Hoofdstuk 3 beschrijft hoe humaan heat shock proteïne (HSP) 60 een rol speelt in het ontstaan van veneuze $\mathrm{IH}$. Het is reeds gesuggereerd dat HSP60 via een auto-immuun reactie bijdraagt tot het ontstaan van atherosclerose. In dit hoofdstuk wordt beschreven dat humaan HSP60 een direct mitogeen effect heeft op veneuze gladde spiercellen door interactie met toll like receptor (TLR) 2 en 4 . Hiermee wordt een nieuw autocrien mechanisme in het ontstaan van IH en een mogelijk interventie doel geponeerd. In hoofdstuk $\mathbf{4}$ wordt het gevolg van hoge zuurstof concentratie op veneuze cellen onderzocht. Omdat een vene geïmplanteerd in de arteriële circulatie naast hemodynamische stress ook aan een verhoogde zuurstofspanning wordt blootgesteld, veronderstelden wij een bijdrage van relatieve hyperoxie aan de pathogenese van veneuze $\mathrm{IH}$. Wij concluderen dat hyperoxie veneuze gladde spiercellen stimuleert tot het uitscheiden van inflammatoire en pro-mitogene cytokinen. Dit proces kan geïnhibeerd worden door farmacologische interventie middels $\mathrm{N}$-acetylcysteine, een antioxidant. Vervolgens blijkt $\mathrm{N}$-acetylcysteine de ontwikkeling van 
veneuze $\mathrm{IH}$ in een proefdier model tegen te gaan. In hoofdstuk 5 wordt de celcyclus als het hart van IH belicht. Een aantal celcyclus eiwitten spelen een belangrijke rol in het aansturen van de celdeling. Na kwantificeren van deze celcyclus eiwitten in gezonde venen en arteriën en $\mathrm{IH}$ laesies blijkt de expressie hiervan sterk gerelateerd te zijn aan het aantal delende cellen in IH laesies. Dit biedt perspectief voor farmacologische interventie om celcyclus progressie tegen te gaan. Een andere farmacologische interventie mogelijkheid wordt in hoofdstuk 6 belicht. Hier wordt het experimentele immuno-suppressivum FK778 onderzocht op anti-proliferatieve eigenschappen. Met behulp van celkweek technieken en een proefdiermodel wordt aangetoond dat FK788 leidt tot vermindering van veneuze celdeling en $\mathrm{IH}$.

Concluderend wordt met de resultaten in dit proefschrift de rol van inflammatie in het ontstaan van veneuze $\mathrm{IH}$ onderstreept. Tevens worden nieuwe moleculaire mechanismen in het ontstaan van $\mathrm{IH}$ belicht en farmacologische interventie mogelijkheden geopperd. 

Dankbetuigingen 
Vanzelfsprekend hebben door de jaren heen veel personen bijgedragen aan het totstandkomen van dit proefschrift en ik ben jullie hiervoor dan ook zeer erkentelijk. Graag wil ik nadrukkelijk dank uit laten gaan naar die mensen zonder wie dit proefschrift niet had kunnen bestaan.

Prof. Dr. Cathrien A. Bruggeman. Vanaf mijn allereerste schreden binnen de wetenschappelijke wereld schiep u de voorwaarden die essentieel bleken om mijn promotietraject af te ronden. Bovenal is het uw ogenschijnlijk filantropische betrokkenheid bij mijn promotieonderzoek hetgeen mij het meeste bij blijtt.

Prof. Dr. Peter J.E.H.M. Kitslaar. Nog altijd zie ik het als een groot geluk dat ik bij u ben begonnen als student-assistent, weliswaar onder directe begeleiding van uw twee AIO's. De directe en indirecte gevolgen van deze initiële stap reiken ver en hebben tot buitengewoon waardevolle ervaringen geleid. Hoe dan ook heeft de aanzet tot wetenschappelijk onderzoek onder uw leiding menig deur geopend waarvan ik tot op heden de vruchten pluk, met als hoogtepunt dit proefschrift.

Dr. Frank Stassen. Je bent het meest direct betrokken geweest bij het creëren van dit proefschrift. Vele ideëen heb ik in de loop der jaren over je uitgestort, hetgeen voor mij meestal het meest interessant was. Ik ben blij dat jij het overzicht hebt gehouden en mijn enthousiasme hebt weten te kanaliseren, zodat uiteindelijk voldoende projecten tot wasdom zijn gekomen.

Prof. Dr. Arnold Hoeks. Na het totstandkomen van het eerst verschenen hoofdstuk hebben wij niet direct samengewerkt, alhoewel dit de volbrenging van mijn proefschrift waarschijnlijk niet heeft gefrustreerd. Ons sporadisch sociale onderhoud blijft zeer interessant, maar ik ben er niet van overtuigd dat mijn talenten toereikend zijn om jouw wetenschappelijke gedachten te allen tijde te kunnen volgen. Desondanks mag het duidelijk zijn dat dit proefschrift er zonder jouw inbreng zeker niet was geweest. De eerste promovendus die zijn proefschrift in het stadspark schrijft moet ik nog zien.

Dr. Tryfon Vainas en Dr. Ruben Dammers. Tryfon, het was een bijzondere ervaring om bij jou te beginnen als "jeugdig" onderzoeker. Je nam niet alleen mijn wetenschappelijke vorming als buitengewoon serieuze taak op je, maar vond dat je me ook nog wat "sociale activiteiten" moest bijbrengen. Dat ik het geleerde in jouw directe nabijheid aan je wou bewijzen leverde wel wat spanningen op, alhoewel van voorbijgaande aard. Gelukkig gaf Ruben je even wat lucht door me onder zijn leiding mijn eerste wetenschappelijke publicatie te laten volbrengen. Ruben, van valse bescheidenheid kan men jou niet betichten. De manier waarop jij op natuurlijk ingetogen wijze jouw ambities 
vervult dwingt zondermeer respect af. Al met al koester ik de tijden in "onze" kamer, met eureka exclamaties na weer een unieke gedachte, gegrom over kortzichtige reviewers, getier op computers en dat alles onder het genot van een ijzersterke margarita. Ik hoop van harte dat onze gezamenlijke liefde voor vasculaire geneeskunde, research en een oude whiskey of frisse cocktail ons nog vaak bij elkaar mag brengen. 

About the author 


\section{Curriculum Vitae}

Rick de Graaf werd op 28 augustus 1972 geboren in Borger. In 1994 behaalde hij het VWO diploma op het Gemeentelijke Scholengemeenschap te Emmen. Datzelfde jaar werd gestart met de studie Geneeskunde aan de Rijksuniversiteit van Antwerpen. In 1998 werd de opleiding geneeskunde vervolgd aan de Rijksuniversiteit Limburg te Maastricht. Tijdens zijn studie was hij studentassistent op de afdeling Vaatchirurgie (Prof. dr. P.J.E.H.M. Kitslaar en Dr. T. Vainas). In deze periode ontving hij de prijs voor "Best Oral Presentation" op het SEOHS te Arnhem. In 2002 ontving hij het "Dr. E. Dekker stipendium" voor een onderzoeksperiode aan het Montefiore Medical Center te New York onder begeleiding van Dr. F. Veith. Tevens werd de aanzet gegeven tot zijn promotieonderzoek, onder begeleiding van Prof. dr. P.J.E.H.M. Kitslaar, Prof. dr. C.A. Bruggeman en Dr. F. Stassen. Voor het onderzoeksvoorstel dat leidde tot dit promotieonderzoek ontving hij in 2004 het "Prof. dr. Kootstra Fellowship". Sinds 1 mei 2005 volgt hij de opleiding tot Radioloog in het Academisch Ziekenhuis Maastricht (opleider Dr. M.W. de Haan). 

List of scientific papers 
Vainas T, Kurvers HA, Mess WH, De Graaf R, Ezzahiri R, Tordoir JH, Schurink GW, Bruggeman CA, Kitslaar PJ. Chlamydia pneumoniae serology is associated with thrombosisrelated but not with plaque-related microembolization during carotid Endarterectomy. Stroke 2002 May;33(5):1249-54

De Graaf R, Dammers R, Vainas T, Hoeks APG, Tordoir JHM. Detection of cell-cycle regulators in failed arteriovenous fistulas. Nephrol Dial Transplant. 2003 Apr;18(4):814-8

Vainas T, De Graaf R, Stassen FRM, Kurvers HAJM, Grauls GELM, Kitslaar PJEHM, Bruggeman CA. Chlamydia pneumoniae serology in cardiovascular disease: comparing a commercial enzyme immunoassay and microimmunofluorescence test in patients with cardiovascular disease. APMIS. 2003 Feb;111(2):363-9

R de Graaf, FJ Veith, N Gargiulo, EC Lipsitz, T Ohki, HAJM Kurvers. Endovascular Abdominal Aortic Aneurysm Repair To Prevent Rupture During Lithotripsy. J Vasc Surg. 2003 Dec; 38(6):1426-9.

R de Graaf, HAJM Kurvers, JD Blankensteijn. Endovasculaire behandeling van carotis stenose is vooralsnog alleen geïndiceerd bij hoog risico patiënten. NTvH, mei 2004

R de Graaf, T. Vainas, Bruggeman CA, Kitslaar PJEHM. Presence of inflammatory cells in veins implanted as bypass grafts is associated with subsequent graft failure. Submitted

R de Graaf, PJEHM Kitslaar, CA Bruggeman, FRM Stassen. Human heat shock protein 60 induces vascular smooth muscle proliferation. Accepted, Microbes and Infection

T Vainas, FRM Stassen, R de Graaf, ELL Twiss, RJThJ Welten, LHJM van den Akker, M van Dieijen-Visser, CA Bruggeman, PJEHM Kitslaar. C-reactive protein and erythrocyte sedimentation rate in peripheral arterial disease. Accepted JVS

G Kloppenburg, R de Graaf, S Herngreen, G Grauls, CA Bruggeman, F Stassen. Cytomegalovirus aggravates intimal hyperplasia in rats by stimulating smooth muscle cell proliferation. Microbes and infection, 2005 Feb;7(2):164-70.

R de Graaf, G Kloppenburg, A Tintu, P Kitslaar, J van Hooff, CA Bruggeman, F Stassen. The new immunosuppressive agent FK778 attenuates neointima formation in an experimental bypass model. Submitted

R de Graaf, G Kloppenburg, A Tintu, P Kitslaar, CA Bruggeman, F Stassen. NAC attenuates hyperoxia induced smooth muscle cell proliferation and neointima in a venous bypass model. Submitted

G Kloppenburg, R de Graaf, G Grauls, CA Bruggeman, F Stassen. Chlamydia pneumoniae aggravates vein graft intimal hyperplasia in a rat model. BMC Microbiol. 2007 Dec 6;7:111 

Color figures 

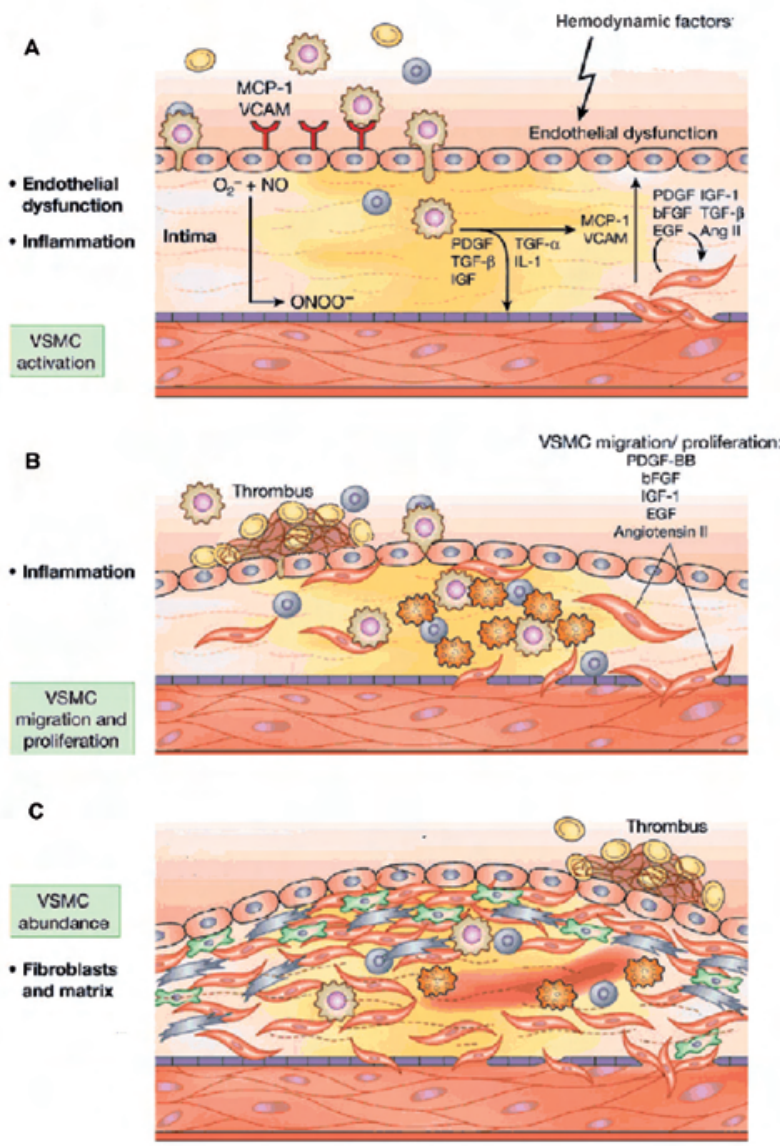

D

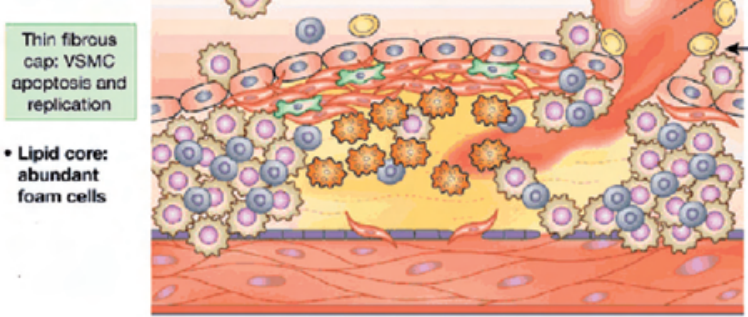

Plaque rupture Collagenases Elastases

\{0\}

\begin{tabular}{|c|c|c|c|c|c|}
\hline$\approx$ & vSMC & 3 & Foam cell & 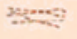 & Matrix \\
\hline (6) & Endothelial cell & () & T-lymphocyte & $\because 2$ & Calcification \\
\hline w & Monocyte & च्ड & Fibroblast & exp & Platelet and fibrin \\
\hline
\end{tabular}




\section{Chapter 1 - Figure 1.}

Different stages of vein graft disease. A. Hemodynamic forces (shear stress, tangential strain) alter the vascular endothelium, which triggers a cascade of events, like recruitment of leukocytes and platelets. B. Aggregation of platelets on the surface of the vessel wall induces thrombus formation which hampers vein graft survival. C. Cytokines and growth factors are released by inflammatory cells, generating a mitogenic milieu. SMCs migrate, proliferate and synthesize extracellular matrix components. D. Late atherosclerosis. Accumulation of macrophages, T-lymphocytes, and foam cells in a fibrocalcific lesion. Inflammatory mediators and proteases induce thinning of the fibrous cap, rendering the plaque weak and susceptible to rupture and thrombus formation. Modified from Dzau et al, 2002.

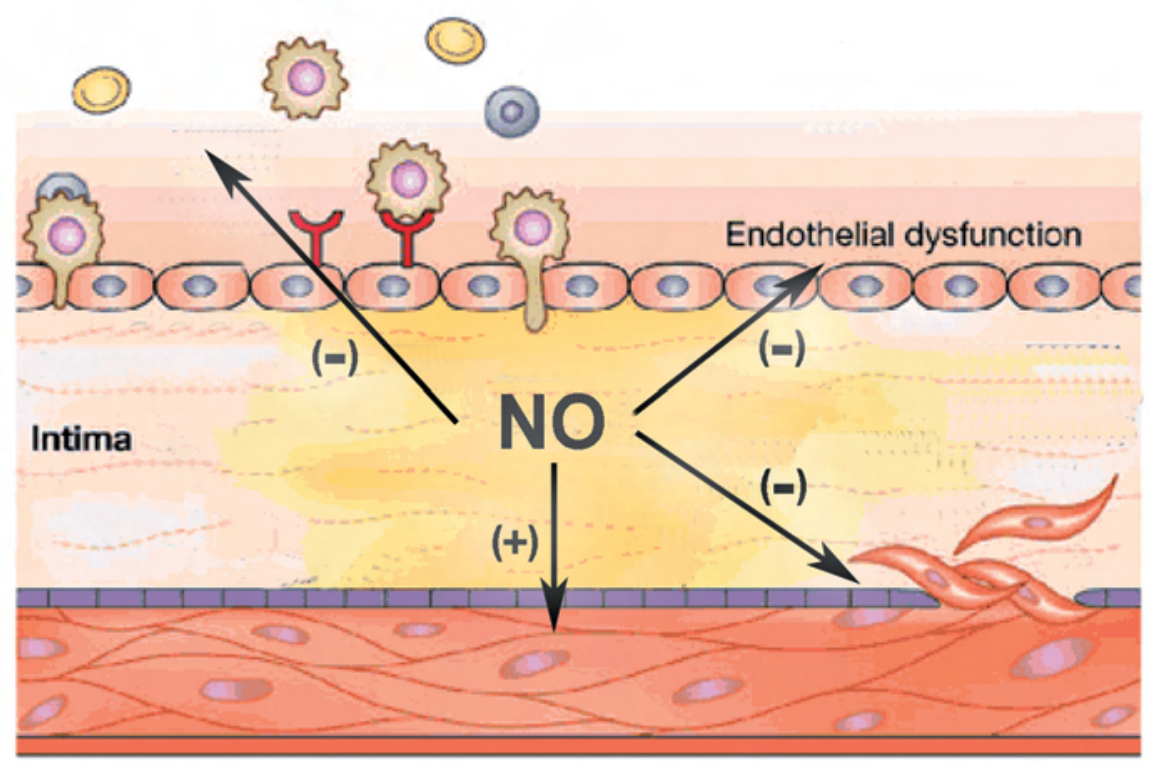

\section{Chapter 1 - Figure 2.}

Illustration showing the beneficial effects of nitric oxide (NO). NO exerts its protective effects by inducing SMC relaxation; inhibiting SMC proliferation, migration, and extracellular matrix synthesis; inhibiting platelet and leukocyte adhesion and activation; and protecting endothelial integrity. Modified from Dzau et al, 2002. 


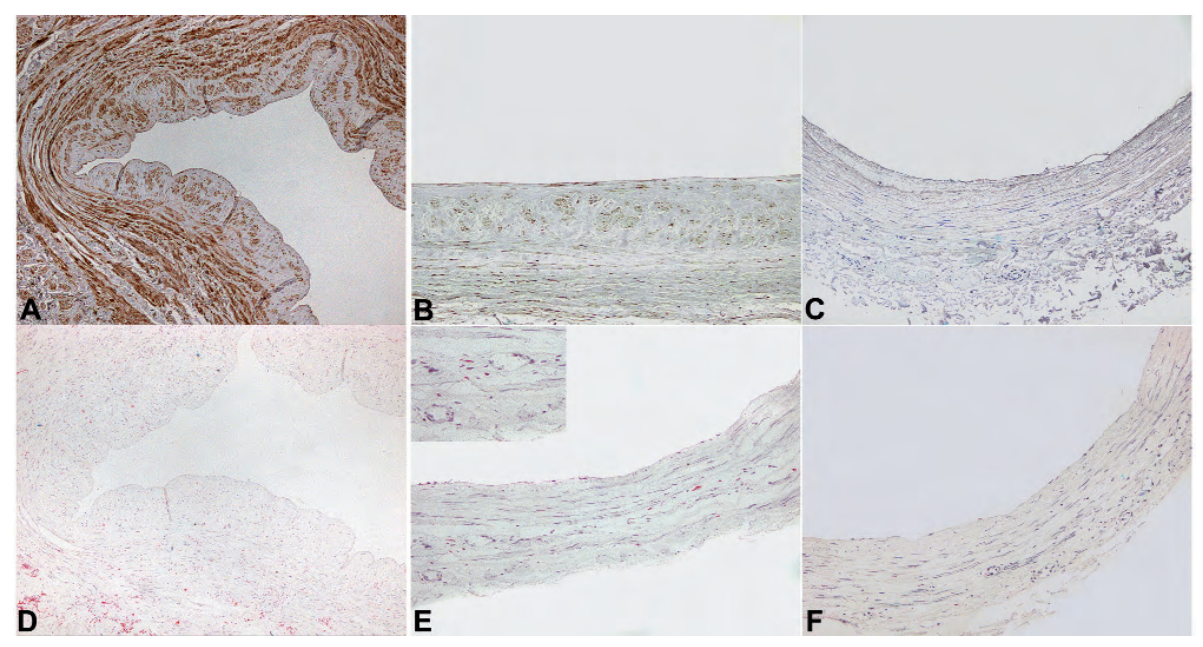

\section{Chapter 2 - Figure 2.}

Immunohistochemical representation of macrophage and T-lymphocyte distribution in failed bypass sections and saphenous vein segments. A-C: abundant expression of CD3 immunoreactivity (T-lymphocyte) in failed bypass graft segment (A), while T-cell presence in DIH vein segment is clearly less pronounced. CD3 expression in NDIH vein segment (C) is virtually absent. D-F: macrophages (CD68 immunoreactivity) mainly localize in the media and adventitia of failed bypass graft segment (D). To a lesser extent, macrophages also are present in the media and adventitia of $\mathrm{DIH}$ vein segments (E). Macrophage count is almost nil in NDIH veins (F). 

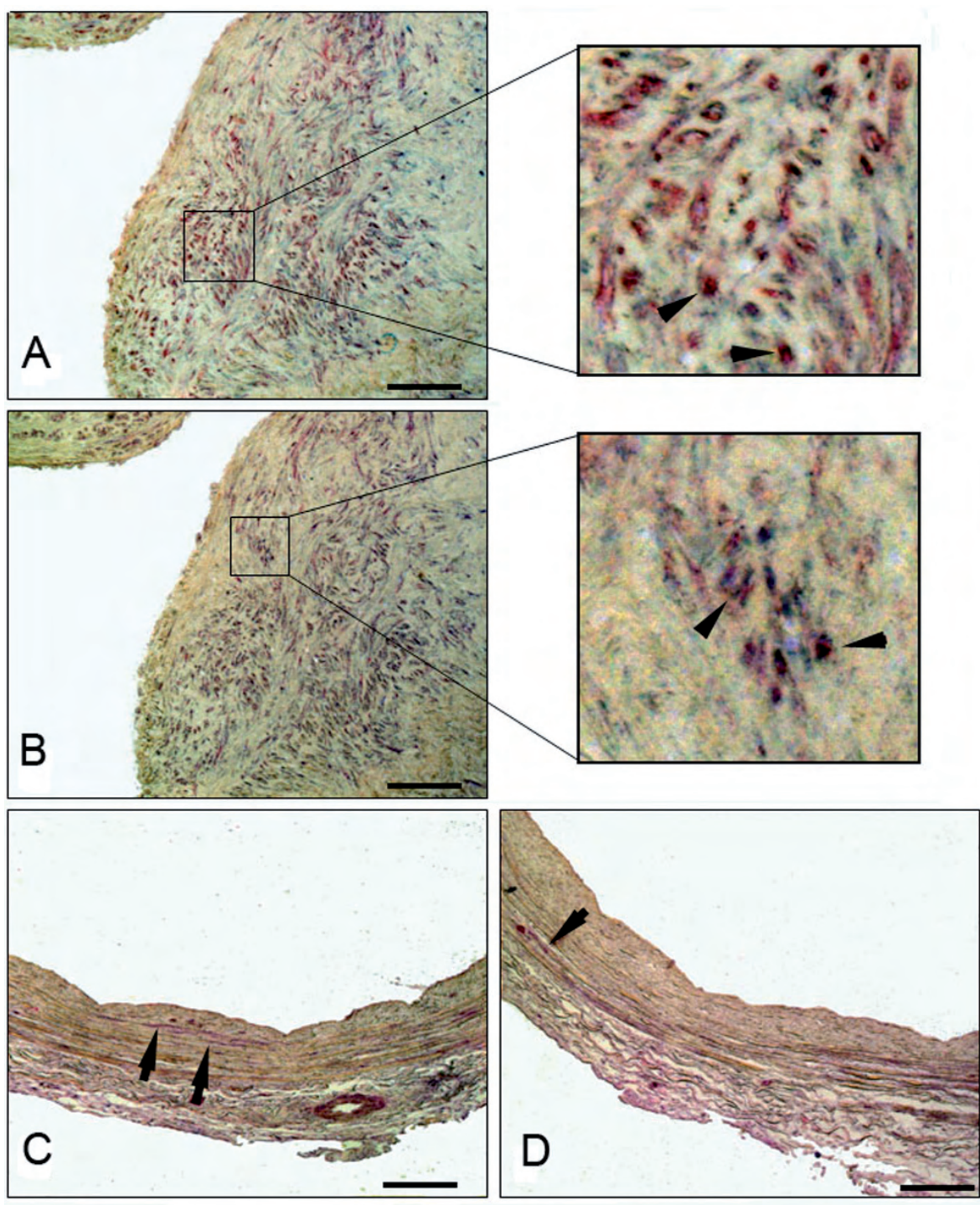

\section{Chapter 3 - Figure 1.}

Immunohistochemical analysis of TLR2, TLR4 and HSP60 proteins. A, doublestaining for TLR4 (red) and HSP60 (blue) in AVF neointimal lesion. Arrows indicate double-positive cells for TLR4 and HSP60 (detail). B, doublestaining for TLR2 (red) and HSP60 (blue). Arrows indicate double-positive cells for TLR2 and HSP60 (detail). C and D, Doublestaining for TLR2 or TLR4 (red) respectively and HSP60 (blue) in control venous segments. Arrows indicate diffuse TLR2 and TLR4 staining in medial

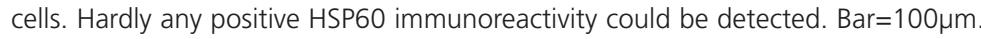




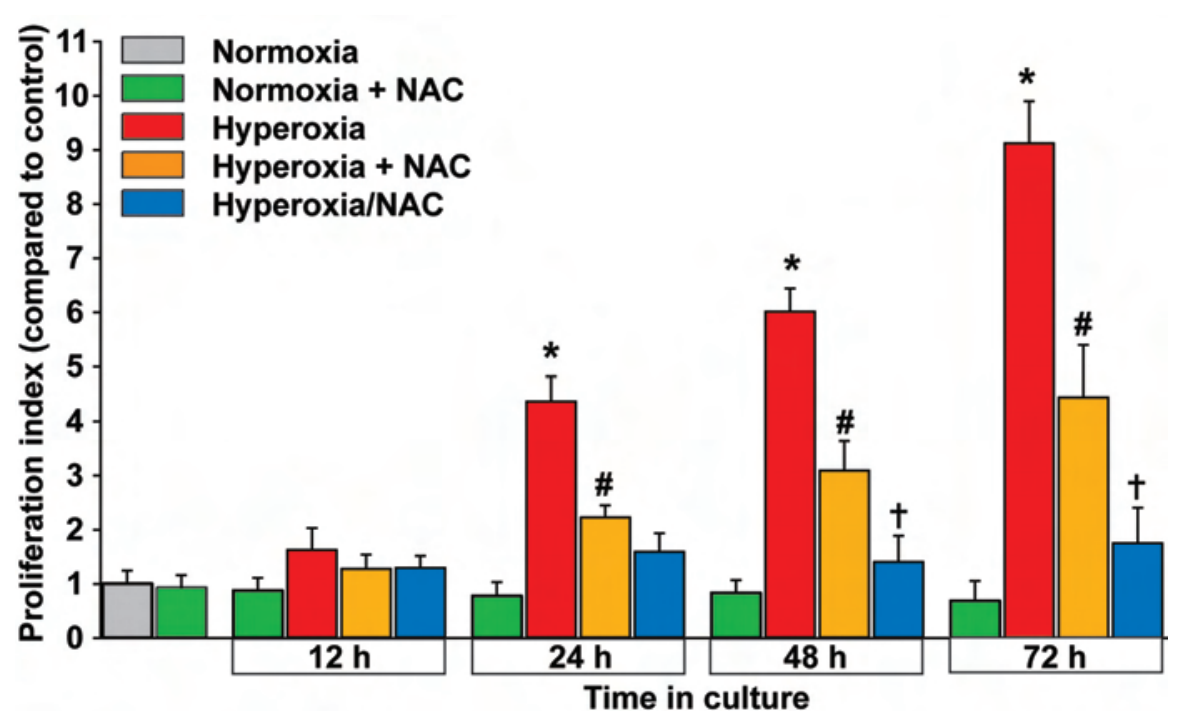

\section{Chapter 4 - Figure 2.}

Medium from hyperoxic VSMCs induces proliferation of quiescent normoxic VSMCs, which is prevented by NAC. Proliferation indices in normoxic VSMCs after 48-h incubation with conditioned medium retrieved from VSMCS after 24-72 $\mathrm{h}$ of hyperoxia induced a significant increase in the number of Ki-67 positive cells (red bars, ${ }^{*} \mathrm{P}<.01$ versus incubation with control medium). Administration of NAC to quiescent VSMCs reduced the proliferative effect of medium from hyperoxic VSMCs (yellow bars, \# P $<.05$ versus medium from hyperoxic VSMCs, ie versus red bars). The proliferative response of quiescent VSMCs was completely abolished by conditioned medium from hyperoxic NAC-treated VSMCs (blue bars, $+\mathrm{P}<.05$ versus medium from hyperoxic VSMCs that had not been treated with NAC, ie versus yellow bars). Data are expressed as mean \pm SE of four experiments. 


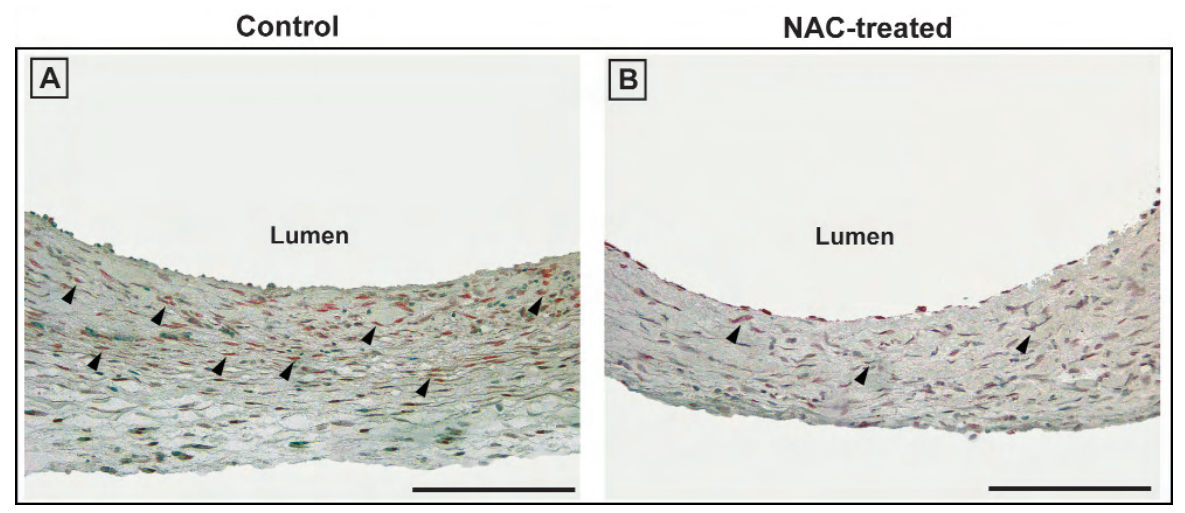

\section{Chapter 4 - Figure 3.}

Systemic treatment with NAC reduces VSMC proliferation in rat venous grafts. VSMC proliferation is significantly lower in vein grafts of NAC-treated $(B ; 150 \mathrm{mg} / \mathrm{kg} / \mathrm{d}$ orally; $n=7)$ compared with control rats $(A ; n=6)$ at 7 days of surgery, as demonstrated by BrdU immunohistochemistry (arrowheads). Scale bars represent $100 \mu \mathrm{m}$.

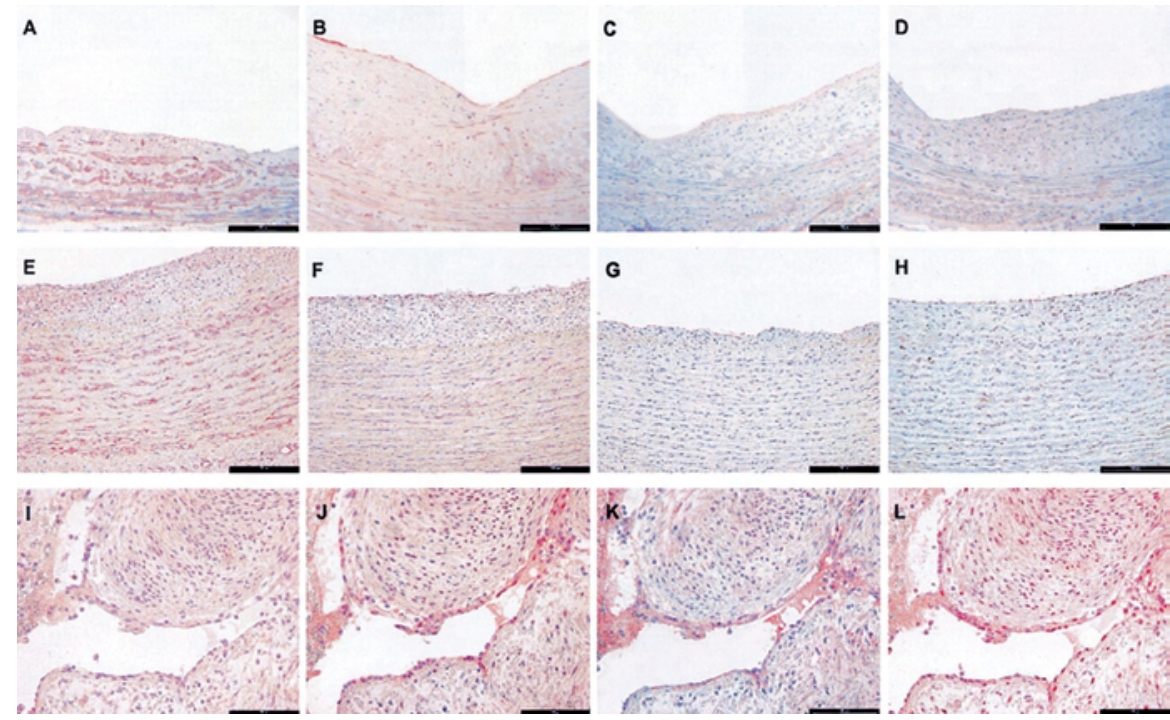

\section{Chapter 5 - Figure 1.}

Immunocytochemical staining of healthy and intimal hyperplastic vascular segments. Shown are Fast Red-stained nuclei in normal veins: (A) p21Waf1, (B) p27Kip1, (C) cdk2, and (D) PCNA; normal arteries: (E) p21Waf1, (F) p27Kip1, (G) cdk2, and (H) PCNA; AVFs: (I) p21Waf1, (J) p27Kip1, (K) cdk2, and (L) PCNA expression. Bar, $100 \mu \mathrm{m}$. 


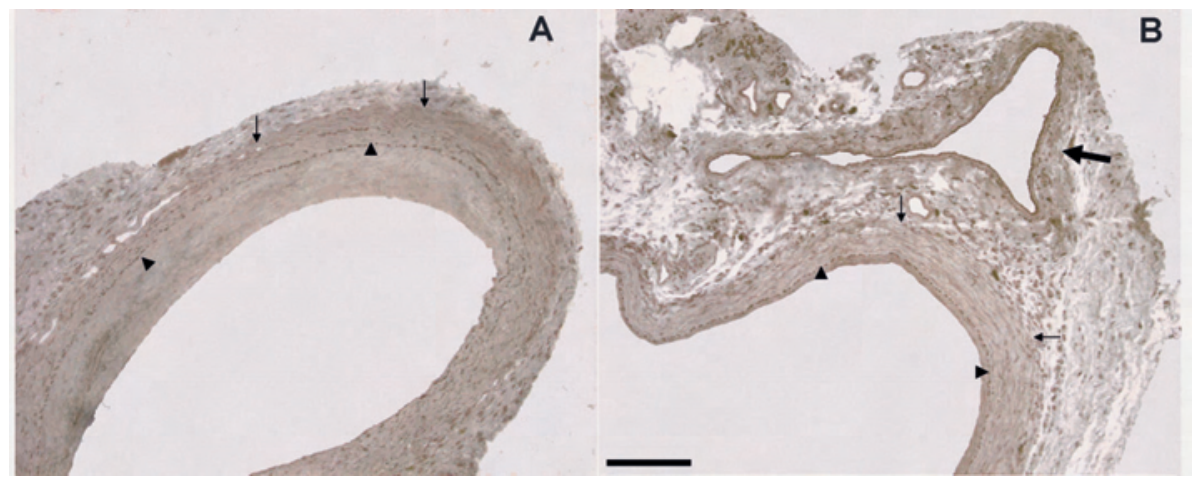

\section{Chapter 6 - Figure 3.}

Three weeks after vein grafting. Representative images after Lawson staining of a control vein graft (A) and FK778 treated vein graft (B). Arrowheads represent the lamina elastica interna. The media-aventitia border is indicated by small arrows. The large arrow indicates the native vein in situ adjacent to the grafted vein, which shows normal intimal and medial thickness. Notice the marked increase in medial thickness of both control and FK778 treated vein grafts compared to the native vein. Moreover, medial thickness is similar in both vein grafts. Scale bar: $100 \mu \mathrm{m}$. 
